SAND88 - 0475

DE9 I 007149

Unlimited Release

Printed January 1991

\title{
G-TUNNEL WELDED TUFF MINING EXPERIMENT PREPARATIONS
}

\author{
by \\ Roger M. Zimmerman \\ Sandia National Laboratories \\ Albuquerque, NM \\ Rotert A. Bellman, Jr., and \\ Kevin L. Marñ \\ Science Applications Inteinational Corporation \\ Las Vegas, NV \\ Daniel P. Zerga \\ Parsons Brinckerhoff Quade and Douglas \\ San Francisco, CA
}

\begin{abstract}
Designers and analysts of radioactive waste repositories must be able to predict the mechanical behavior of the host rock. Sandia National Latoratories elected to conduct a mine-by in welded tuff so that predictive-type information could be obtained regarding the response of the rock to a drill and blast excavation process, where smooth blasting techniques were used. Included in the study were evaluations of and recommendations for various measurement systems that might be used in future mina-by efforts. This report summarizes the preparations leading to the recording of data.
\end{abstract}


This report was prepared under the requirements for Quality Assurance Level III. 
CONTENTS

Page

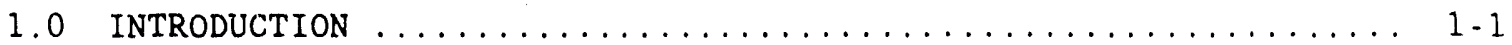

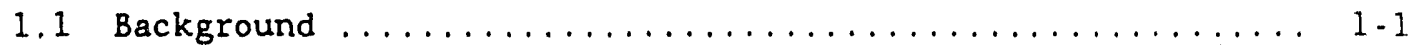

1.2 Purpose ................................ 1-2

1.3 Contents of Report ........................ $1-3 /$

2.0 EXPERIMENT LAYOUTS AND GEOLOGY $\ldots \ldots \ldots \ldots \ldots \ldots \ldots \ldots \ldots \ldots \ldots \ldots$

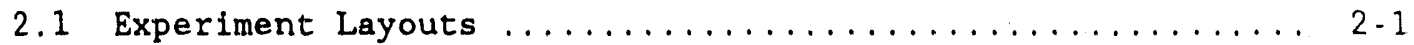

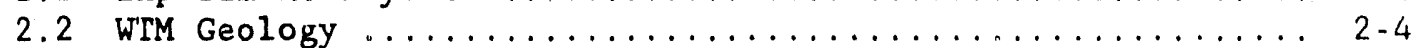

3.0 DATA ACQUISITION SYSTEMS (DASs) $\ldots \ldots \ldots \ldots \ldots \ldots \ldots \ldots \ldots \ldots$

3.1 Computerized Data Acquisition ................... 3-1

3.1 .1 Components of the Data Acquisition System ........ 3.1

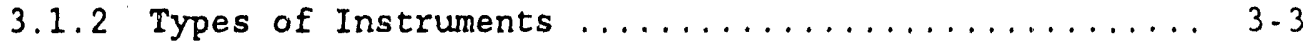

3.1 .3 Data Operations ...................... 3.5

3.2 Manually Recorded Data ...................... $3-6$

4.0 DAS CONNECTED INSTRUMENTATION DESCRIPTIONS $\ldots \ldots \ldots \ldots \ldots \ldots \ldots$

4.1 Multi-Point Borehole Extensometers (MPBX) ...........4-1

4.1 .1 MPBX--Components and Principles ............. 4-1

4.1 .2 MPBX-.Irad Measurement Equipment ............. $4-3$

4.1.3 MPBX--Sinco/Terrametrics Measurement Equipment .... 4-6

4.1.4 MPBX--Geokon Measurement Equipment ........... 4.7

4.1.5 MPBX--Installation Sequences and Protective

Measures......................... 4-7

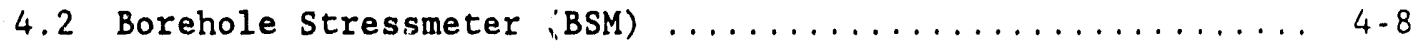

4.2 .1 Measurement Principle ................. 4.8

4.2 .2 Measurement Equipmert ................... 4.9

4.2 .3 Installation Sequence ................. 4-11

4.3 Rock Bolt Load Cell (RBLC) .................... 4-12

4.3.1 Measurement Principle .................. 4-12

4.3.2 RBLC Measurement Equipment ................ 4-12

4.3 .3 Installation Sequence .................. 4-14

5.0 MANUAL MEASUREMENT DESCRIPTIONS $\ldots \ldots \ldots \ldots \ldots \ldots \ldots \ldots \ldots$

5.1 Tape Extensometer (TE) ..................... $5-1$ 
CONTENTS (continued)

Page

5.1.1 Measurement Principle ................... 5-1

5.1 .2 Measurement Equipment ................... 5-1

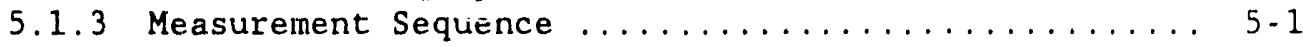

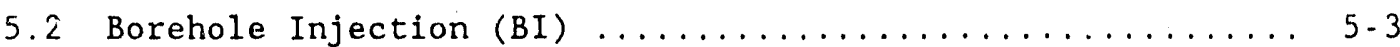

5.2.1 Measurement Principle ................... 5-3

5.2.2 Measurement Equipment .................. 5-6

5.2.3 Measurement Procedures .................... 5-9

5.3 Borehole Deflectometer (BD) $\ldots \ldots \ldots \ldots \ldots \ldots \ldots \ldots \ldots \ldots$. $5-11$

5.3.1 Measurement Principle .................... 5-12

5.3 .2 Measurement Equipment .................... $5-12$

5.3.3 Measurement Procedures .................... 5-15

5.4 Hydraulic Pressure Cells .......................... 5. 15

5.4.1 Measurement Principle ................... 5-16

5.4 .2 Measurement Equipment ................... 5-16

5.4 .3 Installation Features .................. 5-16

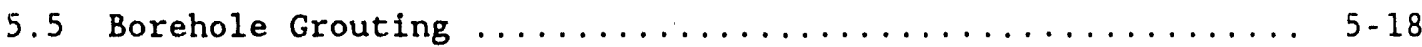

5.5.1 Borehole Grouting Procedures .............. 5-18

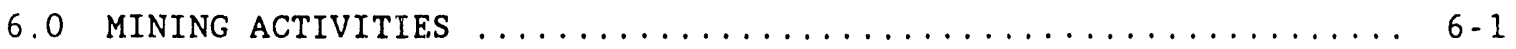

6.1 Controlled Blasting $\ldots \ldots \ldots \ldots \ldots \ldots \ldots \ldots \ldots \ldots \ldots \ldots \ldots \ldots$

6.1.1 Controlled Blasting Objectives for G-Tunne1 ...... 6-1

6.1 .2 Controlled Blasting Techniques .............. $6-3$

6.2 Smooth Blasting $\ldots \ldots \ldots \ldots \ldots \ldots \ldots \ldots \ldots \ldots \ldots \ldots \ldots \ldots \ldots \ldots$

6.2.1 Smooth Blasting Concepts .................. 6-3

6.2.2 Smooth Blasting Factors .................. 6-6

6.2.3 Smooth Blasting Details .................. 6-7

6.2.3.1 Blast Patterns ................. 6-7

6.2.3.2 Explosives ................... 6-10

6.2.3.3 Drilling for Blasting ............. $6-14$

6.3 Ground Support............................ 6-14 


\section{CONTENTS (concluded)}

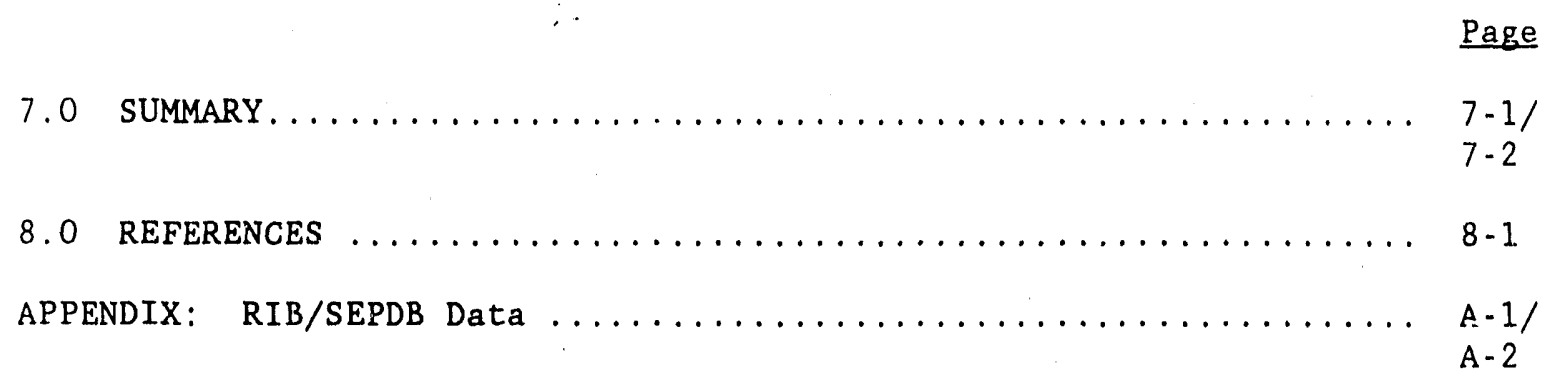


2-1 Plan View of Demonstration Drift Details Associated with

Welded Tuff Mining Experiments .................... 2-2

2-2 Elevation View Showing Location of Instrumentation and Measurement Holes Relative to Major Drifts with Typical Geologic Features ............................. $2-3$

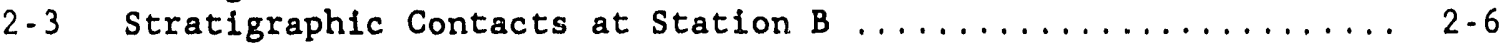

$2-4$ Stratigraphic Contacts at Station $\mathrm{D} \ldots \ldots \ldots \ldots \ldots \ldots \ldots \ldots \ldots$

2-5 Stratigraphic Contacts at Station $F \ldots \ldots \ldots \ldots \ldots \ldots \ldots$

3-1 Block Diagram Illustrating DAS ...................

4-1 Schematic Showing Typical MPBX Arrangement ............. 4-2

4-2 Schematics Showing BSM Placements ................... 4-10

4-3 Elevation View Showing Principal RBLC Features ............ 4-13

4-4 Configuration of Panel Prior to Grottcing ................ 4-15

4-5 Details of Rock Bolt Load Installation in Roof ........... 4-16

5-1 Tape Extensometer Measurement Arrangement .............. 5-2

5-2 Schematics Showing Principle of Borehole Permeability Testing. 5-4

5-3 Schematic of Borehole Injection Testing Apparatus ......... 5-7

5-4 Photograph of Permeability Testing Apparatus ............ 5-8

5-5 Photograph of Borehole Injection Assembly .............. 5-10

5-6 Schematic Showing Mining-Related Deflectometer Measurement.

Concept ................................. 5-13

5.7 Schematic of Borehole Deflectometer in Casing ............ 5-14

5-8 Schematic Showing Major Components of Hydraulic Pressure Cel1 ............................... 5-17

5-9 Schematics Showing HPC Details ..................... 5-19

5-10 Typical Grouting Details for BD and MPBX Boreholes ......... 5-21

6-1 Schematics Showing a Burn Cut and an Angle Cut ............ 6-5

6-2 Plan View Showing Blast Rounds ................... 6-8

6-3 "Hex Burn" Blast Design for Rounds 4 and $5 \ldots \ldots \ldots \ldots$

6.4 "V-Cut" Blast Design for Round $6 \mathrm{~B} \ldots \ldots \ldots \ldots \ldots \ldots \ldots \ldots 11$

6.5 "Triangular Burn Cut" for Rounds 7 through $12 \ldots \ldots \ldots \ldots \ldots 12$

6-6 Final Ground Support for Demonstration Drift............. $6-16$ 


\section{LIST OF TABLES}

Table

Page

2.1 Borehole Descriptive Information ................... 2.5

$2-2$ Stratigraphic Description ....................... 2-9

3-1 Descriptive Information for Computer Based Measurements ...... 3-4

3-2 Descriptive Information for Manually Obtained Data .......... 3-7/

$3-8$

4-1 MPBX Descriptive Information ..................... 4-4 
The authors are indebted to many for their contributions to these welded tuff mining evaluations. In particular, we wish to acknowledge contributions from the following:

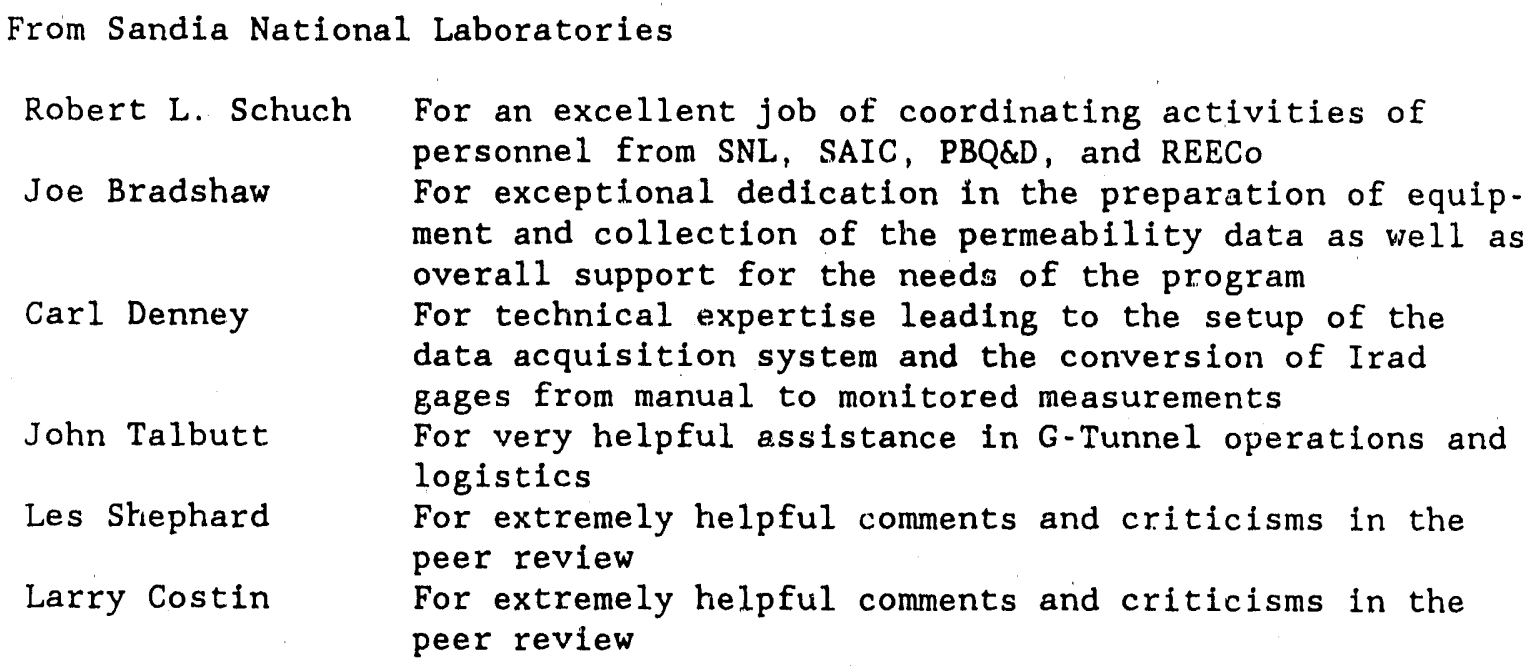

From Science Applications International Corporation

Mike Allen For exceptional dedication in the tape extensometer data collection and the installation of field instruments

Brian Kechi For diligence in support of laboratory and field data collection

From Parsons Brinckerhoff Quade and Douglas

Will Streeter For generous applications of talents in mining activities

From EG\&G

Don Mason For skill in developing the software for the data acquistion system and help in keeping it operating

From Fenix and Scisson

Mike O'Brien For continued support: in geologic interpretations

From REECo

Don Hembre

For assistance as REFCO prifect manager in the planning and conduction of the drilling and mining activities 
ACKNOWLEDGMENTS (concluded)

Lave11 Atkinson

Sam Williams

REECo Miners and Drillers
For assistance as REECo tunnel superintendent in the planning and conduction of the driliing and mining activities

For very helpful assistance in the planning and conduction of the field activities

For their cooperation and patience in doing a

nontraditional job to support underground research 


\subsection{INTRODUCTION}

\subsection{Background}

Yucca Mountain on the Nevada Test Site (NTS) is composed of a thick sequence of volcanic ash-fall and ash-flow tuffs. This mountain is being considered as a site for a nuclear waste repository, and feasibility studies for this purpose are being conducted by the Yucca Mountain Project (YMP) (DOE, 1980). G-Tunnel, located in Rainier Mesa on the NTS, intersects layers of welded and nonwelded tuffs that have thermal and mechanical properties and ntress states (Zimmerman and Finley, 1987) similar to the tuffs in Yucca Mountain. The welded tuff mining (WTM) experiment consists of rock mechanics measurements and evaluations needed to ensure that technologies are adequately developed before testing in the Exploratory Shaft Facility (ESF) at Yucca Mountain. The avallability of G-Tunnel for imnediate field experimentation allows Sandia National Laboratories (SNL), a participant in the YMP, to conduct field characterizations of tuffs without expensive excavation and facility development costs.

Designers and analysts within the YMP are involved in evaluating repository design and performance aspects and developing capahilities for predicting rock mass behavior. Repository designers require adequate predictions 0 : the behavior of the host rock for operating periods over $50 \mathrm{yr}$. Repository performance assessment analysts need to predict containment and isolation of radioactive wastes for more than $10,000 \mathrm{yr}$ after closure. These predictions are made through numerical models that have tn be developed, verified, and validated. Field-scale tests document the response of the host rock to excavations and thermal pulses, and the resulting data are used to confirm the adequacy of the numerical models in a formal validation process. This report documents measurements associated with rock mass convergence resulting from the excavation process. These results are applicable to preliminary repository conceptual designs, where some knowledge of field-based behavior is needed. These measurement results are also compared with calculations from numerical models to provide preliminary assessments that will help guide future analytical and experimental activities. 
In situ site characterization is planned as part of future ES rock mechanics efforts. SNL has responsibility for the geomechanics testing in that effort, and a suite of field experiments is planned (DOE, 1988). The testing discussed in this report includes many testing concepts planned for ES testing. The testing in the ES must satisfy stringent quality assurance requirements that include the use of detalled test procedures. Many of these procedures will be based on experiences gained during this testing.

\subsection{Purpose}

The G-Tunnel WTM evaluations represent a series of measurements and analyses conducted during the excavation of a relatively short drift, with cross-sectional dimensions representative of some repository drifts.

Measurements were malle in a jointed rock mass before, during, and after the excavation process. This is the first time that this has been done in either welded or nonwelded tuffs.

The primary purpose of these evaluations was to document, analyze, and evaluate in a preliminary manner the behavior of the welded tuff before, during, and after the excavation process. Important considerations in this effort were to

- analyze drift convergence phenomena,

- review adequacies of existing rock mass rating techniques, and

- apply and review control blasting techniques.

A secondary purpose was to evaluate measurement systems for later use in ES testing. Important considerations were to

- apply two new methods to measure rock mass responses to the mining process and

- evaluate measurement types, techniques, and procedures. 


\subsection{Contents of Report}

The WTM experiment is documented in four reports (1) preparations, (2) data summary, (3) experiment evaluations and (4) instrumentation evaluations. This document is the first of the four and summarizes the activities leading to and in support of data collection. Major sections in this report are the experiment layout, pertinent geology, the data acquisition system, and mining and instrumentation details. For the latter, each instrument is discussed in terms of the measurement princip1., the equipment used, and the installation details.

The second report (Zimmerman et al., 1989) is a data summary that includes data histories in engineering units. The third report (Zimmerman et al., 1988) summarizes the evaluations and recommendations that apply to the measurement systems and the rock mass behavior. The fourth report (Zimmerman, R. M., R, A. Bellman Jr., K. L. Mann, and T. William Thompson, "G-Tunnel Welded Tuff Mining Experiment Instrumentation Evaluations," SAND88-1331, Sandia National Laboratories, Albuquerque, NM, Draft) summarizes the behavior of the instrumentation and data acquisition system. 


\subsection{EXPERIMENT LAYOUTS AND GEOLOGY}

\subsection{Experiment Layouts}

The WTM experiment was conducted in the G-Tunnel Underground Facility (GTUF) using two drifts. Figure 2-1 shows a plan view of the two drifts. The first drift constructed was the 12-Drift extension. The drift was mined from the U12.g.12 drift that forms a major draft in the G-Turinel network. The 12-Drift contains the tunnel rail system and is located in nonwelded tuff. The 12-Drift was driven on a bearing of $S 55^{\circ} \mathrm{W}$ so thai it would be parallel to an existing drift in the GTUF, called the Extensometer Drift. The plan was that the 12-Drift would be used as the observation or monitoring drift for the mining of the Demonstration Drift. The observation drift preferably would be at the same level as the mine-by drift, but 1t was located at a lower elevation co minimize expenses during this developmental effurt. Boreholes were drilled from the 12-Drift into the rock mass into which the lemonstration Drift would be mined so that measurements could be made before, during, and after the excavation. The Demonstration Drift is located in welded tuff and has the cross-sectional dimensions representative of many large repository drifts. Construction of the drift would demonstrate the ability to construct and stabilize a relatively wide drift in fractured welded tuff.

Figure 2-1 shows the measurement stations that were used for both the Demonstration Drift and the 12-Drift. Pertinent dimensions and geologic structural features (see Section 2.2) are shown in the figure. The statles.o were normally located after each mining round. Two stations, $C$ and $E$, were Iwated at predetermined distances because of the presence of station-dependent 2a:atrumentation originating from the 12-Drift.

Flgure 2-2 shows a representative elevation view of the two drifts with pertinent dimensions and major instrumintation positions. Multiple. point borehole extensometers (MPBXs), with origins in the Demonstration Drift, ware located in Positions 1 through 6, and MPBXs were located with origins in the 12-Drift and identifled with Pusition 7. MPBXs are 


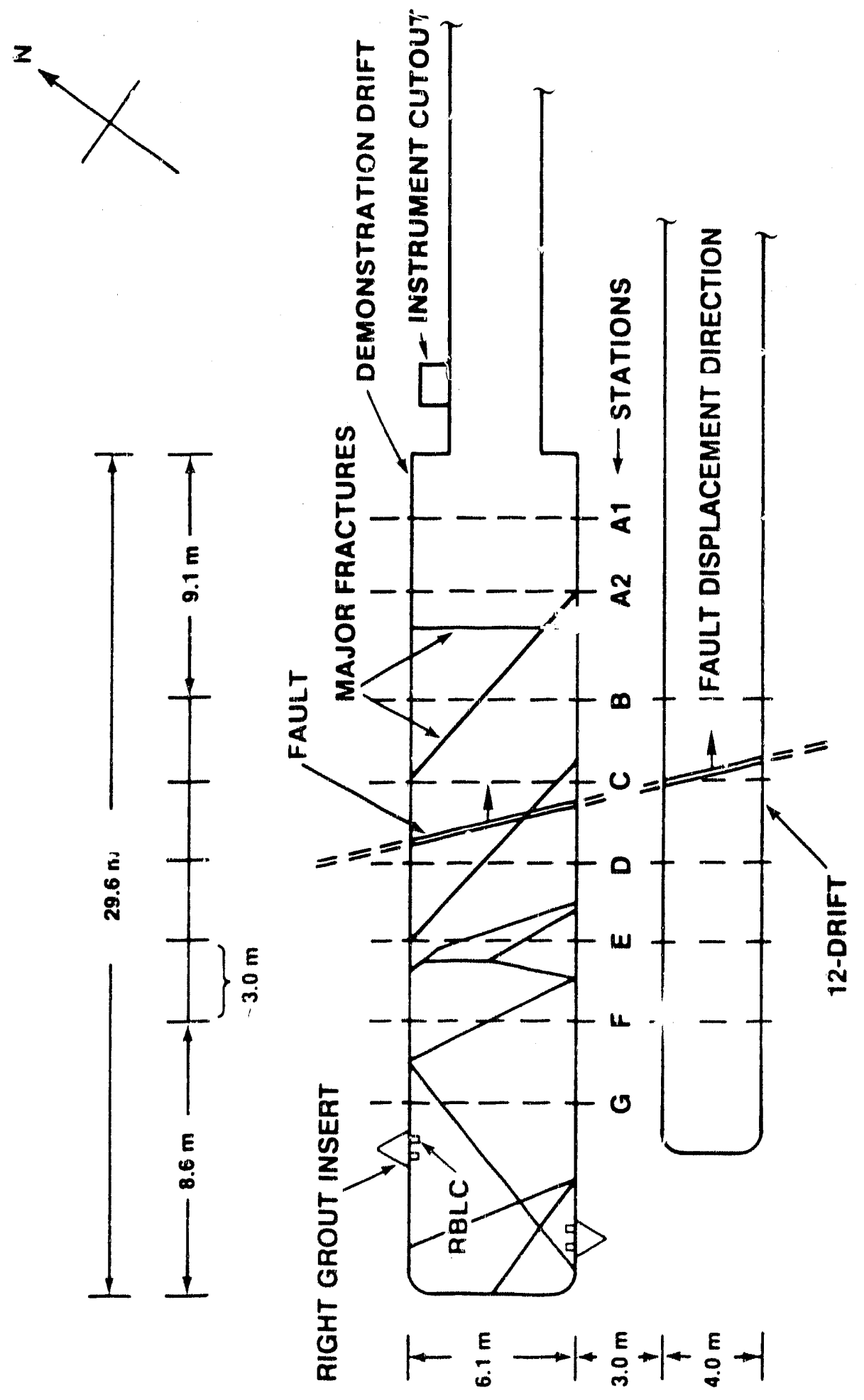

OD 


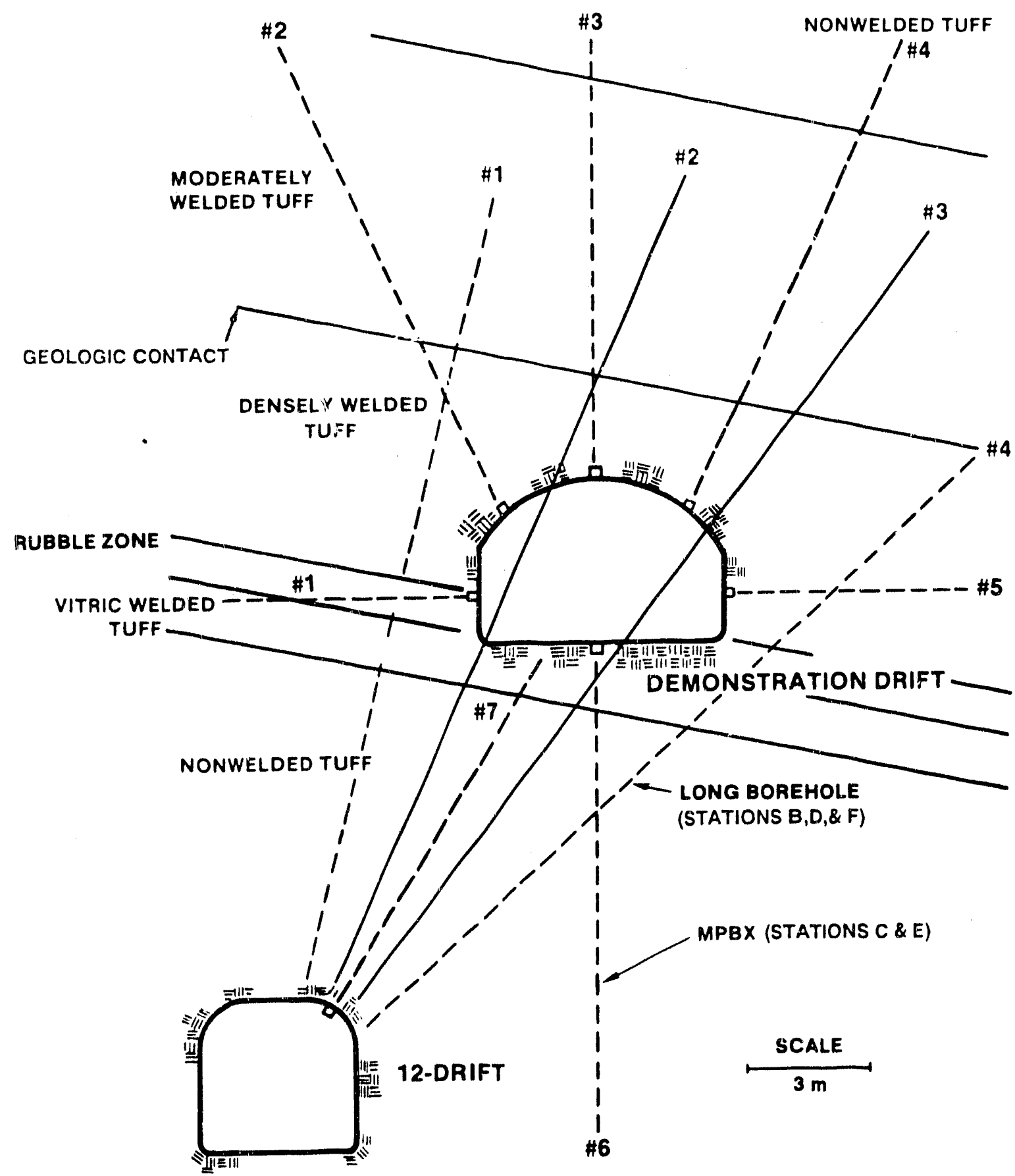

Figure 2-2, Elevation View Showing Location of Instrumentation and Measurement Holes Relative to Major Drifts with Typical Geologic Features 
identified by station and position number. MPBXs were located only at Stations $C$ and E. Thus, a vertical MPBX oriented up at Station $C$ would be identified as MPBX C3.

The four long boreholes originating from the 12-Drift, identified by 1 through 4 in Figure 2-2, were located at Stations $B, D$, and $F$ and were used for special types of pre- and postmining measurements. Measurements in the steepest borehole at Station B would be identified by Borehole BI.

The pertinent dimensions and drilling methods for all of the boreholes are given in Table 2-1.

\subsection{WTM Geology}

Figure 2-1 shows the major geologic structures, including a fault and fractures. These were visually mapped from the inside of the drift by the authors. The unnamed normal fault (Strike $\mathrm{N} 50^{\circ} \mathrm{W}$, dip $75^{\circ}$, displacement $-2.5 \mathrm{~m}$ ) was also observed in the 12 -Drift, where it has a $3.6-\mathrm{m}$ displacement as determined by a G-Tunnel geologist. The major fractures in the Demonstration Drift dip subvertically.

The Demonstration Drift was located in multilayered tuff. Figures 2-3 through 2-5 show stratigraphic variations determined from G-Tunnel core logs for the 12 boreholes driven from the 12-Drift before the mining was started. In some cases, it was hard to identify unit contacts, and these omissions are evident in the figures. The unit contacts in figures show the influence of the fault, located between stations $C$ and $D$. The location of the Demonstration Drift is shown in each figure with the dashed lines. The stratigraphic variations evident in GTUF have been described in other geological investigations (Langkopf and Eshom, 1982). These classifications had been summarized for use here, and the results are in Table 2-2.

It should be noted that the normal fault was not noticed when mining the 12-Drift because there was no significant change in the rock mass characteristics. However, recovered cores indicated differences in depths 


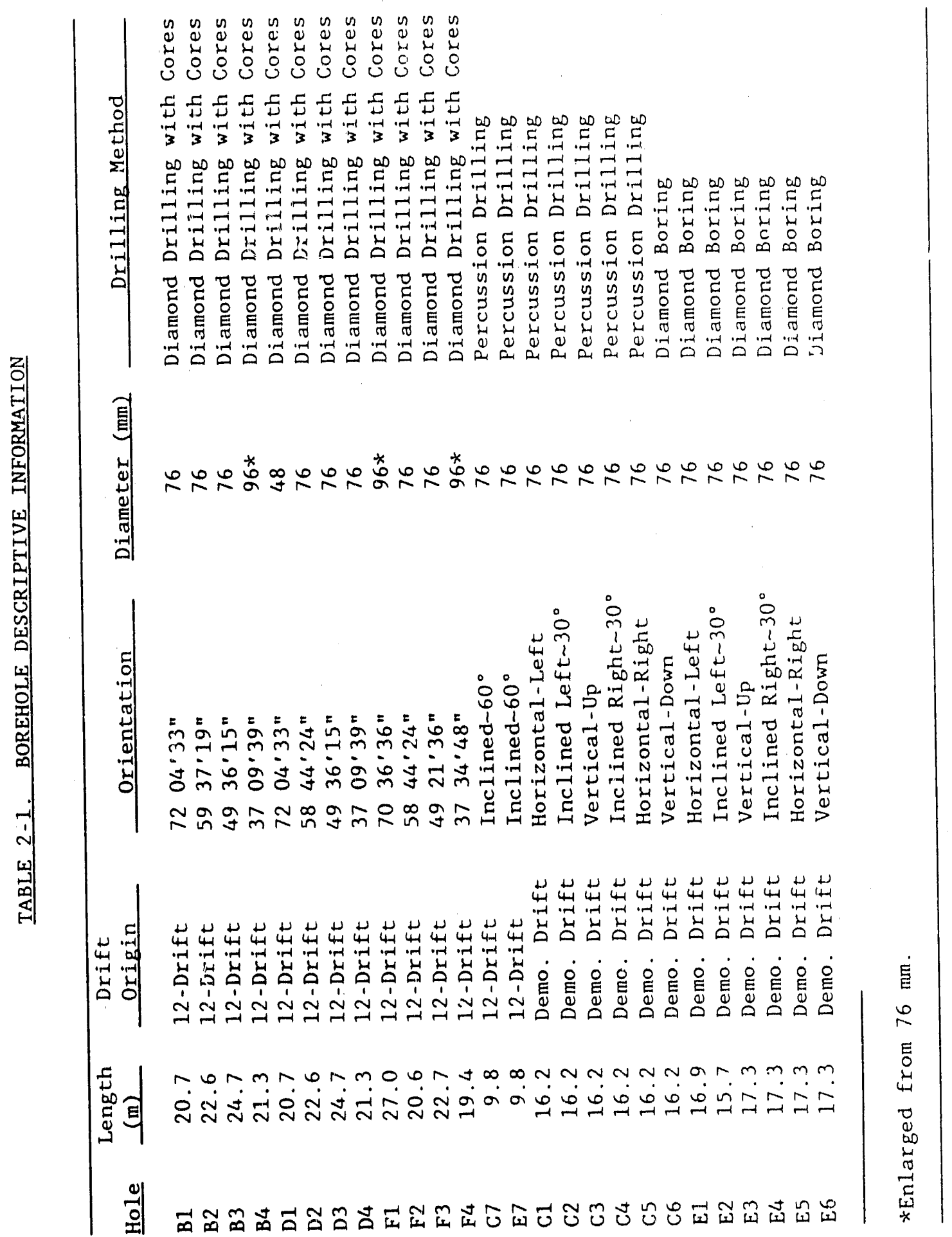




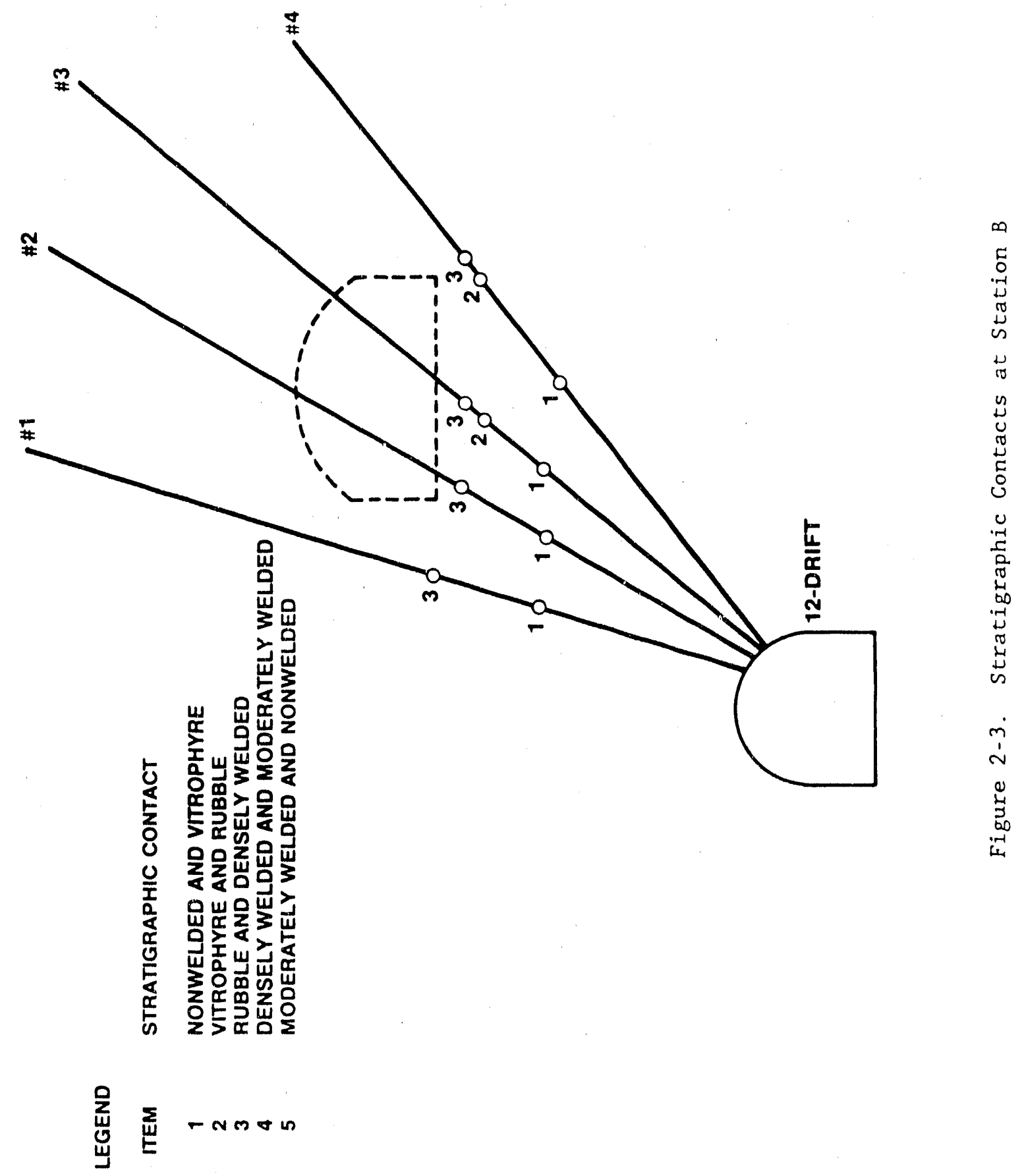




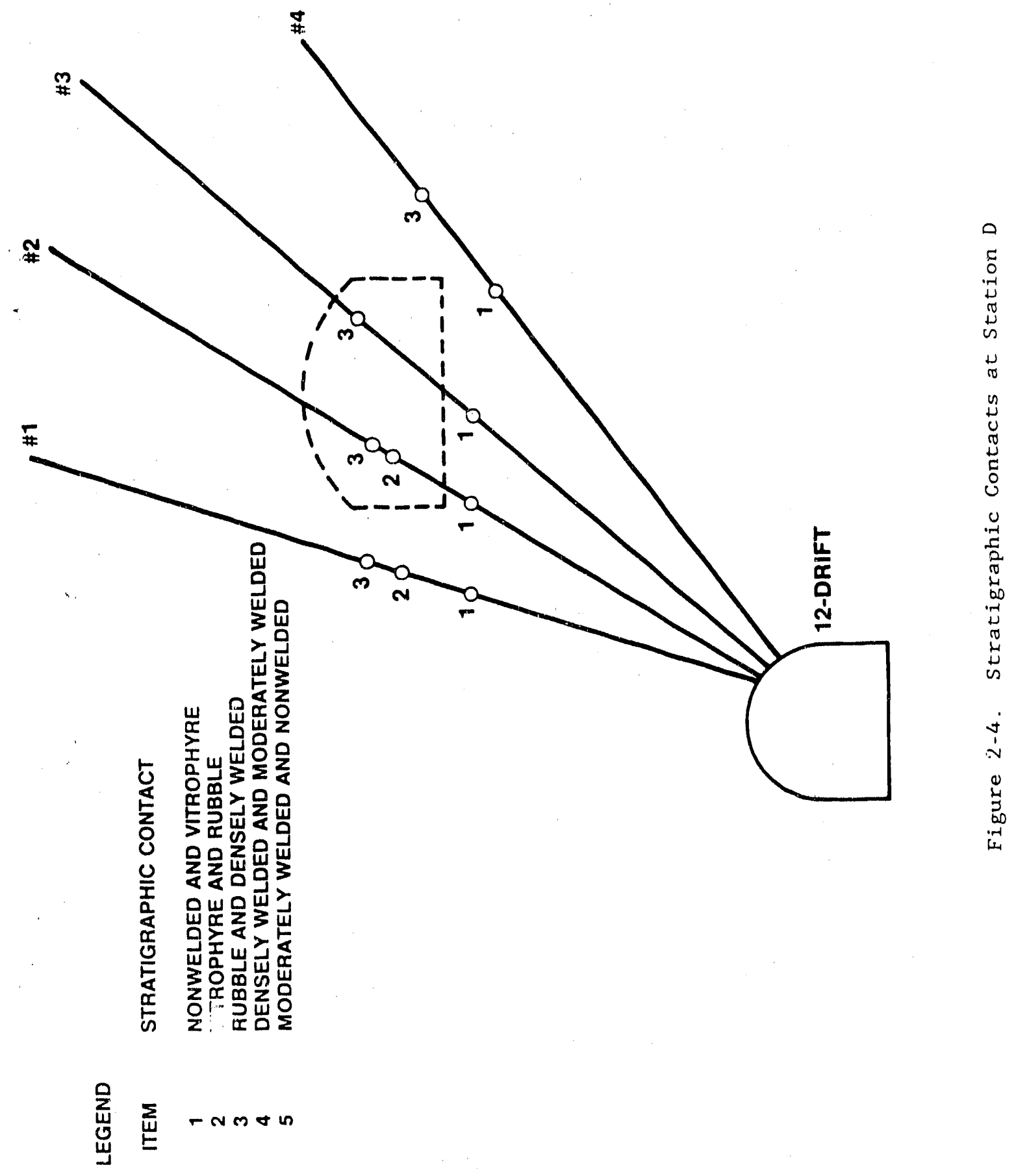




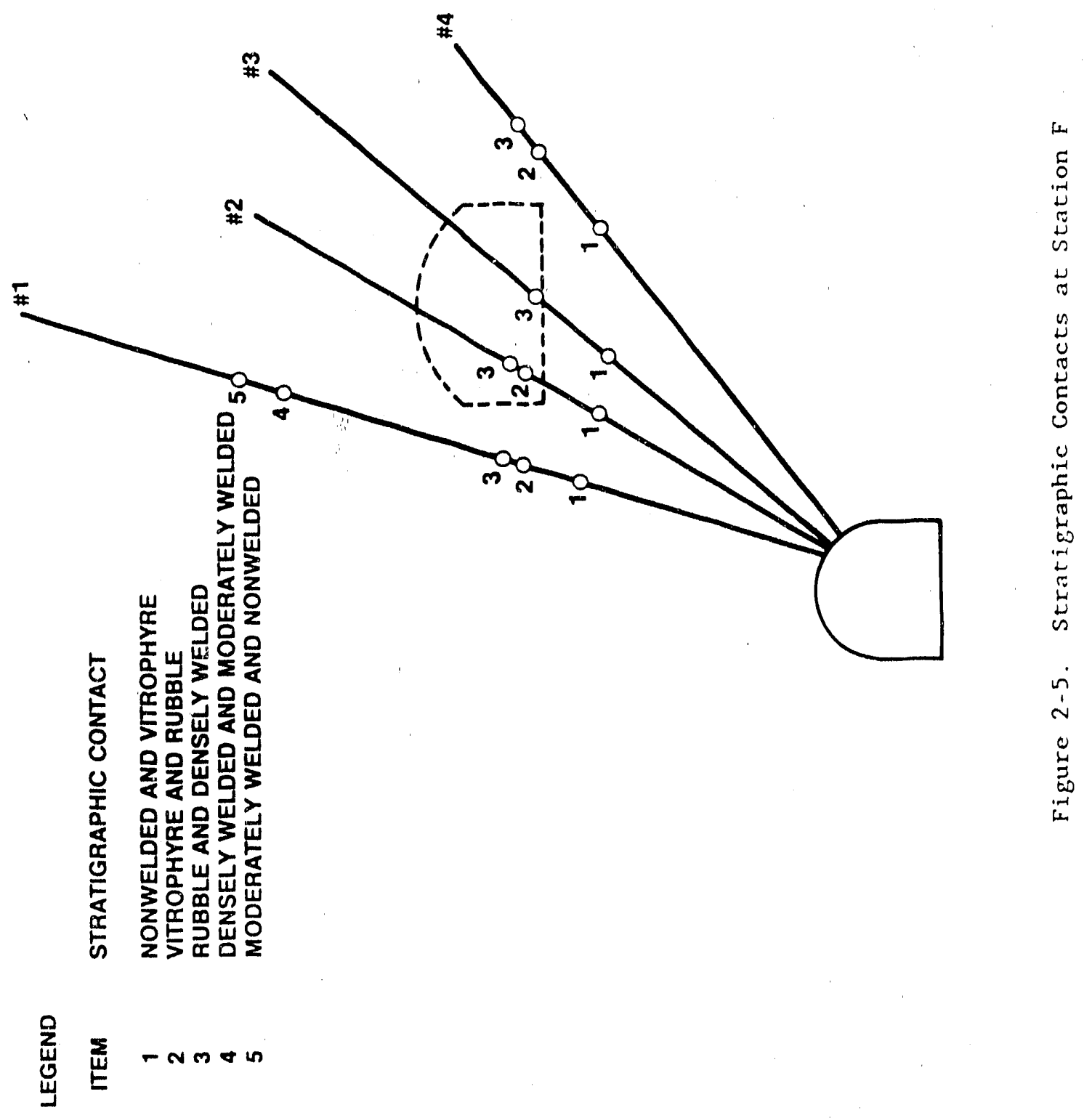


TABLE 2-2, STRATIGRAPHIC DESCRIPTION*

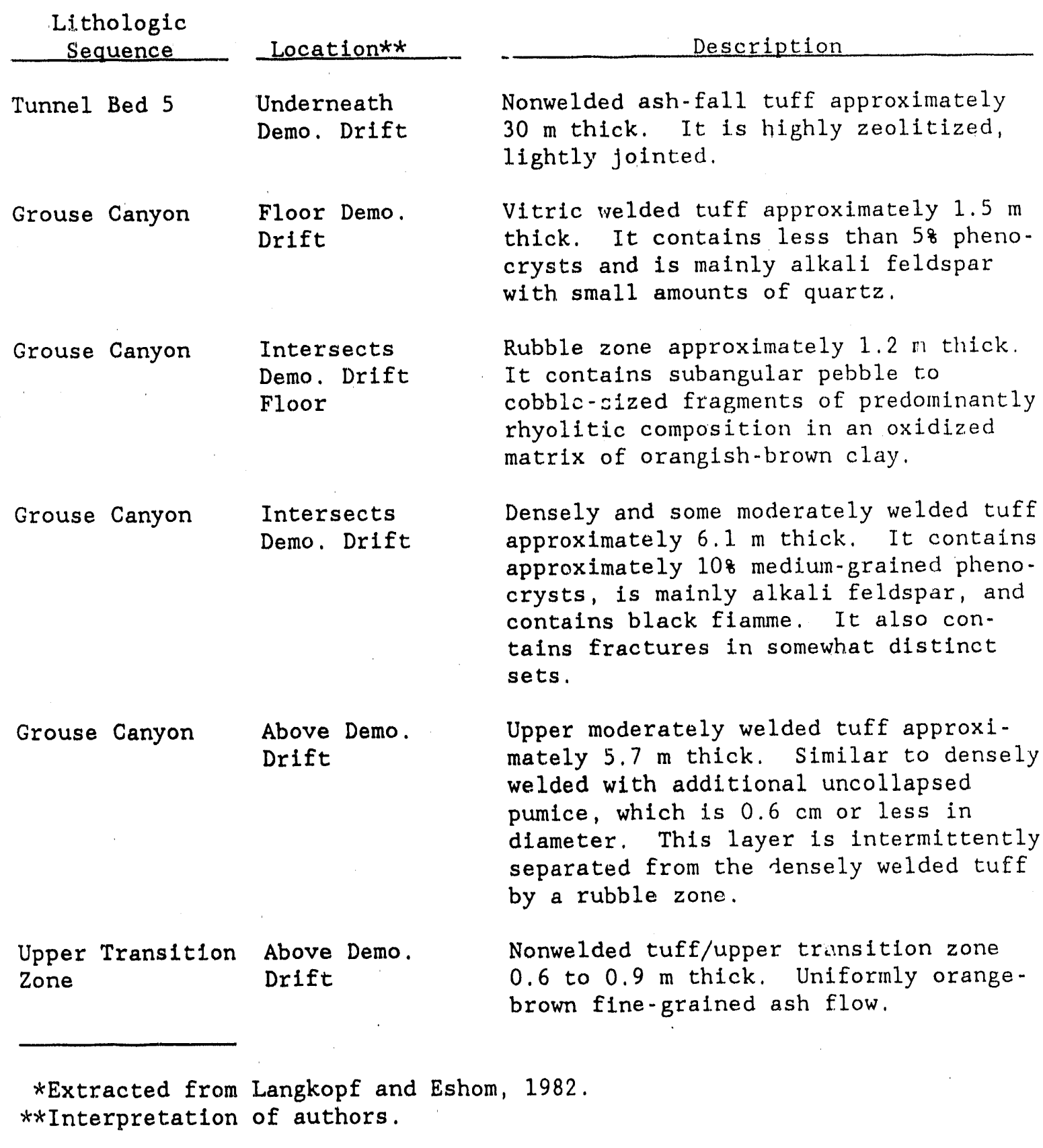


for stratigraphic contacts and sugges ed a fault was present. A fault with a 3.6-m displacement was located in the nonwelded tuff after an inspection by the G-Tunnel geologist.

The original test plan located the Demonstration Drift entirely in dersely welded tuff on the basis of geological logs suggesting that the densely welded tuff was thickening in the direction of the intended mining. The descriptions obtained from the 12-Drift cores showed that the densely welded tuff did not thicken and, in fact, showed that the floor of the planned Demonstration Drift would be located in different parts of the stratigraphy. Figure 2-3, shows that the floor of the Demonstration Drift would be near the rubble zone at Station $C$ and in the vitric zone at Station E. Two options were considered: (1) continue the drift along the original grade and keep the roof in the densely welded tuff or (2) ramp up slightly and keep the entire drift in the densely welded tuff, but keep roof stabilization in overlying moderately welded tuff. Option 1 was selected because it was felt that it was more important to stabilize the drift in the densely welded material and focus the evaluations on the behavior of the roof of the drift. 


\subsection{DATA ACQUISITION SYSTEMS (DASS)}

Data were acquired using either computer-operated systems or manual recordings. These two methods are discussed in Chapters 3 through 5 .

\subsection{Computerized Data Acquisition}

The computer system was located in the Instrumentation Alcove, which is a part of the GTUF.

\subsubsection{Components of the Data Acquisition System}

The block diagram describing the computer-based DAS is shown in Figure 3-1. Essential components of the system are

1. Sensor Excitation and Signals,

2. Digital Voltmeter-Scanner,

3. Desktop Computer,

4. Hard Disk Storage,

5. Floppy Disk Storage,

6. Sensor Power Supplies, and

7. Uninterruptible Power Supply.

These components are briefly discussed in the following paragraphs.

The sensors lised employed one of the following measurement technologies: electrical resistance strain gages, direct current-linear variable differential transformers (DC-LVDT), potentiometers, or sonic wave velocities. These sensors required different types of excitation and signal conditioning; details are discussed in the respective instrumentation sections.

The Hewlett Packard (HP) 3497 digital voltmeter-scanner was the DAS voltage monitoring unit used to record sensor outputs. The sensors were 


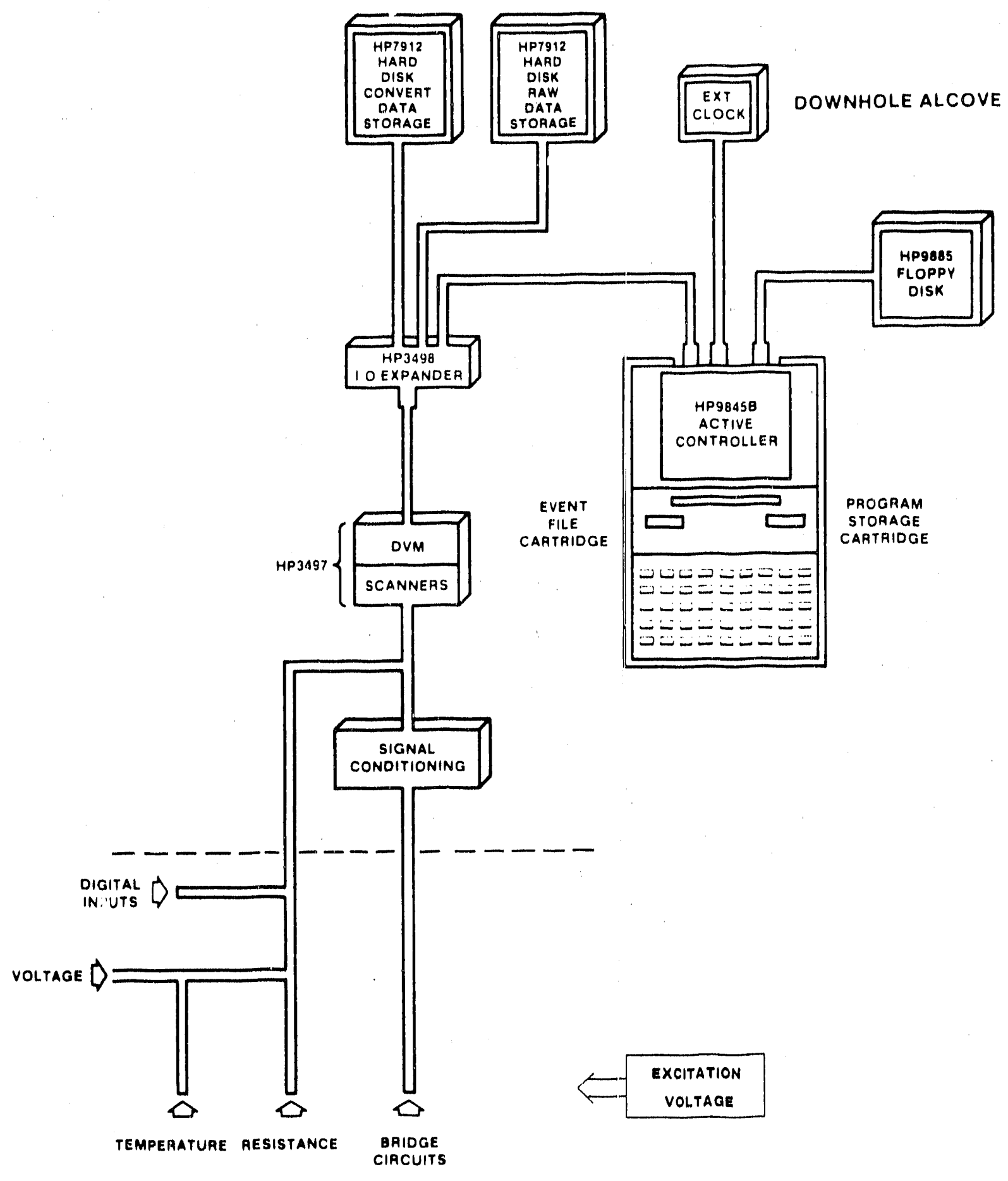

Figure 3-1. Block Diagram Il.lustrating DAS 
under continuous excitation from power supplies located in the Instrumentation Alcove. Eight different power supplies provided excitation voltages directly to the sensors. Different power supplies were used for different types of instruments and for multiple units of simila: instruments. Excitation voltages were continuously monitored in the DAS.

An HP 9845 B desktop computer served as the central processing unit. Acquisition of data occurred at regular intervals that were specified by the investigators and controlled through the computer.

Output signals from the sensors were stored on two HP 7912 hard disks. Raw output voltages were stored on one disk and converted data were stored on the other. Converted data were calculated from software stored in the computer. The computer could provide for conversions from voltages to the corresponding engineering units and would allow a limited amount of data manipulation.

Data were converted from raw voltages using calibration factors and initial values stored in the calibration file. The calibration file was stored on an HP 9885 Fl sppy Disk.

The DAS was powered by an Elcard, Model $252-1,2.5-\mathrm{kW}$ uninterruptible power supply (UPS). The UPS was connected to the tunnel instrumentation power line; thus, it was under continuous charge. The UPS was used to provide (1) continuous and constant voltage power to the DAS and power supplies, (2) stability to variations of instrumentation line power, and (3) uninterrupted power if there was a loss of line power. The UPS could operate at a rate of $2.5 \mathrm{~kW}$ for up to $5 \mathrm{hr}$ without charging.

\section{1 .2 Types of Instruments}

Table 3-1 1ists the number of and different types of instruments that were monitored on the DAS. Different sensors are identified with acronyms for $1 a$ er conventence. Also included in the table are descriptions of the measurement principles and excitation voltage requirements. 
䳝

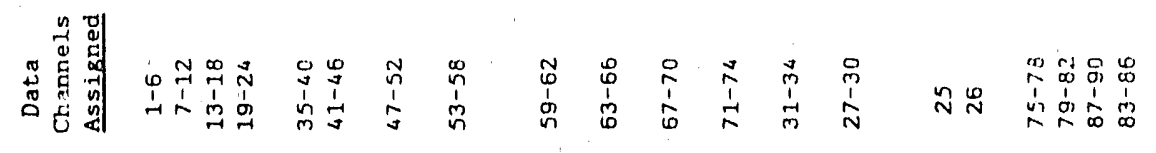

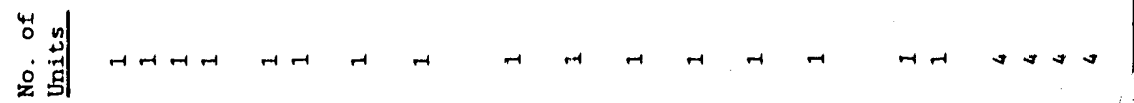

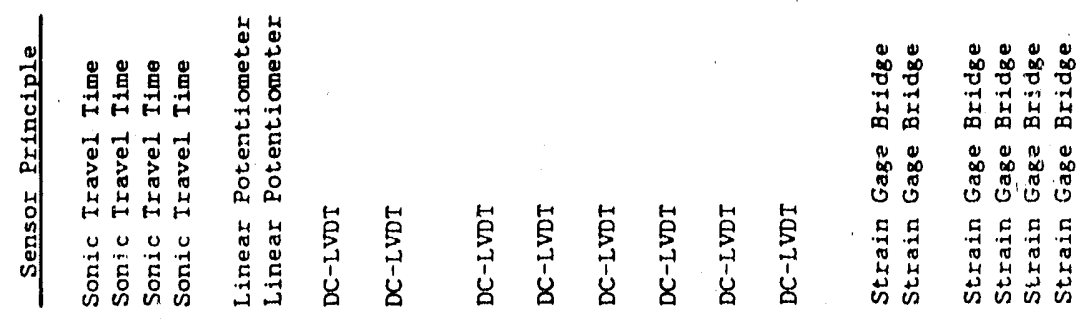

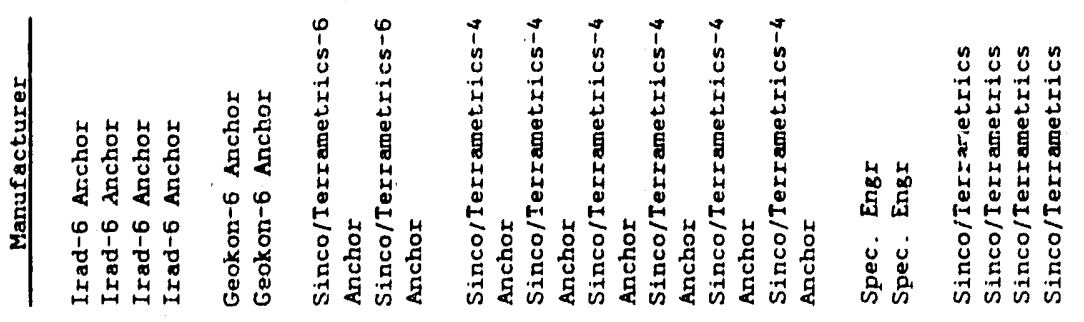

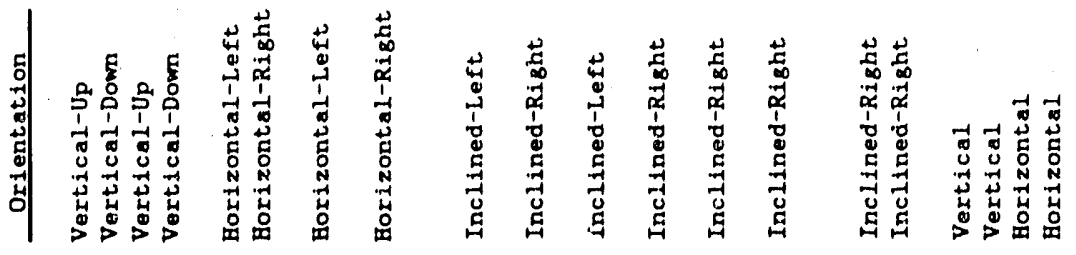

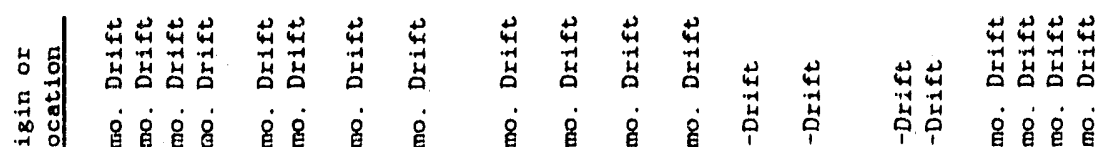

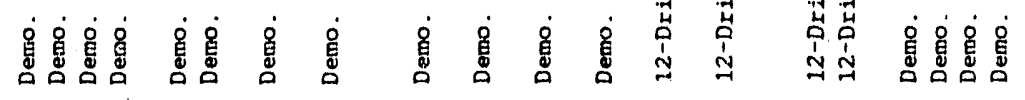
章这

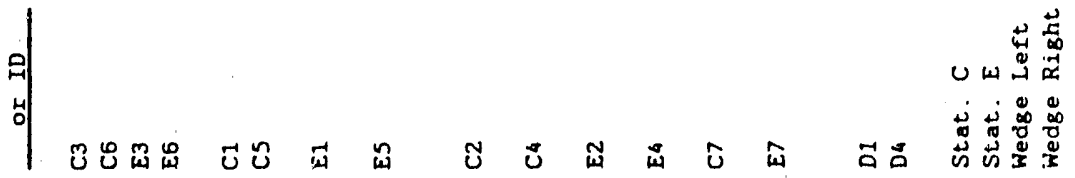

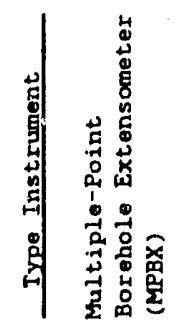

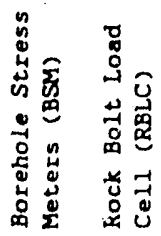




\subsubsection{Data Operations}

The normal mode of oper -ion was for the data to be recorded and stored on the HP 7912 hare .sks at G-Tunnel, and then all available files and programs were transferred to a tape cassette, which was hand-carried to Albuquerque for additional processing for reports. Data were collecred in a series of scans, each of which consisted of recording the DVM-scanner outputs for each channel and then converting the voltages or processed sonic probe quantities to reduced data. Complete processing for a scan took less than $3 \mathrm{~min}$. Each scan (thus each channel) was identified by time, scan number, file number, and calibration file reference number. The latter was used because it was necessary to make changes in the calibration file as new instruments were brought on line and because a complete record of all calibration activities was wanted. The time records were expressed in terms of $\mathrm{J}$-days, which were numerical accountings of days in decimal form starting with the first day of each calendar year.

Scanning frequencies were set by the DAS operator in G-Tunnel through the use of special function keys on the computer. Special function controls were available to do the following:

1. Change the scan rate and set times for scans.

2. Cause the computer to force a scan immediately.

3. Disabie data printing on the internal printer so that there were no hard copy records of scans.

4. Re-enable data printing on the internal printer so that scan records could be printed either as a full record or a single line indicating time, scan number, file number, and calibration file used.

5. Plot data versus time on the internal printer. 
6. View and edit the calibration file. A new file number was automatically recorded if a calibration fllo was changed.

7. Stop the program.

\subsection{Manually Recorded Data}

Manual data were recorded on special forms that were designed for each type of instrument. Table 3-2 summarizes the different types of measurements recorded manually. 


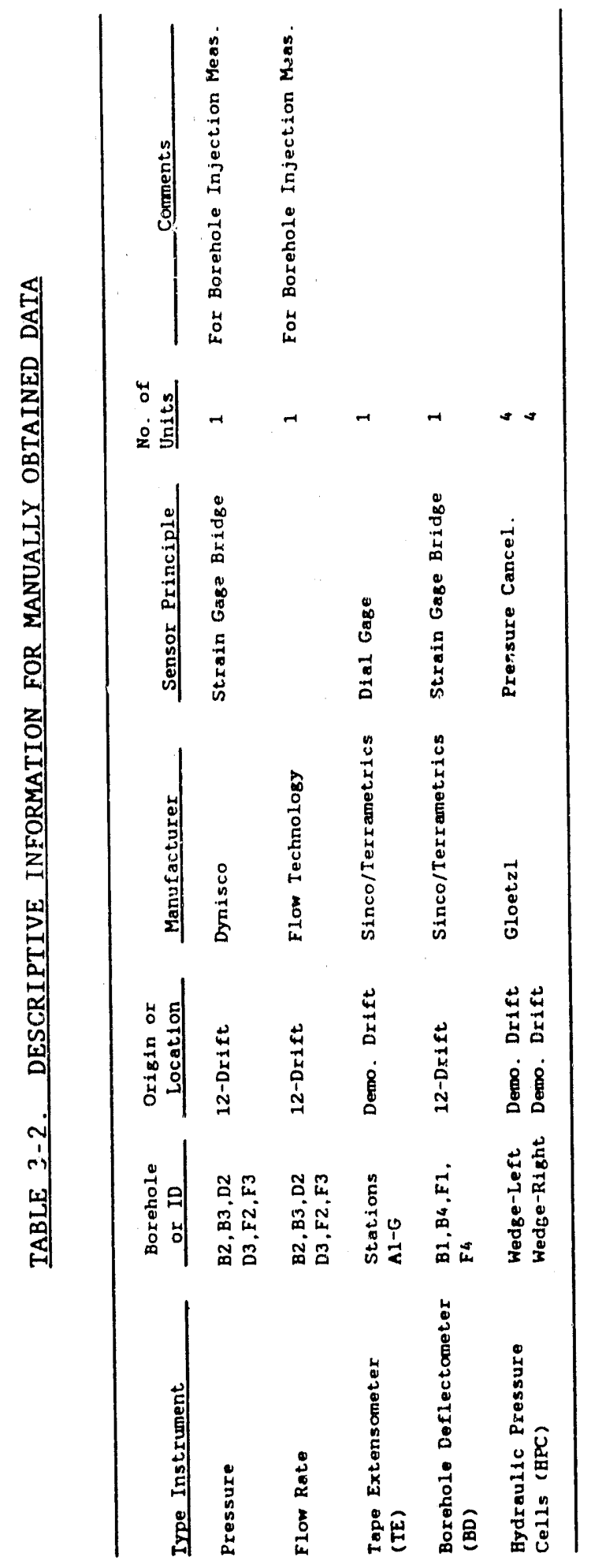




\subsection{DAS CONNECTED INSTRUMENTATION DESCRIPTIONS}

\section{4:1 Multiple-Point Borehole Extensometers (MPBX)}

\subsubsection{MPBX--Components and Principles}

MPBXs are widely used in geomechanics to measure relative displacements between points in a rock mass. Relative displacements between anchors in the rock and the sensing unit on the surface can be used to help describe rock mass stiffness and strength behavior as well as to measure the relaxation phenomena in the rock mass that occurs around an opening. MPBXs can be more effective if they are installed prior to or as part of the excavation process; this is one of the main uses of MPBXs in planned ES testing.

An MPBX consists primarily of (1) a head, (2) the collar pipe, (3) the rods, and (4) the anchors (Figure 4-1). The head contains the sensors. Usually the head has a removable cover to protect the sensors. The main unction of the head is to serve as a fixture to transfer movements of rod ends to appropriate sensors. MPBXs can have sensors that are manually read or monitored by the DAS. The sensors that are monitored by a DAS operate electronically, and the electronic hardware can be sensitive to shock waves created during blasting. Three different types of electronic sensors were evaluated in blasting environments. The three different sensors selected were (1) a sonic probe, manufactured by Irad, (2) a DC-LVDT, manufactured by Sinco/Terrametrics, and (3) a linear potentiometer, manufactured by Geokon.

The collar pipe serves to fix the head to the end of the borehole. Collar pipes are designed by the manufacturers for various purposes. For instance, the collar pipe for the Irad MPBX contained some of the sensing instrumentation and necessarily had to be longer than the others.

The rods serve as connecting mechanisms between the anchors and sensors. The ideal rod remains friction free in the borehole and is 


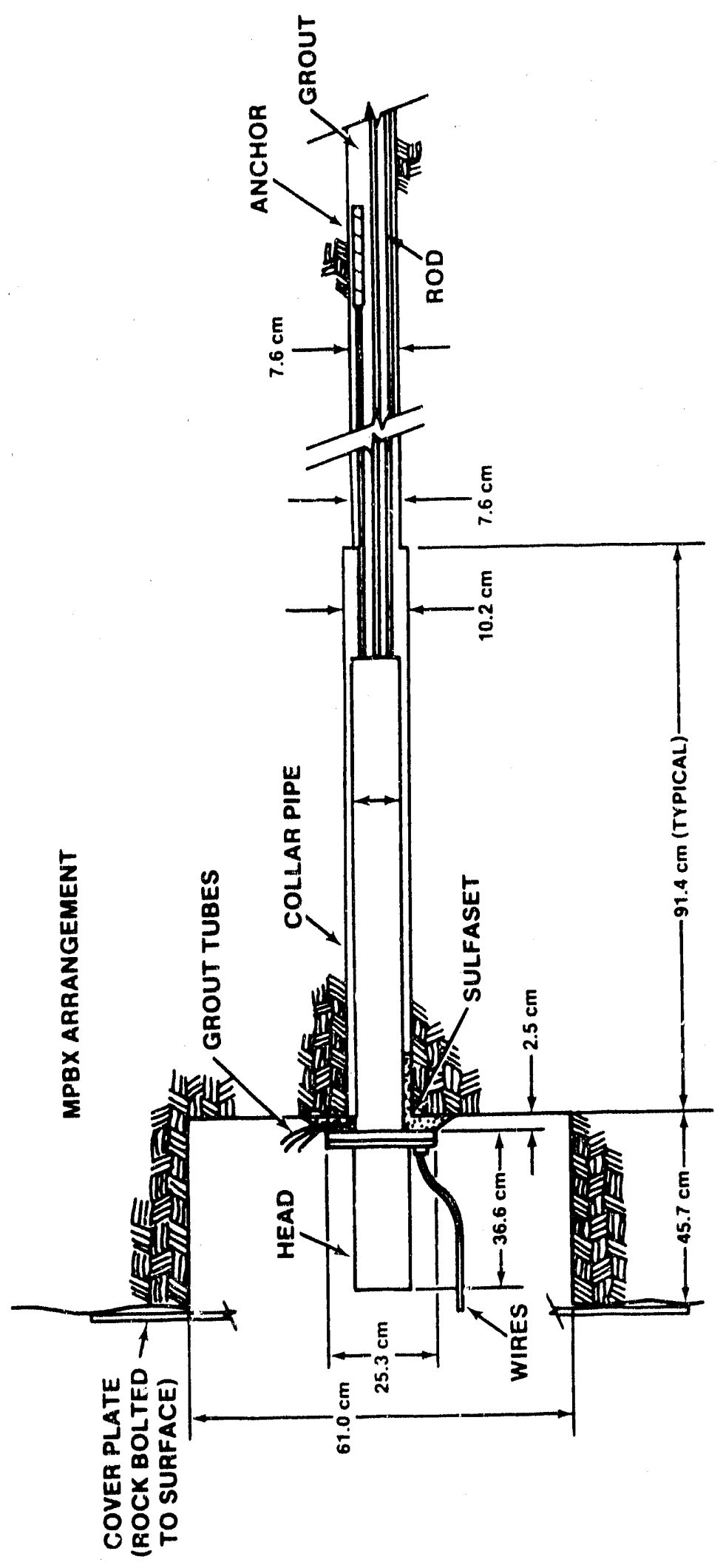

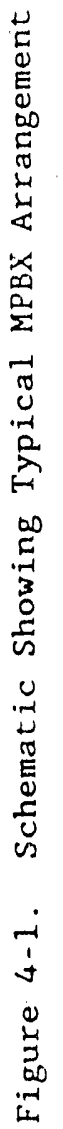


relatively insensitive to thermal gradients. Friction reduction is achieved by enclosing the rod in a plastic or metallic conduit so that grout or loose rocks do not interfere with the rod movements. Special metals, such as invar, are used in MP.BXs for environments with thermal gradients. All WTM work was planned for ambient temperatures, which remain quite stable in the tuff in G-Tunnel, and stainless steel rods were used in all MPBXs.

A number of anchor types are commercially available, such as mechanical, hydraulic, and grouted. Grouted anchors had been selected for use in the fractured welded tuff in other work (Zimmerman et al., 1986) and performed well. Grouted anchors have advantages for long-term monitoring and are considered more stable in a blast environment. Grouted anchors have the disadvantage of the grouting process, which is sometimes difficult to do in an upward direction in fractured rock. Because it was felt that the advantages outweighed the disadvantages, grouted anchors vere selected for this first effort.

Table 4-1 summarizes the MPBX anchor locations and identifies the data channels assigned to each of the anchors.

\subsubsection{MPBX--Irad Measurement Equipment}

Irad (Model 4500-6 anchor) MPBXs were used in the WTM evaluations. The model is designed for use with a dial gage micrometer or a sonic probe. Irad MPBXs were selected for use in the WTM because of two design features: (1) isgh resistance to electrical interference and (2) the ability to interchange electronic and manual (dial gage micromeier) sensing units. The sonic principle used with the Irad units amploys time measurements in the MPBX head, which are transmitted digitally to a readout meter. This ineans that the signal in the cable between the MPBX and the readout meter is insensitive to undesirable voltage surges that can be induced by under. ground mining activities. The unit is designed for data transmission distances up to $183 \mathrm{~m}$. The second design feature was desirable because of the possibility that sensors with electronic components could not be used 
TABLE 4-1. MPBX DESCRIPTIVE INFORMATION

\begin{tabular}{|c|c|c|c|}
\hline $\begin{array}{l}\text { Station- } \\
\text { Position } \\
\text { (Manuf,) }\end{array}$ & Direction & $\begin{array}{c}\text { Data } \\
\text { Channe1 }\end{array}$ & $\begin{array}{l}\text { Anchor Depth } \\
\text { from Collar } \\
\text { (m) }\end{array}$ \\
\hline $\begin{array}{l}\text { C3 } \\
\text { (Irad, 6-Anchor) }\end{array}$ & Up & $\begin{array}{l}1 \\
2 \\
3 \\
4 \\
5 \\
6\end{array}$ & $\begin{array}{r}14.31 \\
1.22 \\
1.65 \\
2.94 \\
3.95 \\
4.94\end{array}$ \\
\hline $\begin{array}{l}\text { C6 } \\
\text { (Irad, 6-Anchor) }\end{array}$ & Down & $\begin{array}{r}7 \\
8 \\
9 \\
10 \\
11 \\
12\end{array}$ & $\begin{array}{r}14.32 \\
1.23 \\
1.95 \\
2.96 \\
3.96 \\
4.95\end{array}$ \\
\hline $\begin{array}{l}\mathrm{C} 1 \\
\text { (Geokon, 6-Anchor) }\end{array}$ & Left & $\begin{array}{l}35 \\
36 \\
37 \\
38 \\
39 \\
40\end{array}$ & $\begin{array}{r}14.00 \\
1.25 \\
2.00 \\
3.00 \\
4.00 \\
5.00\end{array}$ \\
\hline $\begin{array}{l}\text { C5 } \\
\text { (Geokon, 6-Anchor) }\end{array}$ & Right & $\begin{array}{l}41 \\
42 \\
43 \\
44 \\
45 \\
46\end{array}$ & $\begin{array}{r}14.00 \\
1.25 \\
2.00 \\
3.00 \\
4.00 \\
5.00\end{array}$ \\
\hline $\begin{array}{l}\text { C2 } \\
\text { (Sinco/Terrametrics, } \\
4 \text { Tensioned Anchor } \\
\text { Rods) }\end{array}$ & Inclined-Left & $\begin{array}{l}59 \\
60 \\
61 \\
62\end{array}$ & $\begin{array}{r}14.00 \\
1.25 \\
2.00 \\
3.00\end{array}$ \\
\hline $\begin{array}{l}\text { C4 } \\
\text { (Sinco/Terrametrics, } \\
4 \text { Tensioned Anchor } \\
\text { Rods) }\end{array}$ & Inclined-Right & $\begin{array}{l}63 \\
64 \\
65 \\
66\end{array}$ & $\begin{array}{r}14.00 \\
1.25 \\
2.00 \\
3.00\end{array}$ \\
\hline $\begin{array}{l}\text { C7* } \\
\text { (Sinco/Terrametrics, } \\
4 \text { Tensioned Anchor } \\
\text { Rods) }\end{array}$ & Inclined-Remote & $\begin{array}{l}31 \\
32 \\
33 \\
34\end{array}$ & $\begin{array}{r}10.00 \\
9.06 \\
8.12 \\
7.19\end{array}$ \\
\hline
\end{tabular}




\begin{tabular}{|c|c|c|c|}
\hline $\begin{array}{l}\text { Station- } \\
\text { Position } \\
\text { (Manuf.) }\end{array}$ & Direction & $\begin{array}{c}\text { Data } \\
\text { Channe1 } \\
\end{array}$ & $\begin{array}{l}\text { Anchor Depth } \\
\text { from Collar } \\
\text { (m) }\end{array}$ \\
\hline $\begin{array}{l}\text { E3 } \\
\text { (Irad, 6-Anchor) }\end{array}$ & Up & $\begin{array}{l}13 \\
14 \\
15 \\
16 \\
17 \\
18\end{array}$ & $\begin{array}{r}14.00 \\
1.25 \\
2.00 \\
3.00 \\
4.00 \\
5.00\end{array}$ \\
\hline $\begin{array}{l}\text { E6 } \\
\text { (Irad, 6-Al.chor) }\end{array}$ & Down & $\begin{array}{l}19 \\
20 \\
21 \\
22 \\
23 \\
24\end{array}$ & $\begin{array}{r}14.00 \\
1.25 \\
2.00 \\
3.00 \\
4.00 \\
5.00\end{array}$ \\
\hline $\begin{array}{l}\text { E1 } \\
\text { (Sinco/Terrametrics, } \\
6 \text { Tensioned Anchor } \\
\text { Rods) }\end{array}$ & Left & $\begin{array}{l}47 \\
48 \\
49 \\
50 \\
51 \\
52\end{array}$ & $\begin{array}{r}14.00 \\
1.25 \\
2.00 \\
3.00 \\
4.00 \\
5.00\end{array}$ \\
\hline $\begin{array}{l}\text { E5 } \\
\text { (Sinco/Terrametrics, } \\
6 \text { Tensioned Anchor } \\
\text { Rods) }\end{array}$ & Right & $\begin{array}{l}53 \\
54 \\
55 \\
56 \\
57 \\
58\end{array}$ & $\begin{array}{r}14.00 \\
1.25 \\
2.00 \\
3.00 \\
4.00 \\
5.00\end{array}$ \\
\hline $\begin{array}{l}\text { E2 } \\
\text { (Sinco/Terrametrics, } \\
4 \text { Tensioned Anchor } \\
\text { Rods) }\end{array}$ & Incliner-Left & $\begin{array}{l}67 \\
68 \\
69 \\
70\end{array}$ & $\begin{array}{r}14.00 \\
1.25 \\
2.00 \\
3.00\end{array}$ \\
\hline $\begin{array}{l}\text { E4 } \\
\text { (Sinco/Terrametrics, } \\
4 \text { Tensioned Anchor } \\
\text { Rods) }\end{array}$ & $\begin{array}{l}\text { Inclined-Right } \\
-\end{array}$ & $\begin{array}{l}71 \\
72 \\
73 \\
74\end{array}$ & $\begin{array}{r}14.00 \\
1.25 \\
2.00 \\
3.00\end{array}$ \\
\hline $\begin{array}{l}\text { E7* } \\
\text { (Sinco/Terrametrics, } \\
4 \text { Tensioned Anchor } \\
\text { Rods) }\end{array}$ & Inclined-Remote & $\begin{array}{l}27 \\
28 \\
29 \\
30\end{array}$ & $\begin{array}{r}10.00 \\
9.06 \\
8.12 \\
7.19\end{array}$ \\
\hline
\end{tabular}


In instruments placed in close proximlty to the blast face and manual measurements might have to be used unt1l the blast face was located some distance from the instrument. Sonic probes were used for all measurements.

The collar pipe on this model is normally $1.8 \mathrm{~m}$ long. The collar pipe was shortened by Irad to $1.2 \mathrm{~m}$ to facilitate our measurements near the surface. This required a small modification in the location of the first anchor by the manufacturer.

The sonic probe measures the time interval requirad for a stress wave to travel between two or more points in a tube containing a magnetostrictive material. Individual anchors are attached to magnets in the probe through the rods, and movements of the magnets cause changes in the time intervals. The time interval measurement is converted to a displace. ment through an Irad Sonfc Probe MB-7 Digital Readout Meter (DRM). The Irad MPBX was designed to operate as a manually operated unit, and anchor displacements would normally be read directly on the DRM. SNL purchased the DRM with an external BCD connection plug. SNL designes and fabricated a driver circult and a relay switching circult to interface with the DAS and the DRM. These 1 tems were conflgured and controlled with software so that the normal DAS scan operation would address prescribed channels in the DRM and transfer the digital distance output to a recorded value in the DAS .

\subsubsection{MPBX--Sinco/Terrametrics Measurement Equipment}

Sinco/Terrametrics Mode1 6-CSLT (6-anchor) and Mode1 4-CSLT (4-anchor) MPBXs were used in the measurements. These models used Trans Tek Model 043-11 sensors and were selected because of (1) previous satisfactory experlences in the $G$-Tunnel heated block measurements (Zimmerman et al., 1986), (2) use of tensioned anchor rods, and (3) a built-in capability fcr in situ calibrations. The authors wished to evaluate the friction reduction aspects of these instruments in the high-acceleration environment assoclated with the blasting. 
The sensors operate using a direct current LVDT. A DC-LVDT contains two major components: (1) the body, which contains the electronics, and (2) the sliding core, which translates with the anchor movement. When the body is excited with a stable reference voltage, the interaction of the body and the core results in a voltage output indicating the relative position of the two components.

\subsubsection{MPBX--Geokon Measurement Equipment}

Geokon, Model A3, 6-anchor rod-type MPBXs were also used. Geokon MPBXs were selected for use because of two features: (1) simplicity of electronics and (2) potential for use with short collar pipes. The sensors in the Geokon units were linear potentiometers, which have been widely used in underground measurements. Geokon MPBXs use untensioned anchor rods, a practice common in underground measurements involving mining activities. The unt had six rods covered with schedule 40 PVC protective tubing.

\subsubsection{MPBX--Installation Sequences and Protective Measures}

The normal sequence for the installation and operation of all MPBXs at Stations $C$ and $E$ consisted of

1. blasting a recess;

2. drilling the borehole;

3. assembling the rods, protective conduits, grout tubes, and collars, which contain the heads;

4. Inserting the MPBX assembly in the borehole and grouting the collars to the hole;

5. grouting the anchors in place using a staged grouting procedure; 
6. Installing the instrument head in the collar pipe and connecting the electronics through the DAS;

7. performing field calibrations and sensor continuity checks;

8. initializing the DAS and monitoring sensor outputs; and

9. Installing protective cover plates and steel channels before further mining (for MPBXs located in the Demonstration Drift).

Figure 4-1 also shows details associated with the protection of the MPBXs in the rock. Each head was recessed and covered with a protective plate because these MPBXs were placed next to soon-to-be-mined faces. Electrical leads from the MPBXs were protected with steel channels outside the recesses. The channels were welded together to provide continuity and held against the roof with rock bolts.

Recesses and cover plates were not used with Units C7 and E7 because their heads were located in the premined 12-Drift.

\subsection{Borehole Stressmeter (BSM)}

A number of instruments for measuring stress changes within rock masses are available commercially, but only devices that are not easily dislodged during blasting activities are suitable for determining excavation effects. A BSM suitable for such applications was tested and evaluated here for potential use in future ES testing.

\subsubsection{Measurement Principle.}

Hawkes and Bailey (1973) developed a rigid inclusion device by fabricating a stressmeter using a vibrating wire as the sensor; the device is called a vibrating wire stressmeter (VWS). The VWS forms a rigid inclusion in the rock mass, which means that the stressmeter is considerably stiffer than the surrounding rock. The device is wedged in a borehole. The 
wedging action keeps the stressmeter in place during monisoring, and it is considered immovable during rock mass vibrations induced by blasting. Changes in the stress field normal to the borehole are reflected in changes in the dimensions of the stressmeter, which can be experimentally related to force or stress changes in the rock through special calibrations (Hawkes and Bailey, 1973).

Cook and Ames (1979) at SNL found that there were difficulties in setting VWS in relatively soft rocks. They redesigned the VWS units to increase the sizes of the platens and to decrease the stiffness. They changed the measurement method by substituting a strain-gaged prism for the vibrating wire sensor. The VWS requires a special data logger to read its output. The SNL-designed BSM is a speclal version of the VWS and consists of an outer body with an external shape similar to the VWS. The SNLdesigned BSM can be read with a conventilonal data logger. Johnstone et al. (1985) used the SNL-designed unit to measure thermal stress increases in welded tuff and reported time-dependent problems. The problems did not suggest that a smaller platen, such as fis used with the VWS, would be a solution. The readily available technology and experiences with the BSMS at SNL and the simplicity of the data logging requirements led to selection of BSMs for use in the WTM.

The sensing element within the BSM consists of a brass plug containing four alloy grid strain gages (gage factor of 2.05). The strain gages have a thermal coefficient of expansion to match the brass plug that they are bonded to. Two of the strain gages read the compression of the plug and the other two provide temperature compensation in a wheatstone bridge configuration.

\subsubsection{Measurement Fquipment}

The two BSMs used in the WTM evaluations were manufactured by Specialty Engineering Associates. One of the BSMs, identified as $1 \mathrm{~N}$, was installed as issued in Borehole D1 (Figule 2-4), which was $48 \mathrm{~mm}$ in diameter ( $A Q$ size). Figure 4-2a shows a diagram of the unit. The other 

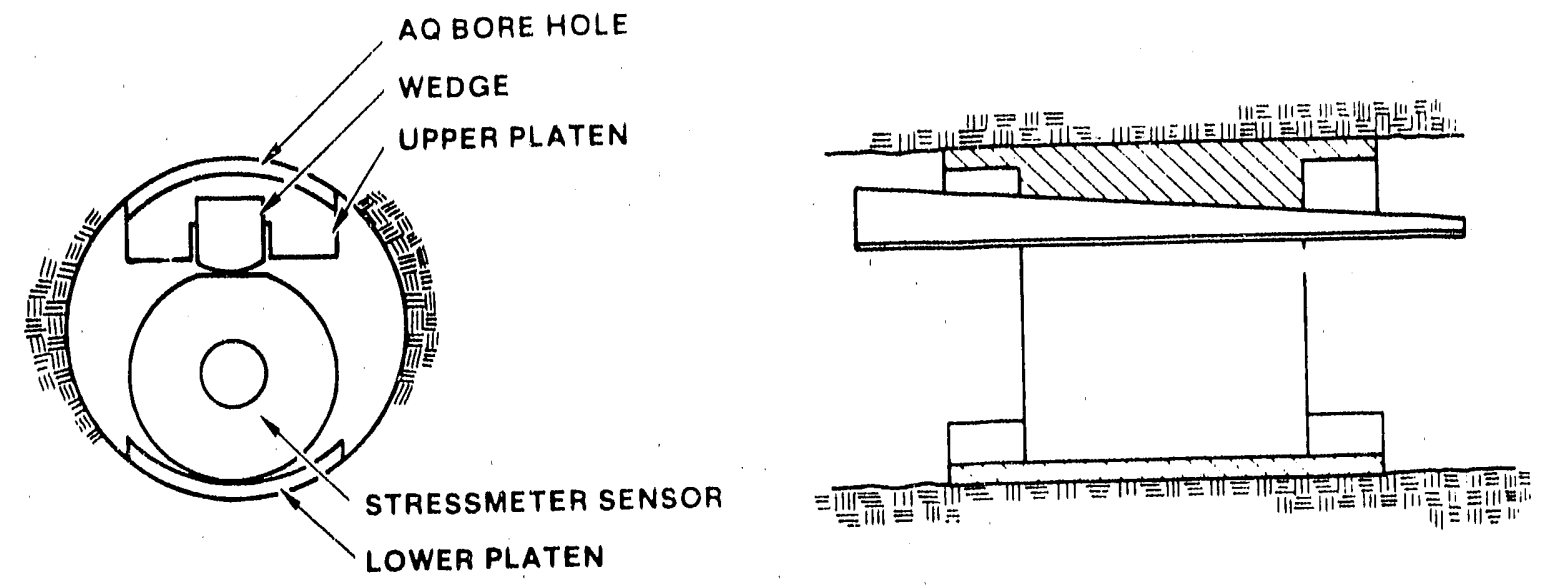

(a) AQ-Sized Hole
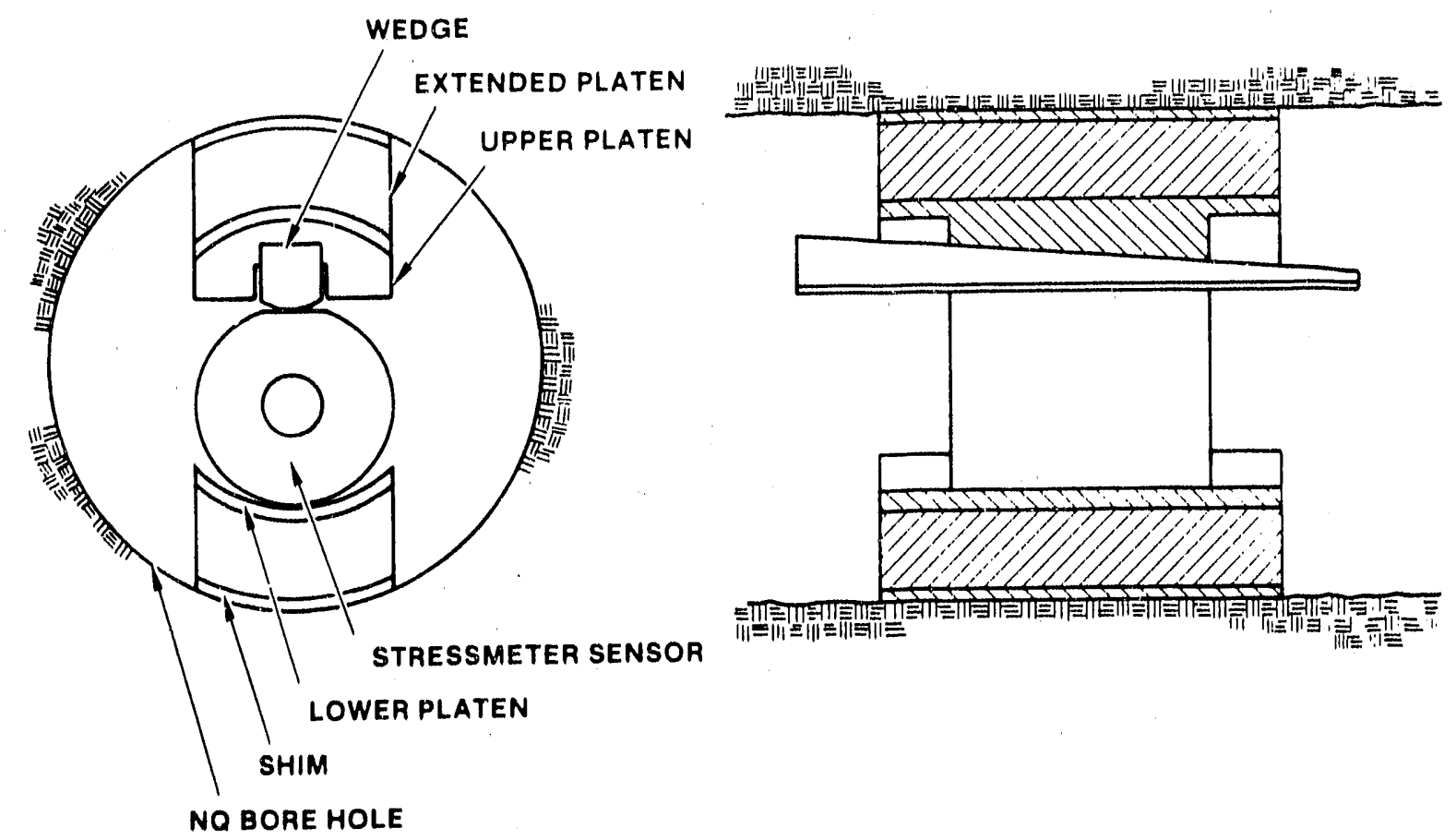

(b) NQ-Sized Hole

Fi.gure 4-2. Schematics Showing BSM Placements 
BSM, Identifled as $6 \mathrm{~N}$, was modifled by Science Applications International Corporation (SAIC) to f1t a larger borehole (D4), which was $76 \mathrm{~mm}$ in diame:er (NQ size). Borehoia D4 was drilled larger than D1 and was the same diameter as the nearby borehole infection (BI) holes. The $6 \mathrm{~N}$ unit was modifled for use by adding speclal bearing plates to the original unit, as shown in Figure 4-2b. The extra bearing plates were bonded to the smaller BSM with Hardman 5-min epoxy.

\section{2 .3 Installation Sequence}

The installation sequence for the BSMs consisted of

1. connecting the setting tool and setting rods to the BSM;

2. connecting the lead wires to the $P 350$ Vishay Strain Indicator at the proper calibration factor;

3. pushing the BSM to the desired depth and orientation in the hole (one BSM was installed in each hole with the sensing direction vertical);

4. slowly pressurizing the setting-tool hydraulic jack and connecting cable until the shear pin, which couples the wedge to the rest of the BSM, shears (accompanying pressure monitoring is used to indicate the pressure required to set the wedge in the rock; setting pressures varied from 11 to $12 \mathrm{MPa}$ );

5. Initializing the BSM on the $P 350$ Vishay Strain Indicator and then connecting the leads to the DAS for initialization.

The BSMs were installed separately. BSM $1 \mathrm{~N}$ was installed at a depth of $12.5 \mathrm{~m}$ in Borehole D1. BSM $6 \mathrm{~N}$ was installed in Borehole D4 at a depth of $13.1 \mathrm{~m}$. 


\subsection{Rock Bolt Load Cell (RBLC)}

RBLCs are normally used to monitor changes in rock bolt forces that occur as a result of displacement changes in the nearby rock mass. They serve as useful monitoring devices in evaluating some aspects of underground safety. They were used here to augment the MPBX system in a manner planned for ES testing.

\subsubsection{Measurement Principle}

Rock bolts are tensioned steel reinforcing bars (rebars) that are placed in percussion drilled holes in the rock mass. The rebars are bonded or anchored to the rock and contain base plates that transmit the tightening forces to the rock surrounding the holes. For measurements, an RBLC is placed at the end of a selected rock bolt to measure the resultant force that is transmitted to the base plate. The RBLCs contain strain-gaged elements that are used with Wheatstone bridges to relate force changes to voltage changes.

Ordinarily, RBLCs are applied under conditions where the rock bolts are anchored on the ends and the tensile forces are distributed between the base plates and the anchors. In view of NTS safety considerations in the GTUF, the rock bolts were fully grouted. Thus, it is assumed that only a fraction of the total force transmitted to the rock bolt was distributed to a base plate.

\subsubsection{RBLC Measurement Equipment}

Sinco/Terrametrics, Model PC-60, steel units were selected for the evaluations. The units have a capacity of $535 \mathrm{kN}(120,000 \mathrm{lbf})$ with a nominal sensitivity of $\pm 267 \mathrm{~N}$ (60 1bf). Sixteen units were purchased for the evaluations. Four RBLCs were installed at each of two stations, as illustrated in Figure 4-3. These were used to monitor changes in the roof forces. The remaining eight RBLius were positioned on grout inserts tha: 


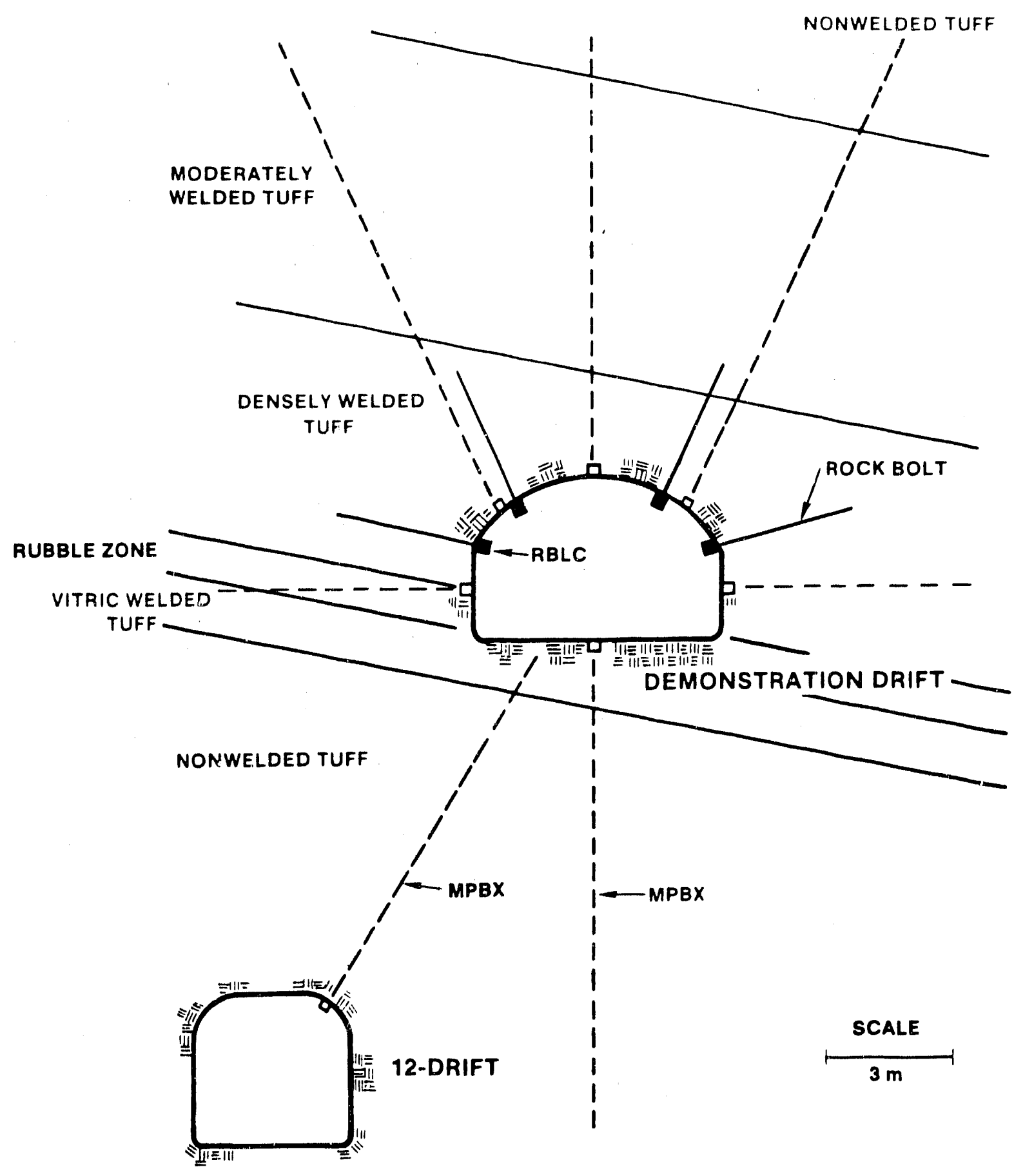

Figure 4-3. Elevation View Showing Principal RBLC Features 
contalned hydraulfc pressure cells (HPCs) and only the bottom $30 \mathrm{~cm}$ of connecting rock bolts were anchored. The inserts were cast in the sides of the Demonstration Drift for HPC evaluations, and RBLCs were applied to surfaces of the inserts (Figure 4-4) to pick up any load that the inserts might receive. The goal was to observe any RBLC load changes that were compatible with pressure changes in the HPCs.

The use of RBLCs in fractured rock can be improved by properly considering load cell alignment. The base plate bearing against the uneven rock surface can cause the RBLC and rock bolt to be out of line resulting in bending stresses in the rock bolts and possibly the RBLCs. The potential problem was addressed by grouting the base plates to the rock and by providing a spherical seat between the rock and the RBLC tension plate, as shown in Figure 4-5. The spherical seats were machined from ANSI 4340 steel by SAIC. The seats were proof tested through the full load range to establish acceptance. The actual bearing surface was covered with a thin layer of molybdenum grease to facilitate relative movements of the two parts.

\subsubsection{Installation Sequence}

Installation of the RBLCs consisted of

1. drilling a hole to proper depth;

2. Installing, the rock bolt with an attachment for RBLC installation, i.e., longer extension into the drift;

3. grouting the base plate;

4. initializing RBLC voltage to zero load before installing;

5. Installing the RBLC, spherical seat, tension plate, and tension nut; and 

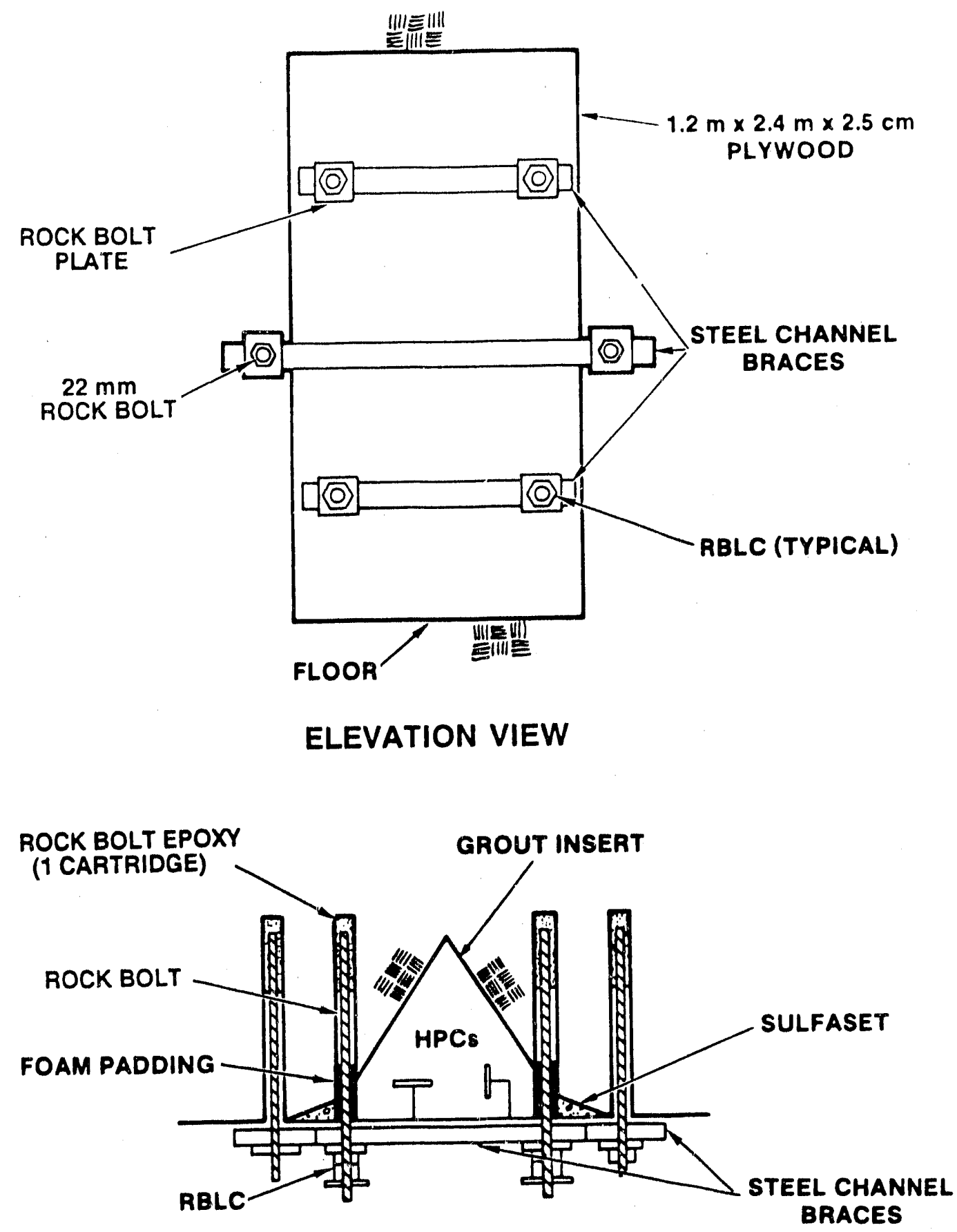

PLAN VIEW

Figure 4-4. Configuration of Panel Prior to Grouting 


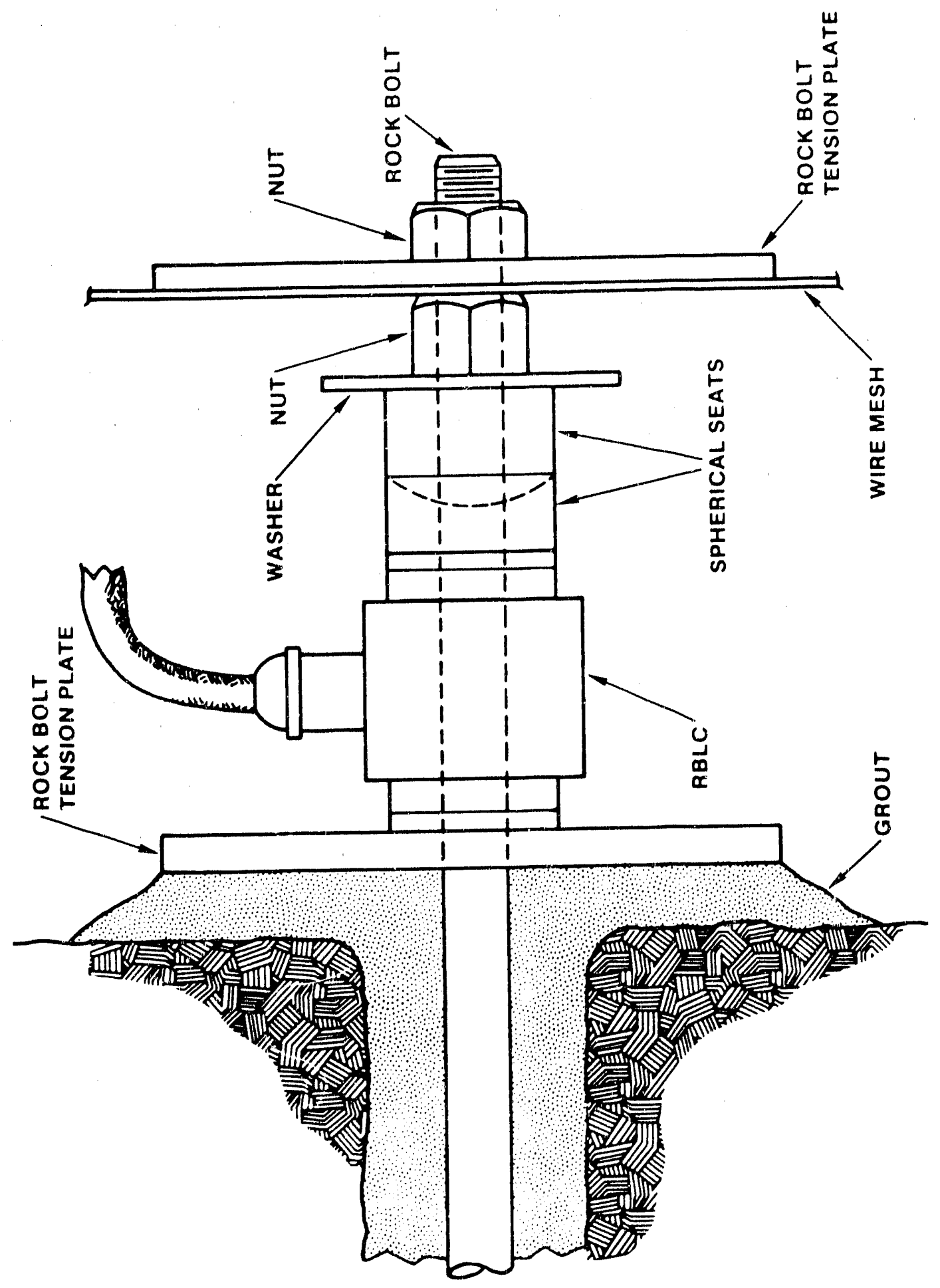

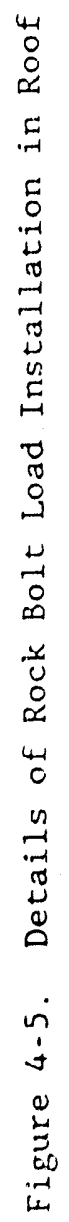


6. connecting the leads to the DAS, tightening the nut covering the tension plate, and initializing the force in the DAS.

The tightening process consisted of tightening the external nut until an air-driven socket wrench stalled out. The wrench produced a maximum torque of approximately $340 \mathrm{~N}-\mathrm{m}(250 \mathrm{ft}-\mathrm{lb})$. The output voltages were read after installation, and initial forces were set in the reference cali. bration file. Initial forces were set by manually tightening the external nuts until forces in the vicinity of $4.0 \mathrm{E}+4 \mathrm{~N}$ were achieved. No attempt was made to precisely set initial forces to a common value. 


\subsection{MANUAL MEASUREMENT DESCRIPTIONS}

\subsection{Tape Extensometer (TE)}

A $T E$ is a standard instrument consisting of a steel tape for measuring drift convergence phenomena between two anchors. TE measurements provided the most significant measurement set describing the drift convergence phenomena. TE stations were set at the end of nearly every blast round, and measurements were taken as the mining face advanced.

\section{1 .1 Messurement Principle}

A TE measurement is a direct measurement of the distance between two anchors located on opposite sides of the Demonstration Drift. The measurement is made using a special steel tape and an apparatus containing a dial indicator. Figure 5-1 illustrates a typical measurement.

\section{1 .2 Measurement Equipment}

A Sinco/Terrametrics tape extensometer was used for all measurements. The TE has a precision steel tape perforated at fixed intervals and a dial indicator capable of reading to $0.025 \mathrm{~mm}$. The $\mathrm{TE}$ has a special tensioning device that is used to ensure that the same tension is applied at each reading. With the tensioning device, readings are assumed accurate to $\pm 0.13 \mathrm{~mm}$ according to the manufacturer.

Measurements were made between anchors fabricated from $22-\mathrm{mm}$-dia rebar with eyelets attached at the measurement ends. The SAIC-fabricated anchors were epoxied into percussion-drilled holes along a $38-\mathrm{cm}$ length, with the eyelets recessed to prevent possible damage due to blasting.

\section{1 .3 Measurement Sequence}

The normal measurement sequence was to 


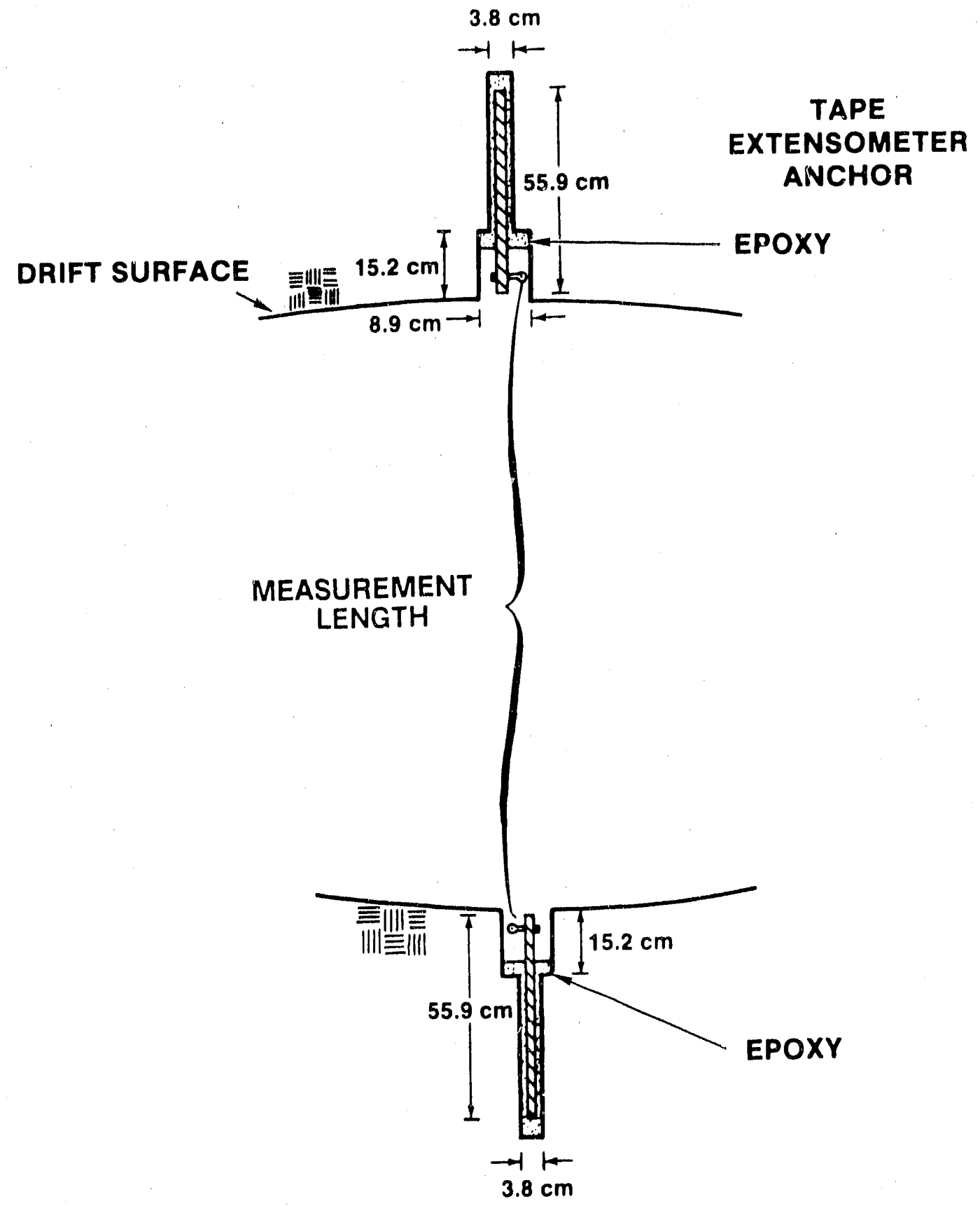

Figure 5-1. Tape Extensometer Measurement Arrangement 
1. drill new holes, with either a vertical or horizontal orientation, in solid rock within $1 \mathrm{~m}$ of a freshly mined face, thus establishing an anchor station,

2. Install anchors, and

3. Initiate measurement sequence with $T E$.

\subsection{Borehole Injection (BI)}

Water was injected in fixed intervals in six boreholes before and after the mining as a technique to evaluate changes in the rock mass as a result of the mining process. The water pressures and flow rates were measured and combined into a hydraulic quotient (HQ). This testing was a developmental effort where HQ measurements are used to attempt to determine changes in the rock mass caused by the excavation process.

\subsubsection{Measurement Principle}

The use of flow measurements to estimate fracture properties in boreholes is an established technique in rock mechanics. In a recent effort, Hodgkinson (1984) used flow measurements, called permeability measurements, to define fracture conditions as a function of borehole depth. He published results for measurements of flow rate per unit pressure head for each 1-m section of a borehole. His measurements were directed toward demonstrating the limitations of using a continuum approach in describing rock mass flows, and he was primarily concerned with demonstrating fracture effects in rock masses. Figure 5-2 shows a schematic illustrating the movable measurement interval, which is the basic measurement approach used in this study.

This developmental effort is an extension of the Hodgkinson work. The BI testing here involved taking the same type of measurements before and after the Demonstration Drift was mined through a welded tuff rock 


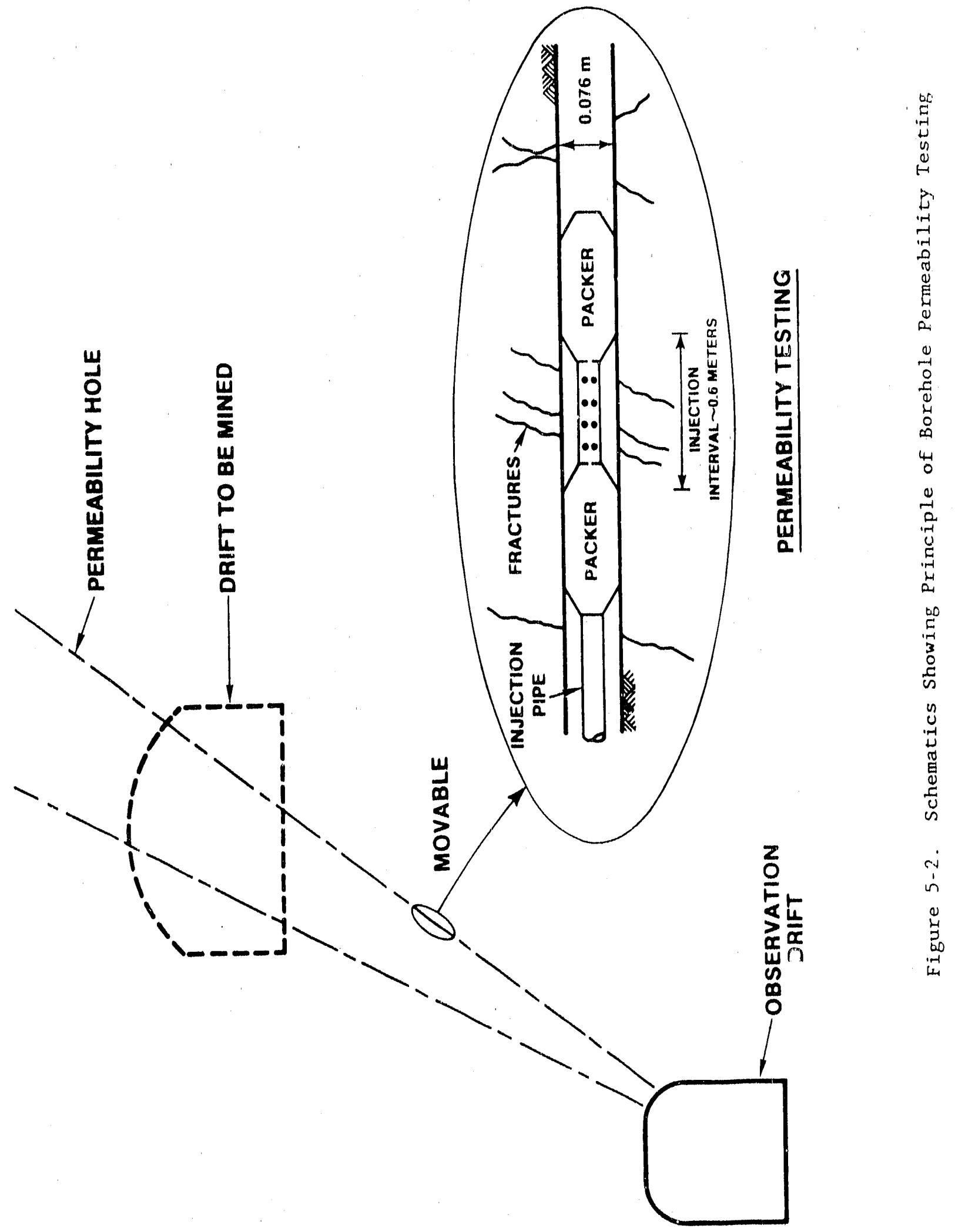


formation. BI measurements were taken along the lengths of six boreholes, which were arranged in pairs of two at three stations, B, D, and F. Figure 5-2 shows how two boreholes were orlented at one station. The holes originated in the 12-Drift, and they were drilled before the mining of the Demonistration Drift.

The flow properties are described by the single HQ parameter, which was created for these evaluations. The HQ quantity is computed from manually recorded flow rate and pressure measurements. Successive HQ measurements taken at $0.6-\mathrm{m}$ intervals along the length of a borehole constitute an HQ borehole profile.

The HQ is extracted from the cublc law that is used with parallel plate theory in relating flow properties to the average hydraulic apertures of fractures. The basic equation for injections in a singla borehole is (Rock Testing Handbook, 1980)

$$
e=\left(\frac{12 \cdot Q \cdot \operatorname{Ln}(\ell / x) \cdot \mu}{\left(2 \cdot \pi \cdot n \cdot H_{0} \cdot \gamma_{w}\right)}\right)^{1 / 3}
$$

where

$$
\begin{aligned}
& \text { e - average aperture of fractures (L)* } \\
& Q \text { - flow rate }\left(L^{3} / T\right) \\
& \ell \text { - length of infected section (L) } \\
& r \text { - radius of borehole (L) } \\
& \mu \text { - dynamic viscosity of water }(F \cdot T) / L^{2} \\
& \mathrm{n} \text { - number of intersecting fractures } \\
& \mathrm{H}_{0} \text { - pressure head on interval (L) } \\
& \gamma_{w}=\text { weight per unft volume of water }\left(F / L^{3}\right)
\end{aligned}
$$

\footnotetext{
* Note that generic units are indicated in parentheses following the descriptions.
} 
The HQ quantity is taken as the ratio of: $\left[Q /\left(H_{0} \bullet \gamma_{w} \bullet n\right)\right]$ in Equation 5-1, where $\mathrm{n}$ is assumed to be unity. The HQ quantity has the generic units of $\mathrm{L}^{5} /(\mathrm{F} \bullet \mathrm{T})$ as extracted from Equation 5-1. In this experiment, the HQ has the units of $\mathrm{m}^{3} /(\mathrm{s} \bullet \mathrm{kPa})$ so that flow rate and pressure measurements are directly convertible from the data manually recorded in G-Tunnel.

Equation 5-1 may be used to calculate the hydraulic aperture of a fracture using the flow measurements if the length and number of fractures are known; however, the authors were not prinarily interested in determining either the sizes of the fracture apertures in the intervals or the number of fractures. They were interested in determining how the hydraulic flow and pressure properties changed as a result of the mining and the subsequent relaxation of the rock around the opening. Thus, their goal was to perform the same type of flow measurements at the same locations in boreholes under the same environmental conditions. Since HQ data can be used to describe the general rock mass parmeabilities, hydraulic conductivities can be estimated from the premining measurements to serve as a reference for those interested in welded tuff flow characteristics.

\subsubsection{Measurement Equipment}

Figure 5-3 shows a schematic of the BI testing apparatus. The equipment was assembled from components available in G-Tunnel and attached to a fermeability cart, which had been fabricated for another SNL study. Figure $5-4$ shows a photograph of the permeability cart.

The key controls for the hydraulic system were valves regulating the flow rate. Water was pumped at a constant rate of $6 \times 10^{-4} \mathrm{~m}^{3} / \mathrm{s}(9.5$ gal/min). The flow rate to the injection piping was regulated until a desired pressure at the injection packer was achieved. The excess water was returned to the tank through a bypass valve (Figure 5-3). Once the desired pressure was achieved, the flow rate in the injection pipe was maintained at a steady-state condition and nonitored for a specified time. There were three key measurements in determining the HQ quantities:

(1) flow rate, (2) pressure at the injection interval, and (3) time. Additional pressure measurements were taken neat the flowmeter, which was 


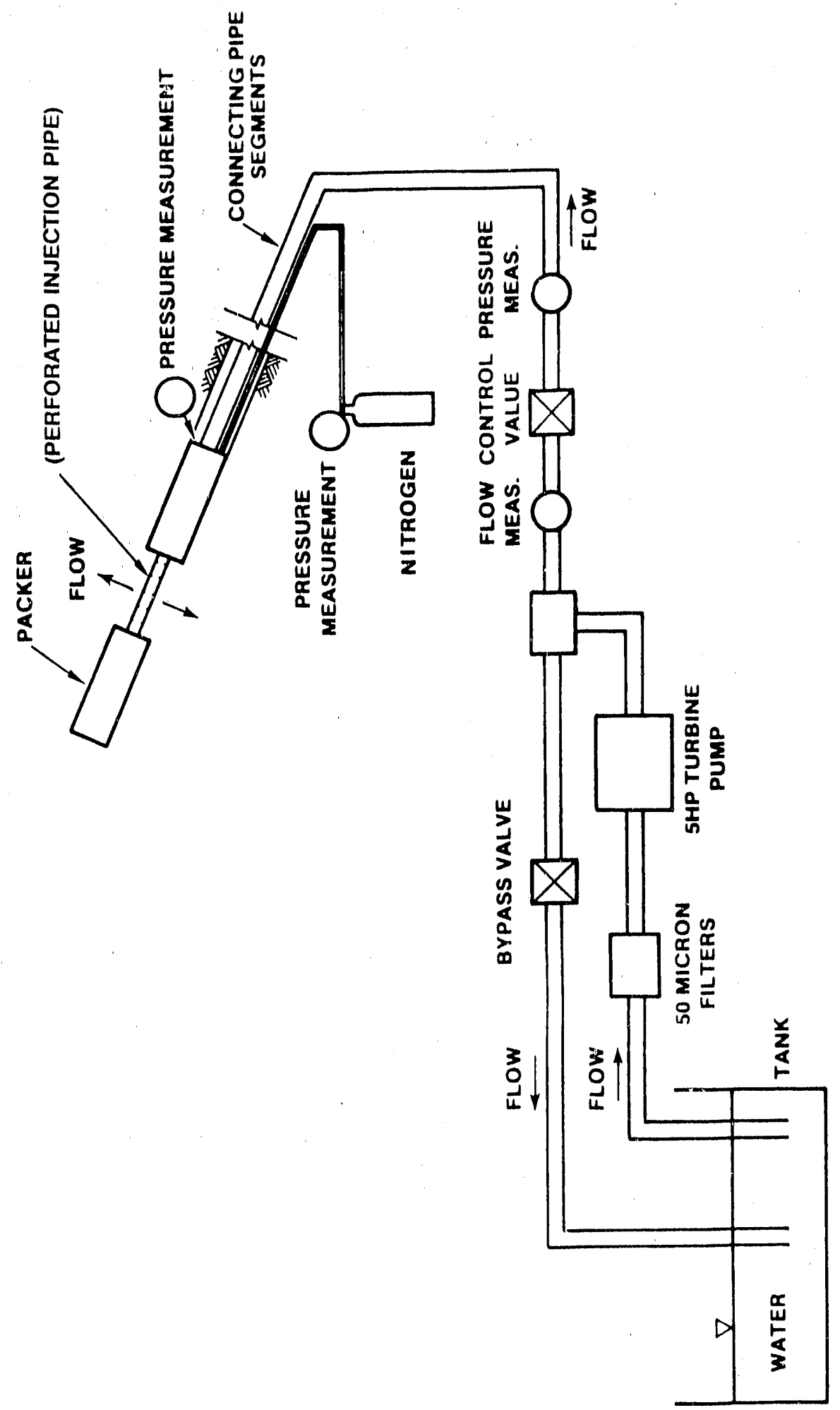

D 


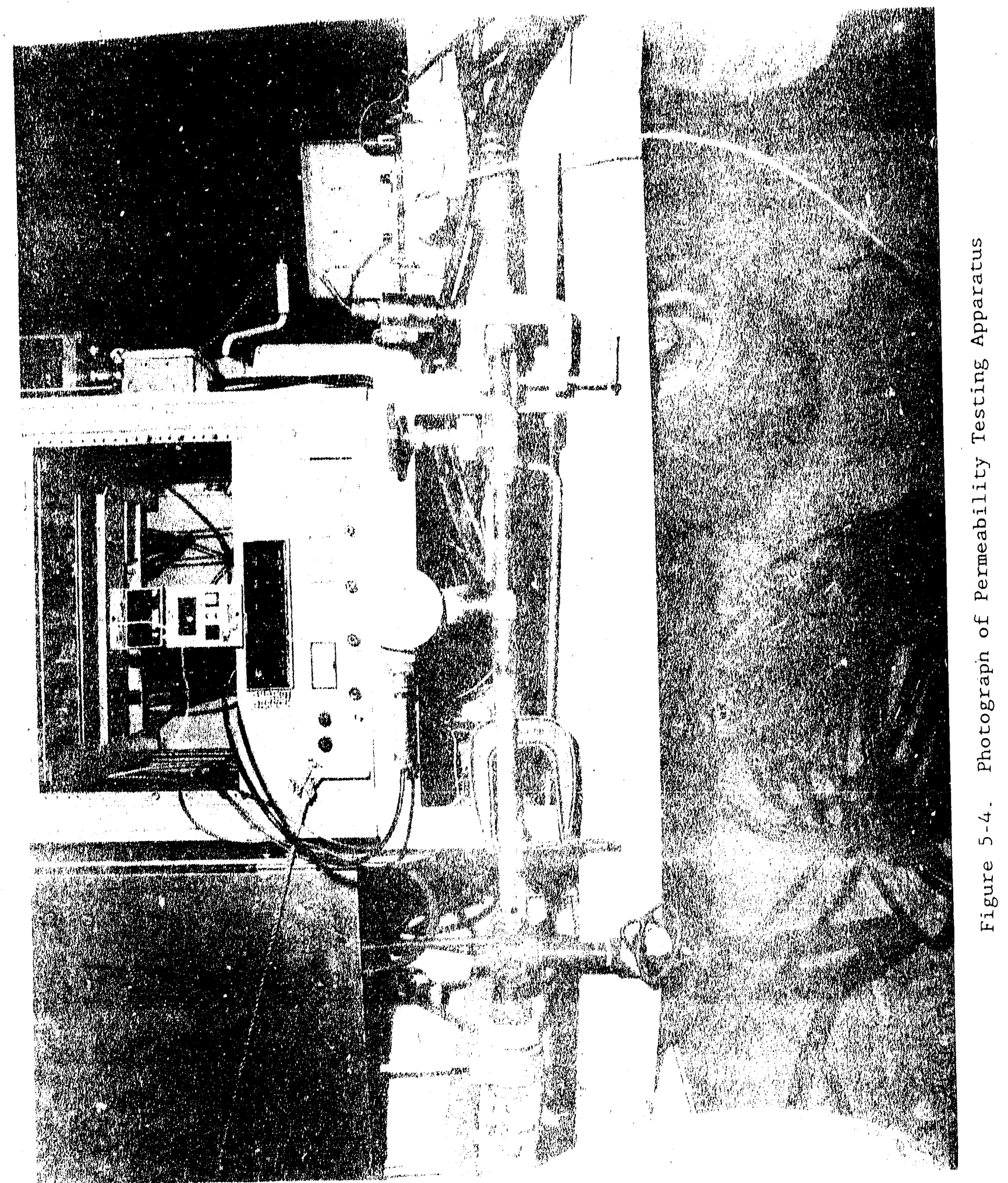


located on the permeability cart, to provide a better record of the hydraulic behavior of the flow system. Also, total flow volume was measured with the flowmeter to facililate quality controls.

The flow rate and total flow volume were measured by a flowmeter manufactured by Flow Technology (Model FTE). The flowmeter could measure flow rates up to $6 \times 10^{-4} \mathrm{~m}^{3} / \mathrm{s}(9.5 \mathrm{gal} / \mathrm{min})$. The lowest reading of the flowmeter was $6 \times 10^{-7} \mathrm{~m}^{3} / \mathrm{s}(0.01 \mathrm{gal} / \mathrm{min})$. The flow volume was read to the nearest $3.8 \times 10^{-4} \mathrm{~m}^{3}(0.1 \mathrm{gal})$.

The primary pressure gage, manufactured by Kulite (Model XTM-1902006), had a range up to $1.4 \mathrm{MPa}$ (200 psi). Pressure could be read to the nearest $0.7 \mathrm{kPa}(0.1 \mathrm{psi})$.

The borehole injection equipment was fabricated for these measurements. The straddle packers were commercially available. Figure 5-5 shows the operator inserting the perforated injection pipe and straddle packers into a borehole. The pipe size and number of perforations were selected after trial pumping tests. The purpose of the perforated pipe was to maximize the amount of water that could flow with a minimum injection length and pressure loss. A goal in the design of the packer assembly was to create as small an interval as practical. The resulting length of the perforated pipe was $0.28 \mathrm{~m}$. Each connected straddle packer has an overall length of $0.69 \mathrm{~m}$; thus, the total length of the packer assembly was $1.66 \mathrm{~m}$. The injection interval, taken between packer-rock contact points, was determined to be $0.68 \mathrm{~m}$. As a matter of convenience, the packer assembly was advanced in $0.61-\mathrm{m}(24-\mathrm{in}$.$) increments in obtaining HQ measurements.$

\subsubsection{Measurement Procedures}

The packer assembly was positicned in the boreholes by manually adding pipe segments, $19 \mathrm{~mm}(3 / 4 \mathrm{in.})$ in dla. and $2.1 \mathrm{~m}(7 \mathrm{ft})$ long, to the packer assembly and connecting the hose from the permeability cart. The position of the measurement interval was determined by measuring the distance from a 


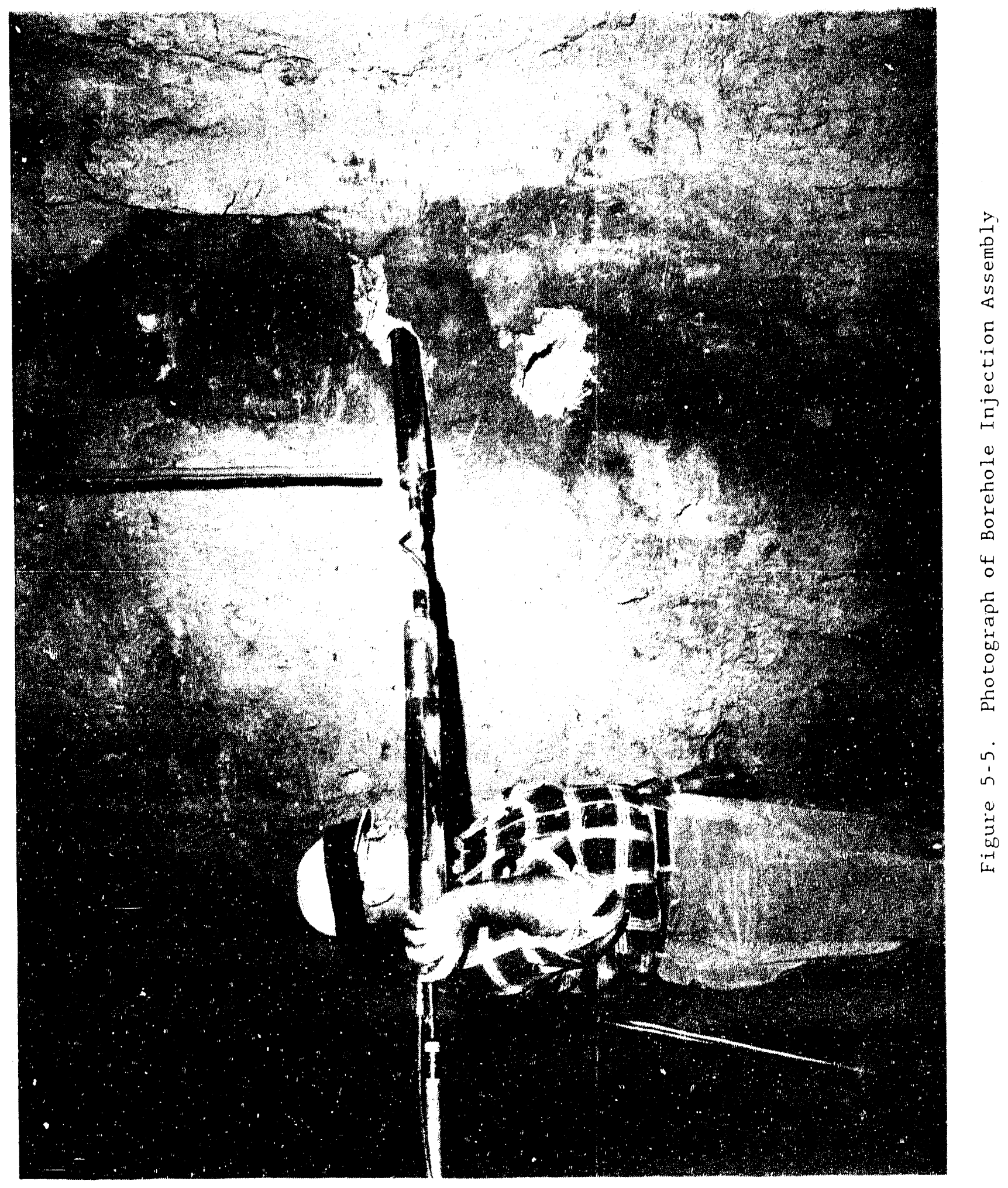


permanent reference point near the collar of the hole to the center of the packer assembly. It is estimated that distance measurements could be repeated to the nearest $1.2 \mathrm{~cm}(0.5 \mathrm{in.})$

The measurement pattern used for each interval in a borehole consisted of measuring flow rates occurring at three different pressures that were organized in a set of five steps. The nominal pattern was to take flow rate measurements while holding the pressure constant at increasing and decreasing injection pressures of $0.2,0.4,0.6,0.4$, and $0.2 \mathrm{MPa}$ ( 30 , $60,90,60$, and $30 \mathrm{psi}$ ) for periods of 2 to $3 \mathrm{~min}$. In some cases, the fracture flow properties were such that the maximum pressure was reduced to some attainable value and then the other pressures were proportioned accordingly.

The general measurement procedure consisted of

1. locating the packer interval at the desired depth in the borehole, 2. pressurizing the packers to seal the interval,

3. determining the maximum pressure attainable, and

4. initiating the five-step pressure measurement sequence.

Steps 2 and 3 established pressure conditions that affected the borehole. The packers were pressurized to a nominal pressure of $2.4 \mathrm{MPa}$. The water pressures varied from 0 to $0.6 \mathrm{MPa}$. Thus, there was a pressure differential along the length of the borehole. Packer and water pressures were selected after analyzing pressure effects on boreholes and considering previous testing histories (Zimmerman and Vollendorf, 1982) and rock tensile strengths (Zimmerman and Finley, 1987).

\subsection{Borehole Deflectometer (BD)}

A BD was used to determine angle changes in boreholes drilled around the excavated region. The changes were to be related to mining effects. This was another developrnental effort because measurements of this type had not previously been taken in a hard rock. The method was selected to 
determine whether it could be used in lieu of using MPBXs, which were not as sensitive to rock mass changes perpendicular to the borehole (Heuze et a1., 1981).

\subsubsection{Measurement Principle}

Figure 5-6 shows a schematic illustrating the basic principle involved in these measurements. The figure shows a borehole in the pre- and postmined position. After mining, the borehole axis is expected to move toward the excavated region and deform slightly. Ideally, angle changes in the borehole axis can be obtained by making the same type of measurements before and after the mining prucess. The borehole deflections are small and measurements are possible because of the availability of an extremely sensitive $B D$, which can have an inherent sensitivity of 1.0 arc-second $(1 / 206,000)$.

The borehole profile can be measured with a BD by taking angle change measurements as a function of the borehole length. This is called a borehole traverse, and the plot of the resulting angle change measurements is called a borehole angle change profile. A profile was established in these efforts by measuring angle changes at intervals of $0.76 \mathrm{~m}(2.5 \mathrm{ft})$. At each interval, a reading representing an angle between two parts of an articulated deflectometer was displayed in digital form on equipment located outside the borehole. The digital readings were manually recorded and later converted to degrees using a constant conversion factor.

Figure 5-7 is a schematic of the $B D$ and shows the angle that can be measured. Also shown is a representation of the tangential deflection. The tangential deflection is a useful extension of the angle measurements because it translates angle measurements into linear measurements.

\section{3 .2 Measurement Equipment}

The $B D$ was manufactured by Sinco/Terrametrics, ModeI PBD/TCD. The BD consists of two straight, fixed-length segments linked together with a 


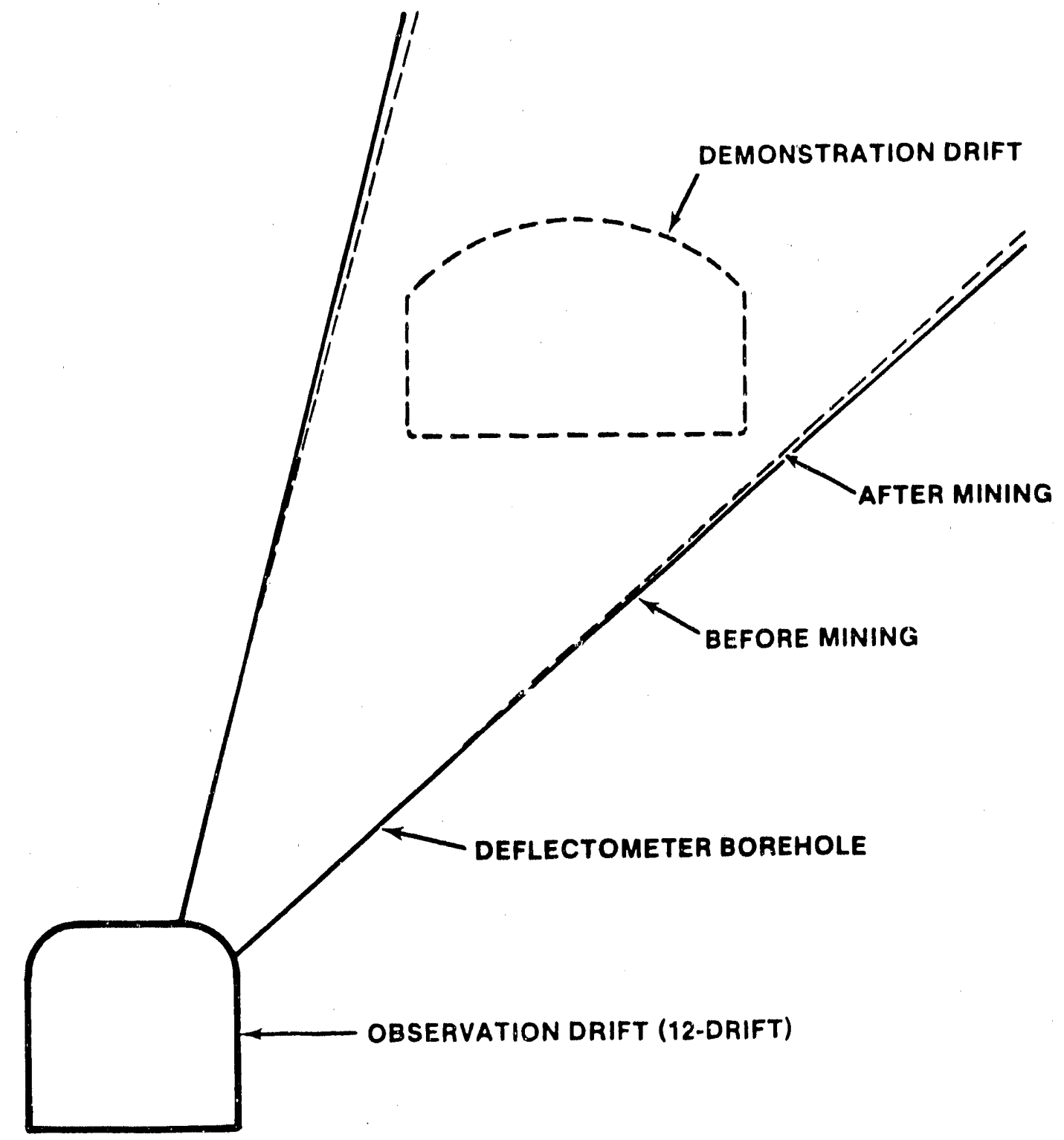

Figure 5-6. Schematic Showing Mining-Related Deflectometer Measurement Concept 


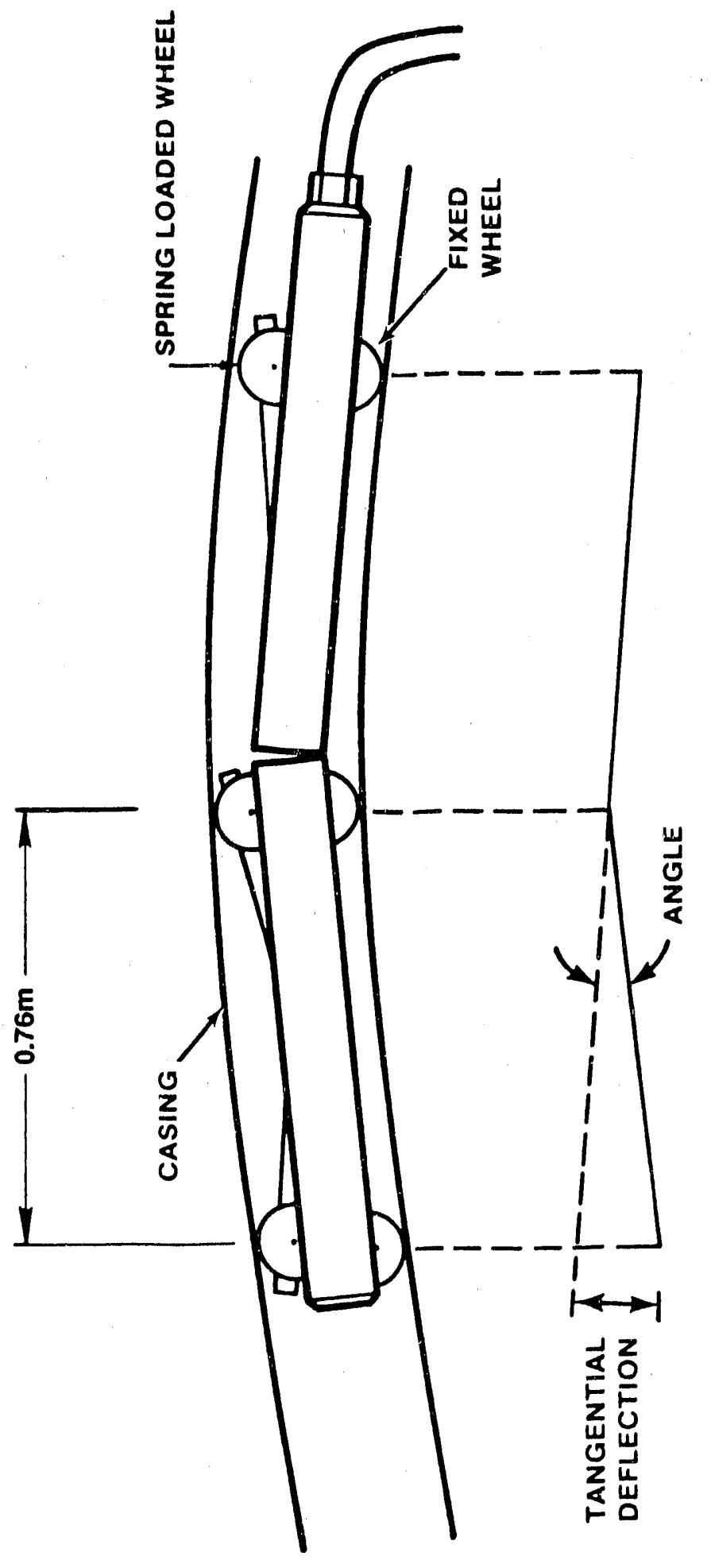

D 
strain-gaged flexible connection. The BD was manufactured so that the three permanently positioned wheels were the primary reference set for traverses and a set of three spring-mounted wheels was used to keep the $B D$ aligned in a grooved PVC casing. During a traverse, the flexible connection transmits a continuous signal that is the analog of the angle changes between the two segments.

A specially grooved PVC casing was grouted into each of the boreholes to ensure good coupling with the rock. The casing, $69.5 \mathrm{~mm}$ in diameter, was purchased in $3.0-\mathrm{m}$ lengths and glued together during installation. The casing was fabricated so that the $B D$ could be oriented in two orthogonal positions. Specifically, the casing has four small grooves $[1.65 \times 5.1 \mathrm{~mm}$ $(0.065 \times 0.2 \mathrm{in.})]$ cut in the inside wall of the casing at four quadrant points.

\subsubsection{Measurement Procedures}

Measurement procedures were recommended by the manufacturer. The normal procedure was

1. to insert the $B D$ in the casing and initialize it, and

2. to repeat the measurements at $0.76-\mathrm{m}(2.5-\mathrm{ft})$ intervals along the length of the borehole.

\subsection{Hydraulic Pressure Cells}

HPCs were installed in wedge-shaped grout inserts to simulate underground installation conditions for planned ES testing. HPCs are used in underground applications to measure changes in stresses in concrete liners or possibly in cavities cut in rock surfaces. HPCs are planned for use in the ES liner, and the testing described here represents a familiarization effort in working with the cells. 


\subsubsection{Measurement Principle}

Figure 5-8 is a schematic showing the major components of an HPC in place. Normally, the pressure cell with hydraulic transducer and connecting pressure lines are cast in concrete. The cell fluid is mercury, and hydraulic oils are used in the pressure system. After the concrete has set up, the end of the repressuring tube is squeezed, thus driving the surfaces of the pressure cell firmly against the concrete surface surrounding the cell. This action integrates the HPC into the concrete structure. The repressuring line is fixed so that the mating of the cell to the surrounding material is permanent, and the action is called "lockoff." It is assumed that the cell becomes a part of the concrete structure. The pressure cell then detects any changes in the concrete stress field acting normal to the cell, and the changes in the cell pressure are assumed to be equal to the stress changes in the concrete. The pressure measurement is made with the aid of the hydraulic system. Fluid is pumped into the pressure line, and it bears against the diaphragm. When the input hydraulic pressure is slightly greater than the cell fluid pressure, the diaphragm in the hydraulic transducer causes a valve to open and the hydraulic fluid is pumped back to a reservoir near the hydraulic pump in the return ine. In this testing, grout was substituted for concrete.

\subsubsection{Measurement Equipment}

Glotzl Concrete Stress Cells, Model B 10/20, were used in the grout inserts. The pressure cell was capable of measuring pressures up to $30.4 \mathrm{MPa}$ (4400 psi) with a reported accuracy of $\pm 30 \mathrm{kPa}$. Each unit was $10 \times 20 \mathrm{~cm}(4 \times 8 \mathrm{in.})$. The cells were pressurized with an M1H16 hand pump, and the pressure was read directly with a pressure gage provided with the cells. The pressure gage was calibrated by the manufacturer.

\section{4 .3 Installation Features}

The main purpose for using the HPCs was to evaluate installation procedures that might be used in the ES. The authors were concerned about 


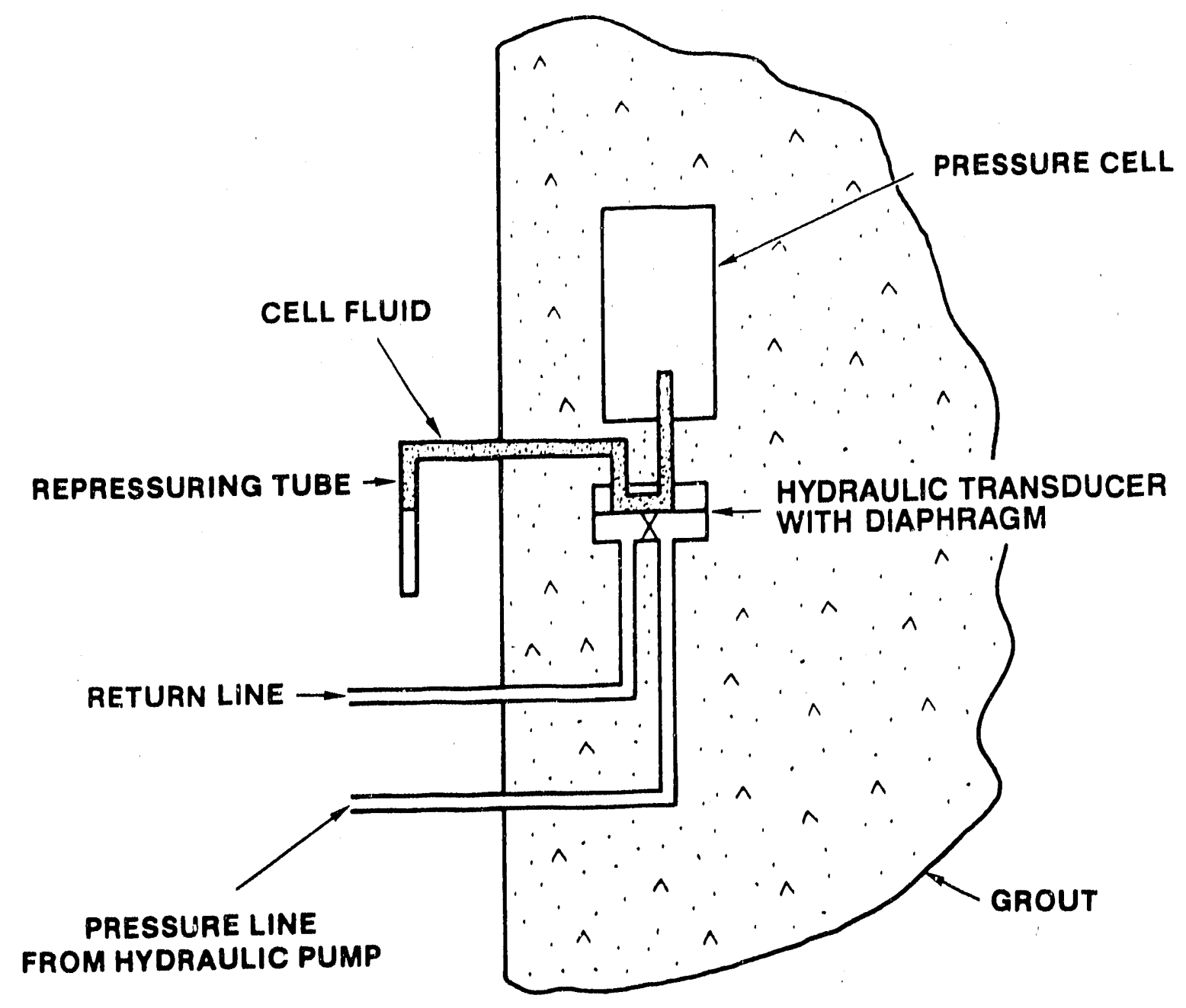

Figure 5-8. Schematic Showing Major Components of Hydraulic Pressure Cell 
(1) falling concrete disturbing the HPC placement, and (2) air pockets forming around the HPCs during the concrete placement. They attempted to simulate the concrete with a relatively dry grout mix.

Figure 5-9 shows the testing concept. A wedge-shaped cavity was mined into two ribs of the Demonstration Drift. The cavity was covered with a sheet of plywood that was rock-bolted to the rock, forming an enclosed cavity (see Figure 4-4). The plywood held the HPCs in configurations expected for the 0.3-m-thick ES liner. An opening was made at the top of the plywood so that a stiff grout, a substitute for concrete, was pumped in to fill the cavity, forming a grout insert. After the grout had hardened, the pressure cells were activated to establish the lockoff pressure, and then pressures were monitored periodically.

Only one technique was used in grouting the inserts for the HPCs, and no meaningful procedure developments evolved. As a matter of record, the grout used had the following proportions:

\begin{tabular}{lr} 
Chemcomp & $1164 \mathrm{~kg} / \mathrm{m}^{3}$ \\
Gypsun & 93 \\
Water & 582 \\
Friction Reducer & 12 \\
\hline
\end{tabular}

$1851 \mathrm{~kg} / \mathrm{m}^{3}$

The grout was pumped in at a rate of $0.06 \mathrm{~m}^{3} / \mathrm{min}$. Approximately $1.5 \mathrm{~m}^{3}$ was pumped into the left insert and $1.6 \mathrm{~m}^{3}$ into the right insert.

\subsection{Borehole Grouting}

\subsubsection{Borehole Grouting Procedures}

Grouts were applied to boreholes to anchor equipment in the boreholes. In one case, the grout was to hold the PVC casing in place for the BD measurements, and in the other, the grout was to hold the MPBX anchors in place. 

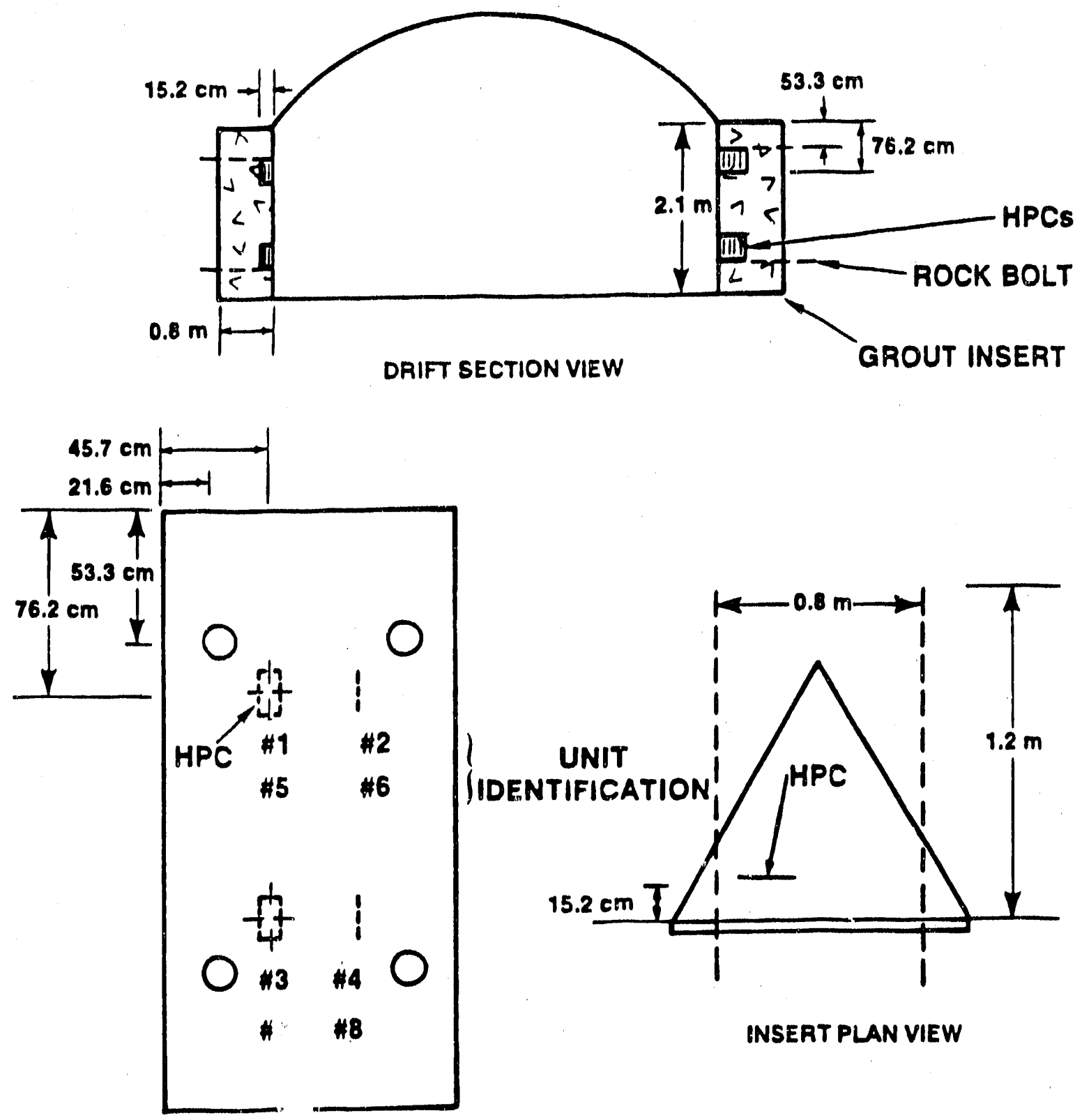

INSERT ELEVATION VIEW

Figure 5-9. Schematics Showing HPC Details 
Two types of grout were used, Sulfaset was used as a fast-setting, gypsum-based grout. An expansive cement, Chemcomp, was used as the Portland-cement-based grout. Both grouts were mixed to viscosities fudged sufficient to pump through the various size grout tubes. The intent was to reach the maximum viscosity that could be pumped through the tubes so the grout would bridge across fractures.

The grouting process for the $B D$ tubing was started first and required modifications in the procedures. Originally, the four boreholes for the $B D$ measurements were drilled to a diameter of $76 \mathrm{~mm}$ (NQ size). Grouting was started in Hole B1 with uncertain success. The casing had a $6.4-\mathrm{mm}$ feed tube near the bottom of the hole, and thare was a bleed line at the top. In this way, the grout would be pumped into the bottom to completely fill the annulus between the outside of the casing and the borehole surface. The grouting scheme was to put a slug of water on top of the grout column at the bottom of the hole. When the hole was fully grouted, the water would appear in the bleed Iine, and the hole would be assumed to be fully grouted. The bleed line would not fit between the casing and the borehole wall; it had to be located within the calsing and a seal provided at the top. Calculations showed that 0.011 to $0.015 \mathrm{~m}^{3}$ (3 to 4 gal) of grout should fill the annulus. Approximately five times this amount of grout was pumped into the hole, and no water showed in the bleed tube. Water did show in Holes $B 2$ and $B 3$, indicating interconnecting fractures. No grout showed in the other holes probably because of its increased viscosity. The end of the shift arrived, and still the hole had not been filled up and the grouting process had to cease. As a followup on another day, approximately $0.08 \mathrm{~m}^{3}$ of grout was pumped into the bleed tube to attempt to close the upper part of the annulus. The inside of the casing was cleaned, and it was assumed that the casing was grouted in place.

The lessons learned in grouting Hole Bl suggested that the remaining holes should be enlarged, and Holes B4, F1, and F4 were reamed out to a diameter of $96 \mathrm{~mm}$. For these holes, flve grout tubes, $9.5 \mathrm{~mm}$ in diameter, and a similar-sized bleed tube were added to the outside of the casing (Figure 5-10). The grout tubes were terminated at regular intervals. The 
NOTE: CLOSE-UP SHOWS GROUT TUBING

ANGLE CUT, SO AS NOT TO

HANG-UP ON BOREHOLE WALLS.
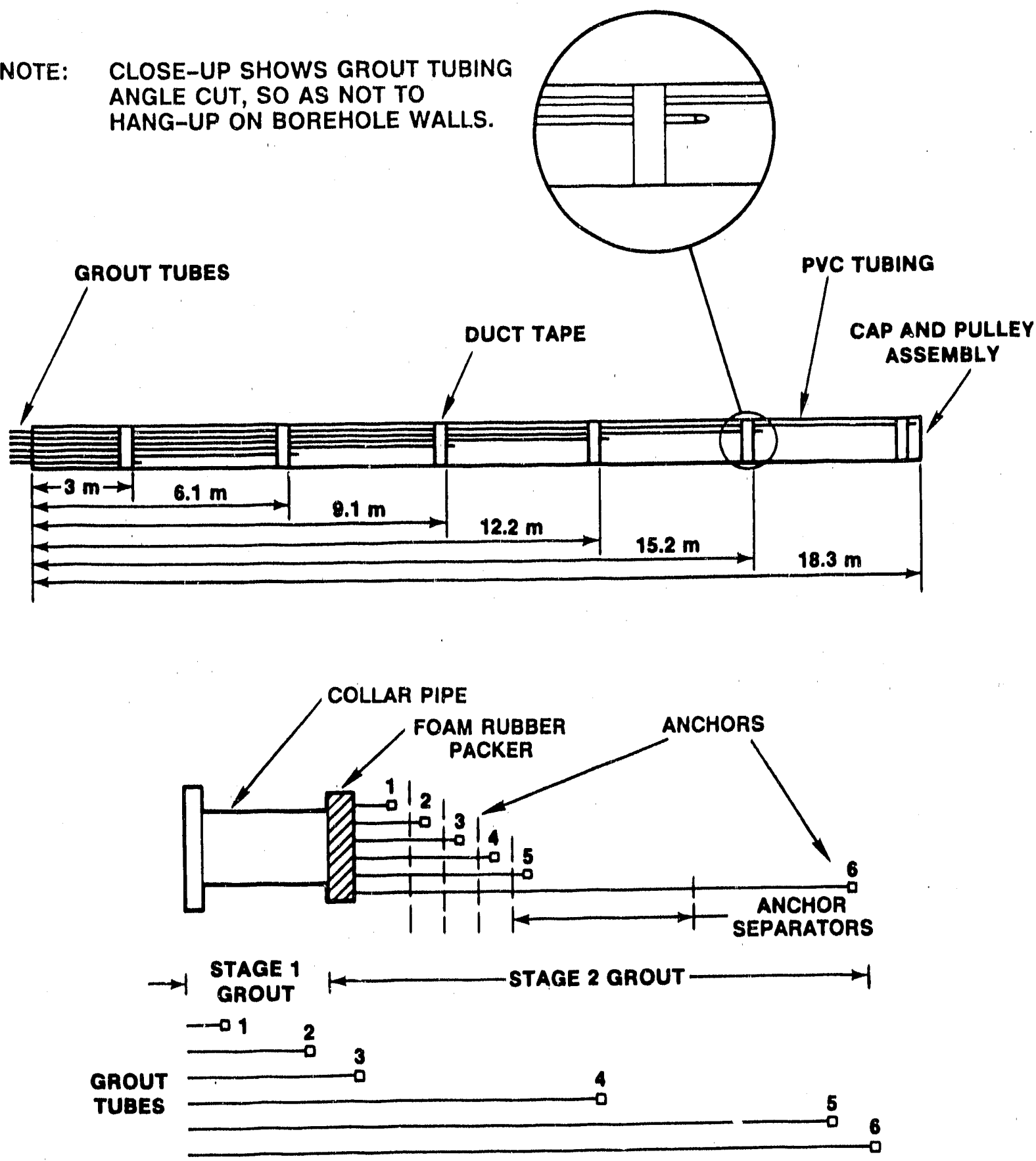

Figure 5-10. Typical Grouting Detalls for BD and MPBX Boreholes 
bleed tube was located at a distance of $18.3 \mathrm{~m}$. The collar of the casing was sealed with a Sulfaset to prevent grout flow into the drift. The Portland-cement-based grout was started in the shortest tube. When the grout showed by return flow in the next longest tube, the first tube was closed off, the pumping was switched to the return tube, and the shutoff/switching process was repeated until the grout was observed in the longest tube. The grouting procedure was terminated at this showing. This staged grouting procedure worked well, and the expected amount of grout was added to each of the holes. There was no check of the adequacy of the grouting, but the second process gave the authors more confidence that the grouting was adequate.

Grouting for the MPBXs was similar in nature to the BD casings, but the MPBXs required more preparation. The MPBXs required separation of the anchors so that they could act independently. This meant that the grout columns should be interrupted between the anchors. This was accomplished by fabricating cardboard donuts near the anchors. The donuts were undersized so that the grout could flow past.

The first two MPBXs that were grouted in were $\mathrm{C7}$ and $\mathrm{E7}$. The general procedures used with the most recent BD casing installations were tried. The major difference was that the ends of grout tubes were placed near the anchors. The longest tube served as the last return tube, and grout return there signaled the end of the grouting. Drift excavation to Station $C$ revealed that the last anchor was partially grouted; hence, the grouting procedures were modified again for subsequent MPBX installations.

The borehole grouting procedures for the MPBXs installed in the Demonstration Drift are discussed in reference to Figure 5-10. Grouting occurred in two stages in those holes, and there were some differences in the procedures for up (roof) and down (floor) holes. A foam packer was added to the end of the MPBX collar. This packer served the purpose of helping to separate the grout column from the collar pipe. Six 9.5-mm-dia. 
tubes were connected to the MPBX anchor assembly. Two tubes were located along the pipe between the collar and foam packer and the remaining four were located between the foam packer and the deepest anchor.

For inclined boreholes oriented near the horizontal, stage 1 grouting consisted of pumping Sulfaset into the shortest tube and filling the void up to the next tube. The Sulfaset was used to establish a good borehole seal at the bottom of the grout column and to ensure that the pipe and all grout tubes were firmly installed. After the Sulfaset cured for approximately $1 \mathrm{hr}$, the Stage 2 grouting began. Stage 2 grouting consisted of pumping Portland-cement-based grout in four tubes using the same pump/shutoff/switch technique used in grouting the BD holes. The shortest of the four tubes was terminated above the packer, the next longest was terminated above the five anchors, and the remaining two were terminated slightly below and slightly above the deepest anchor. As an additional step in ensuring full grouting in the space between the next deepest and deepest anchors, the grouting procedure was changed when the grout collum reached the next longest grout tube. When grout returned from this line, the grout operation was stopped, the line was cleaned, and the grout in the borehole was allowed to set up for a period of $2 \mathrm{hr}$. Then, the grout was pumped in the next longest line and stcpped when there was return in the line that was beyond the deepest anchor. At the termination of pumping, all lines were closed and the grout was allowed to cure for at least 2 days before tensioning anchor rods or working with the MPBX.

For the down holes, the Stage 1 grouting consisted of pumping Sulfaset in the space between the collar and foam packer. The Sulfaset was allowed to harden for $2 \mathrm{hr}$ to set up a good seal for the collar pipe. Next, the gront was added to the longest tube, and the pump/shutoff/switch procedure was followed until there was grout return in the tube nearest the foam packer. 


\subsection{MINING ACTIVITIES}

\subsection{Controlled Blasting}

\subsubsection{Controlled Blasting Objectives for G-Tunnel}

The construction of the Demonstration Drift represents the first documented effort of mining in welded tuff for purposes of repository evaluations. The drift was sized to dimensions of some drifts planned for repository drifts to provide NNWSI engineers with a prototype for use in later ES developments and ongoing repository designs. Within limits, the focus was on providing information for the ES because this is the next planned excavation in welded tuff. It is realized, however, that the results are also applicable to repository designs. The limits were that the controlled blasting evaluations would have to be performed during the mining of a relatively short, $29.6 \mathrm{~m}$ long, drift. This meant that there would be limited opportunities to optimize blast resigns or significantly change techniques or equipment.

The three objectives of the G-Tunnel. WTM were formulated by personnel from Parsons Brinckerhoff Quade and Douglas (PBQ\&D) and SNL and consisted of the following:

1. Minimize overbreak and damage to the surrounding rock.

There are three important concerns that are influenced by blast design and execution:

- stability and rock strength,

- drift dimensions and rock surface conditions, and

- crack propagations about the perimeter.

By applying controlled blasting techniques, all three concerns are addressed and moderated. First, ground support efficiency is improved as a resuit of less ciamage to the surrounding rock. This means reduced ground support requirements and subsequently 
less maintenance. Second, drift dimensions are more exact as a result of less overbreak, which means that there is less rock to handle. Also, the contour of the perimeter is smoother, allowing for more efficient ventilation. Third, controlled blasting reduces crack propagations into the surrounding rock mass. Such cracks can contribute to deteriorations of the rock and/or become preferential pathways for fluid or gas flows. Currently, the candidate repository at Yucca Mountain is located in the unsaturated zone above the static water table and fluid flows are not expected during the operational periods, yet there is a need to minimize the development of preferential pathways so that repository waste package and sealing programs will benefit. ES testing programs are designed to assess these aspects, and the work in G-Tunnel is the pioneering effort.

2. Attain a 3-m full-face advance.

Expected ES and repository mining plans call for applications of drill and blast techniques as well as mechanical mining techniques. In most cases, where blasting is used, full-face blasting will be used in the underground excavations for the ES because of the need to advance drifts as quickly as possible. A goal in these evaluations was to establish an effective blast pattern design for use in future welded tuff mining efforts. A 3-m advance was selected as an initial goal based on historical blast data (Langefors and Kihlstrom, 1979). They suggest that face advances equal to one-half the round width $(6.1 \mathrm{~m})$ are reasonable. Greater advance rates are desirable and most likely will be pursued in future mining efforts.

3. Evaluate Fragmentation.

An understanding of rock size distribution as a product of various blasting techniques and procedures is important to facilitate the design of efficient muck removal and dust control 
systems. The goal in these evaluations was to document the muck sample size distributions from a typical round for these general considerations.

\section{1 .2 Controlled Blasting Techniques}

Hoek and Brown (1980) discuss blasting in underground applications and indicate smooth blasting and presplitting as the two most commonly used techniques to control damage in excavations. In either case, the objective is to minimize crack propagation about the designed perimeter of the excavation.

In smooth blasting, there are closely spaced parallel holes on the perimeter that contain low-density charges. The perimeter charges are detonated last, and the final slab of rock is explosively driven into the cavity formed from previously blasted rock that was nearer to the center of the round. The low-density perimeter charges minimize the damage to the remaining final excavation surface.

Presplitting differs from smooth blasting in that the boundary charges, placed in very closely spaced perimeter holes, are detonated first. This causes a bounding crack defining the shape of the opening. In many cases, the perimeter is blasted separately from the remainder of the round. According to Hoek and Brown, presplitting is usually used in benching operations where there is a greater need to relieve horizontal stresses. Presplitting is slower than smooth blasting because of the need for more perimeter holes and the extra step in the mining cycle. Smooth blasting was therefore selected by $P B Q \& D$ as the most suitable control blasting technique for continuous underground developments.

\subsection{Smooth Blasting}

\subsubsection{Smooth Blasting Concepts}

The most important principle associated with blast design is the concept of blasting to a "free face." That is, the explosive energy is not 
completely confined in the rock but is used to move the fragmented rock away from its resting place. There are two popular techniques to initiate a "free face" when smooth blasting a full-face heading: the burn cut and the angle cut. In competent rock, the burn cut is preferred over the angle cut chiefly because there can be greater advance per round while allowing for applications of smooth blasting techniques.

The basic principle of a burn cut blast pattern is that the empty hole(s) (burn holes) in the center of the pattern act as the free face to the burn reliever holes, as shown in Figure 6-1. Different types of holes are identified with special symbols in the figure. The explosive energy of the reliever holes is used to break a wedge of rock toward the empty burn hole, which enlarges the free face of the burn hole to include the burn reliever holes. Subsequently, in a blast delay sequence, the production (stope) holes break to the enlarging void area to further expand the blast opening. The lifters (along the floor) and perimeter holes (around walls and roof) fire last to complete the blast delay sequence.

The basic principle of an angle cut blast pattern is to remove a large wedge of rock near the central portion of the round to provide the needed void space for subsequent blast relief. This is accomplished by drilling pairs of holes into the face forming a V-shaped pattern, as shown in Figure 6-1. These holes are loaded with explosives, which are fired first and usually in pairs, resulting in the wedge of rock exploding into the drift. As with the burn cut, the subsequent production holes follow in sequence and break into the newly opened wedge area. Again the lifters and perimeter holes are fired last to complete the blast.

One of the important concepts associated with smooth blasting is the use of the "lookout angle." To maintain the uniform shape of the drift cross section from one round to the next, the perimeter holes have to be angled out to provide sufficient space for the driling equipment. It is important that the "lookout angle" be as small as possible and that all perimeter holes should be nearly parallel so that the spacing between holes stays constant as a function of depth. 

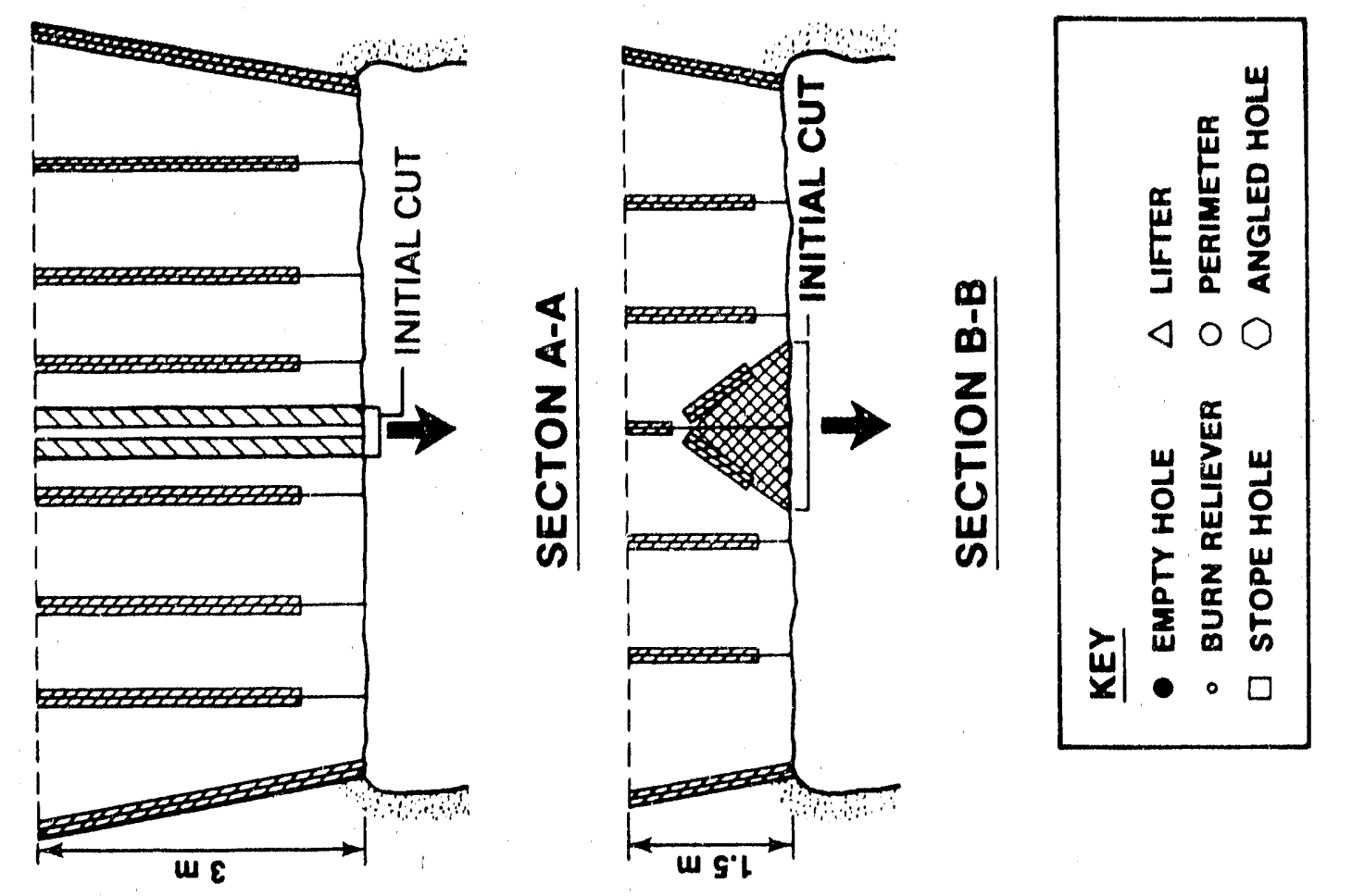

J
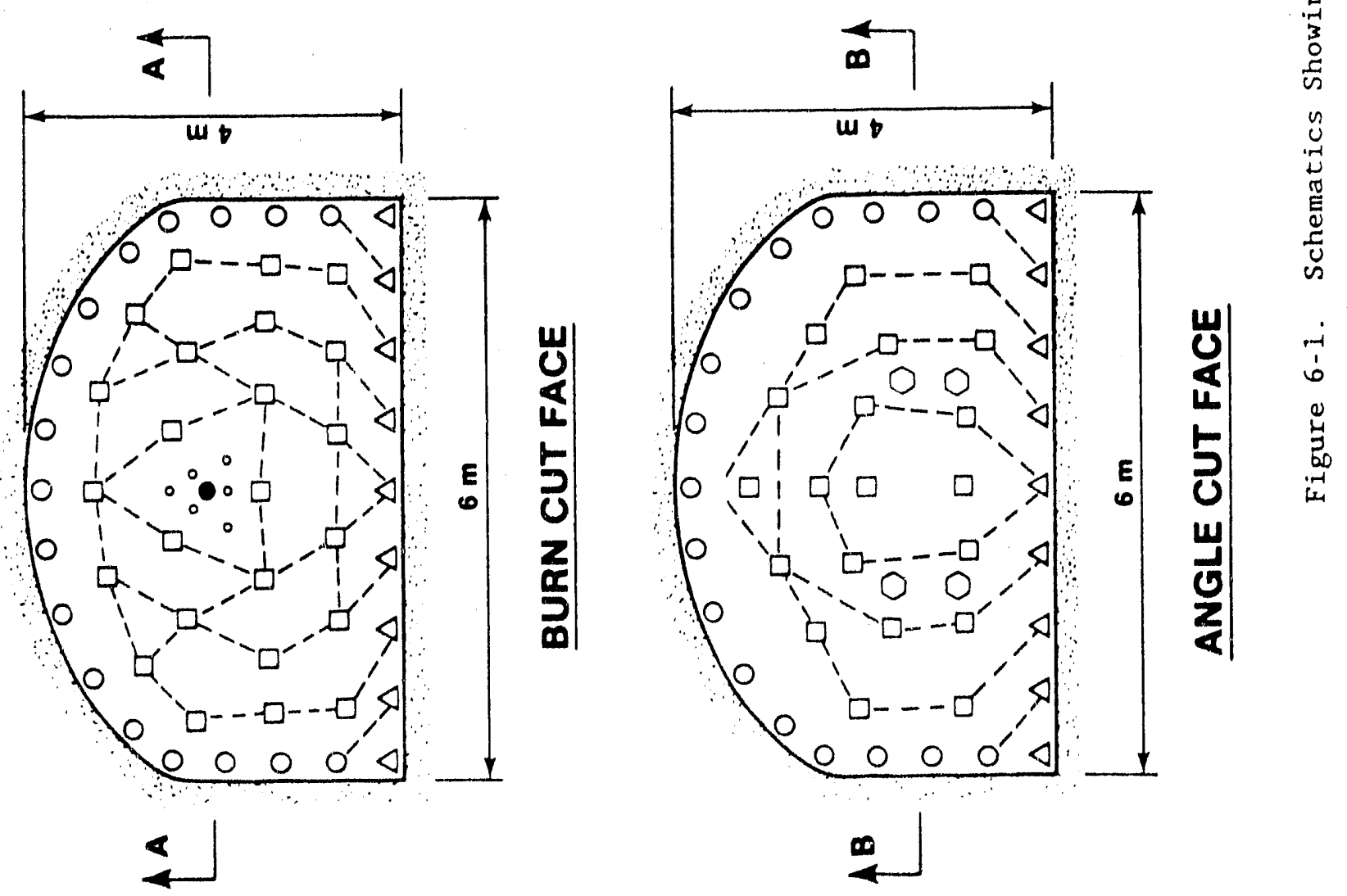


\subsubsection{Smooth Blasting Factors}

Once the burn or angle cut technique is selected for a round, there are a number of factors that have to be considered. These relate to the physical details associated with blasting a round. They are summarized and discussed here so that descriptive quantities have a reference base. The following are the factors that must be considered:

1. Excavation height and width-These are the rectangular crosssectional dimensions used to describe the excavated shape. The actual shape is defined with a drilling pattern.

2. Number of perimeter holes--This factor identifies the number and spacings of perimeter and lifter holes. Svanholm et al. (1977) recommended that the center-to-center spacing of the perimeter holes should be about 15 times the hole diameter.

3. Number of production holes--This is the number of holes, in addition to the cut and perimeter holes, that contain the remainder of explosives. These are also called stope holes.

4. Number of cut holes--This is the number of holes used to pull the initial cut in the rock. For the burn cut, they are called burn relievers, and for an angle cut, they are called angle holes.

5. Length of holes--These are the design length of holes required to pull the round to advance the distance desired.

6. Perimeter explosive type--A description of the explosives used in the perimeter holes. Usually these explosives are smaller than the holes to allow expansion and minimize the explosive energy on the perimeter. The perimeter explosive weight is the total weight of explosives used in the perimeter holes. 
7. Production explosive type-A description of the explosives used in the production holes. The production explosive weight is the total weight of the explosives used in the production holes.

8. Cut explosive type--A description of the explosives used in the cut. Explosives vary with the cut design used.

9. Number of delays--Description of the number of delays used with the nonelectric caps.

10. Powder factor--An empirical factor describing the ratio of the total quantity of explosive used per blast round to the volume of rock removed. It is computed using the volume of rock that was in place before the blast and the sum of perimeter, production, and cut explosive weights.

\subsubsection{Smooth Blasting Details}

\subsubsection{Blast Patterns}

Figure 6-2 shows a plan view illustrating the individual blast rounds. Rounds are identified by number. The mining was conducted in four stages, as shown. Stage I consisted of three smaller size rounds followed by additional removal of the right and left ribs. The Stage I space had to be excavated so that a twin boom drill jumbo could be positioned for full-face drilling. The smaller-size rounds were used to gain familiarization with the welded tuff. The drilling for rib removal had to be performed using jacklegs. Different types of explosives and loading procedures were tried in the mining in this stage.

Stage II was the start of full-face mining using the drilling jumbo. Stage II blasting consisted of two rounds that were shot using a hex burn cut design. Figure 6-3 shows the details. Different symbols are used to indicate perimeter, lifter, production, and burn holes. The numbers associated with the holes are the blast delay sequences. 


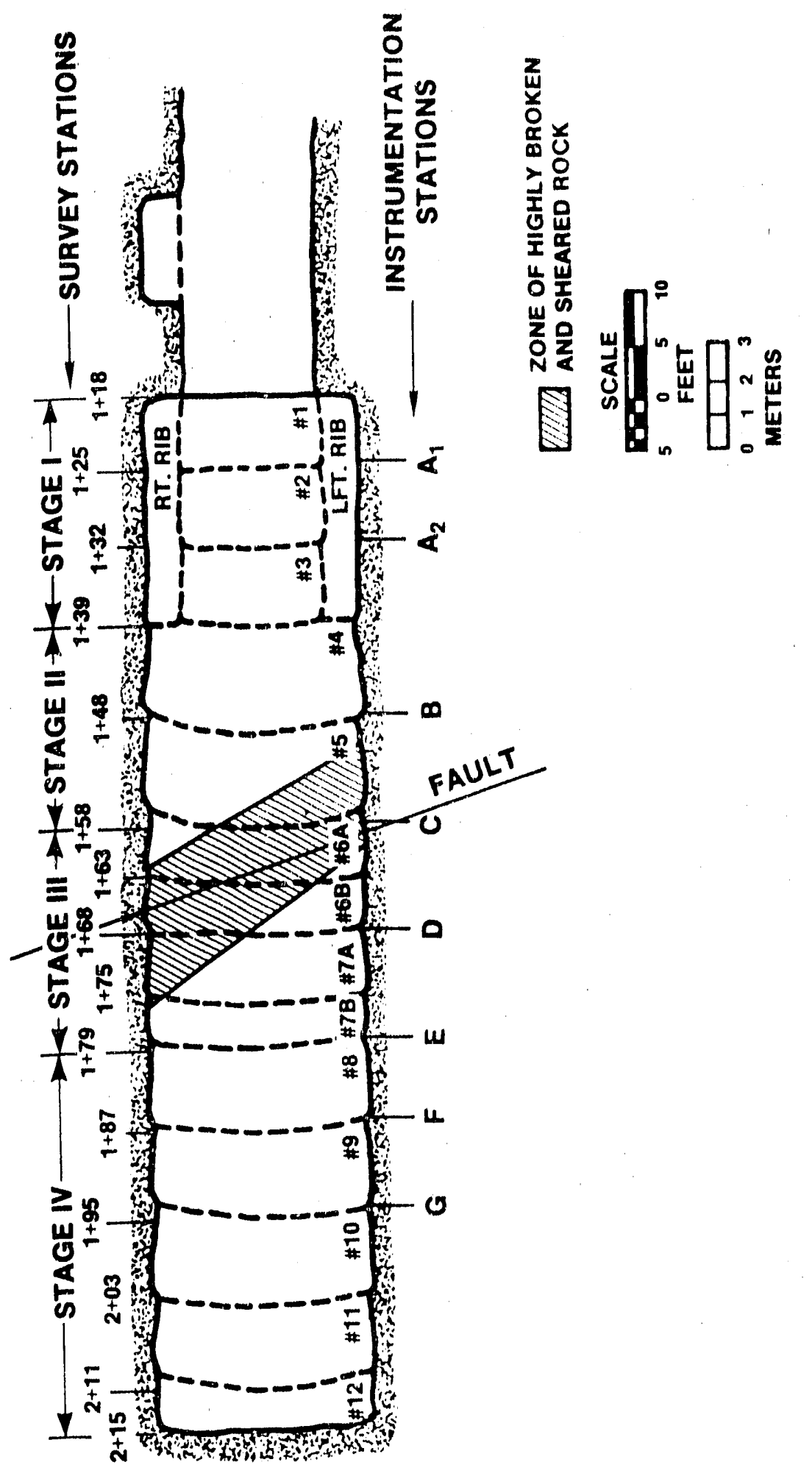

D 


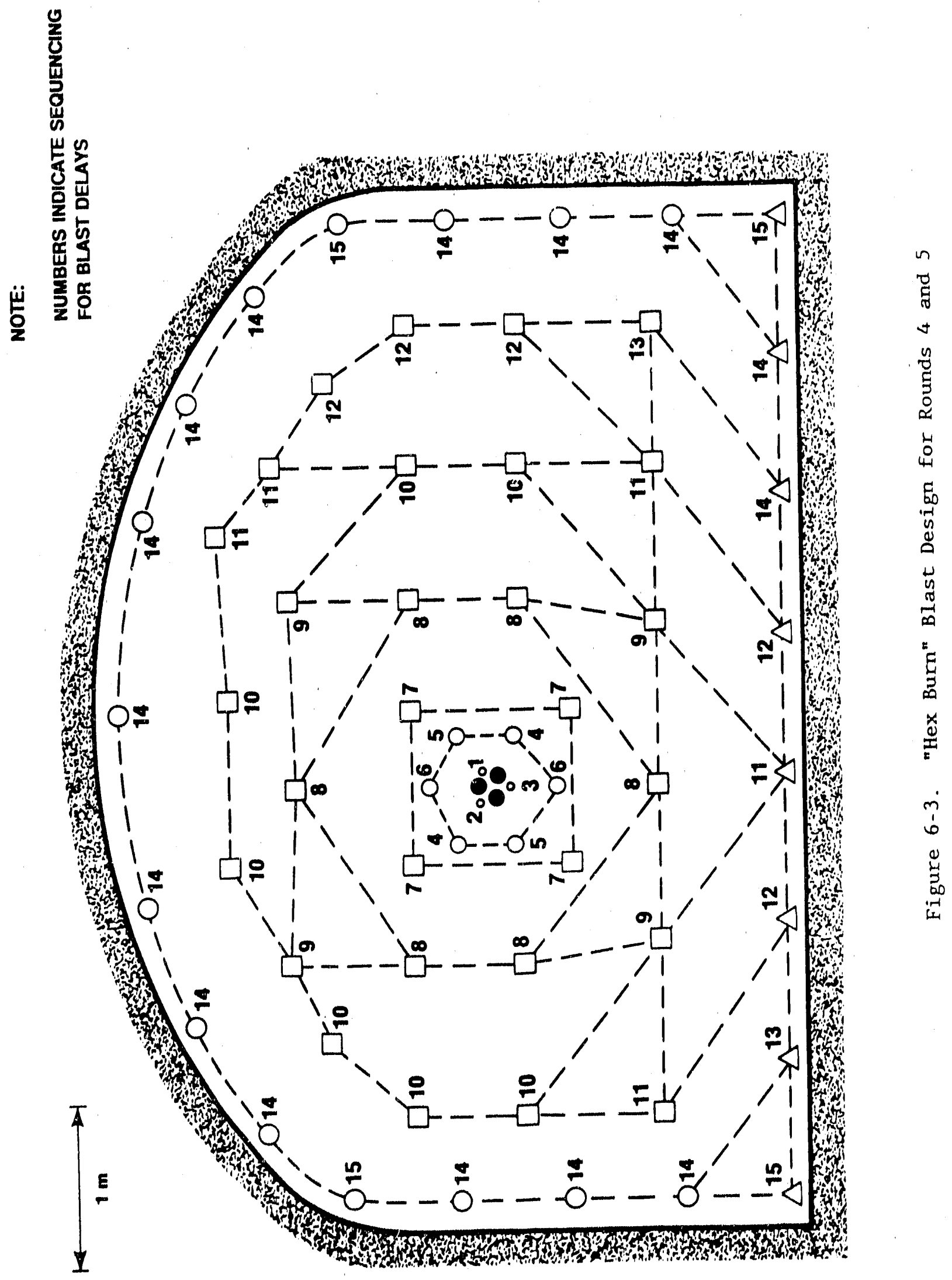


Two factors influenced the mining for Stage III. The end of Round 5 was the location for the Station $C$ instrumentation. First, it was decided that the rounds between Station $C$ and $E$ would be short rounds so that the drift convergence studies would be enhanced. The second factor was the observation that the rock quality was deteriorating somewhat because of the presence of the fault beyond Station C. A burn cut was used for Round 6A; however, drillers encountered rubble in the rock during the drilling operations. Because a burn cut is difficult to drill in rubble, a V-cut blast pattern was selected for Round 6B. The V-cut blast design is shown in Figure 6-4. The next Round, 7A, was still in the fault/shear zone, but the central part was in relatively competent welded tuff and a burn cut was used. The last round for Stage III was a short round needed to reach the Station E instrumentation locativi. Round 7B was only $1.2 \mathrm{~m}$ long.

Stage IV of the blasting program consisted of the excavation of five rounds to complete the Demonstration Drift. Originally, the goal was to complete this last stage with full 3.0-m rounds. However, it was necessary to replace drills on the jumbo, and only $2.4-\mathrm{m}$ long drill steels were readily available. Thus, the last five rounds were shorter. All blast patterns for Stage IV were essentially the same. A triangular burn cut was used, as shown in Figure 6-5. The pattern was selected to

1. simplify burn and blast patterns,

2. reduce drilling,

3. Lower the powder factor, and

4. maintain or improve perimeter control blasting.

\section{2 .3 .2 Explosives}

The explosives used were selected from those normally available at the NTS. Two types of explosives were used for general production hole charging: ANFO and Hercodyne. A special product, Hercosplit, was selected for use in the perimeter holes. These explosives are briefly discussed.

ANFO, a prill-type explosive (ammonium nitrate and fuel oil), was used in the production and lifter holes for much of the Stage I mining. The 


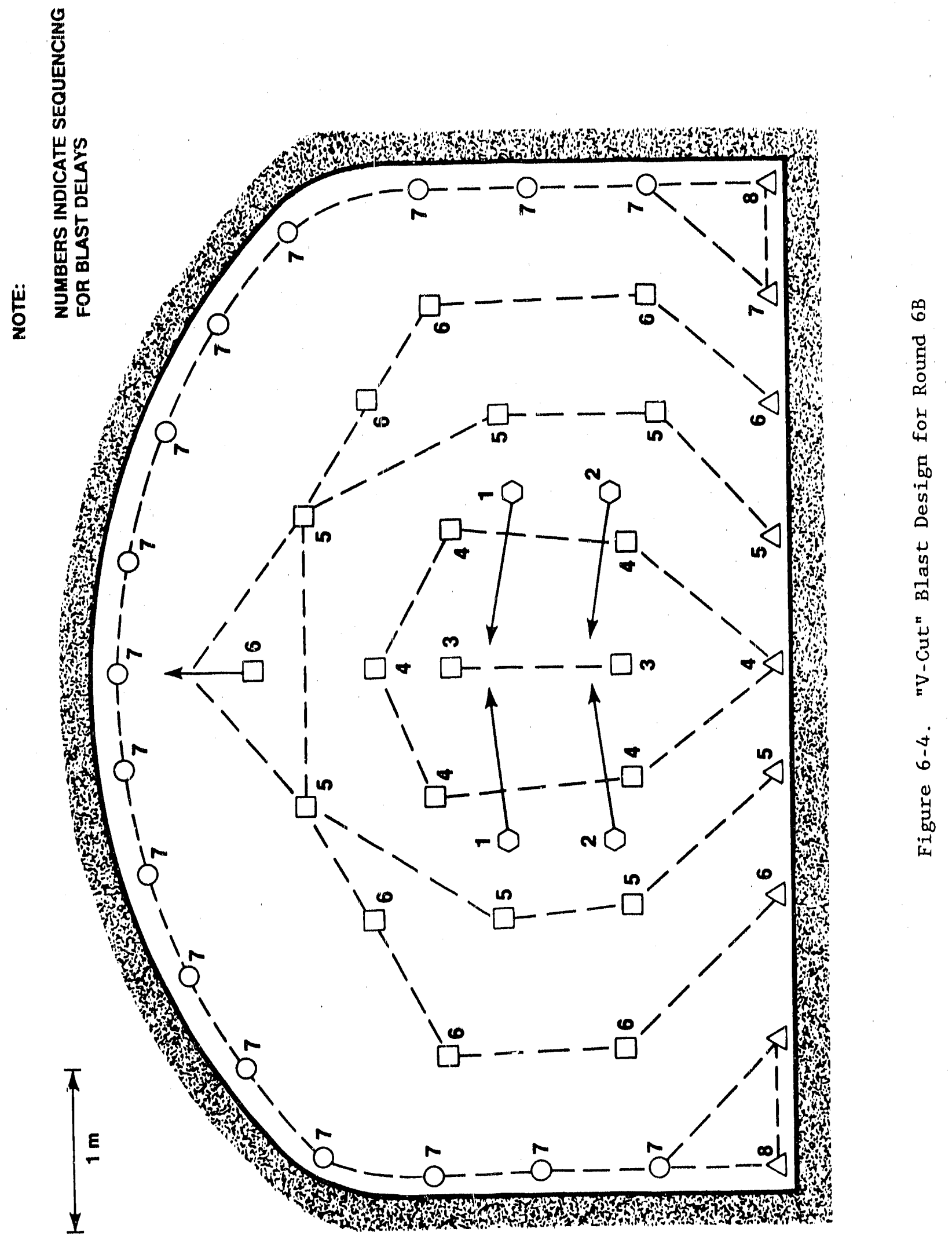




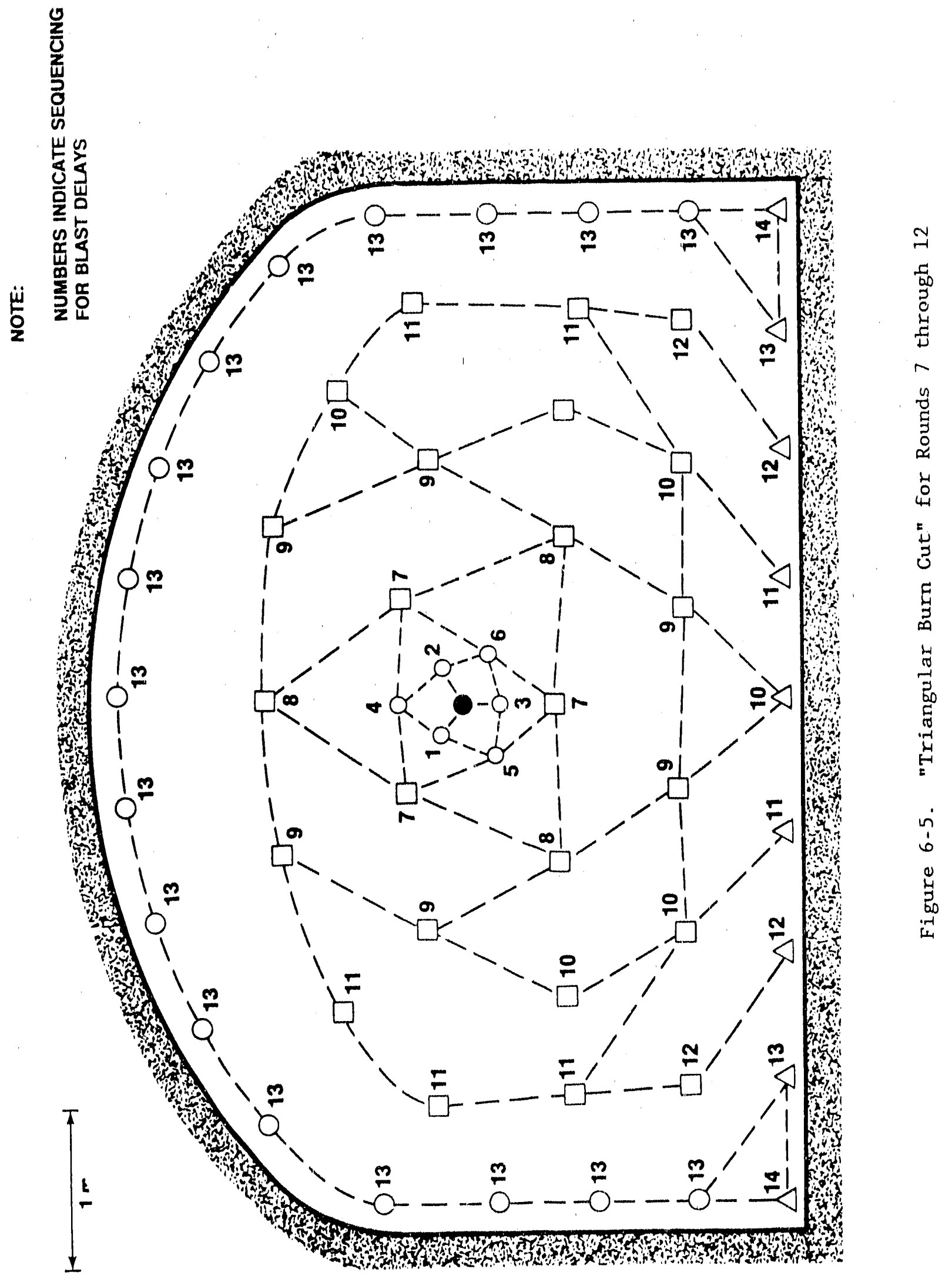


ANFO prills are blown into a hole and pneumatically loaded to a density of approximately $0.95 \mathrm{~g} / \mathrm{cm}^{3}$. This entity yields a load of about $1.49 \mathrm{~kg} / \mathrm{m}$ for holes approximately $45 \mathrm{~mm}$ in diameter. A cartridge of Hercodyne was located at the back of the holes and served as a primer booster to activate the ANFO. It was difficult maintaining quality control in loading the ANFO in this particular rock type; thus, it was not used in the three remaining blasting stages.

Hercodyne is a cartridge-packed ammonium nitrate (nonnitroglycerin) high explosive. Cartridges are avallable in diameters of 25-and 32 -mm and in lengths of 203 and $406 \mathrm{~mm}$. Hercodyne cartridges can be tamped into holes to achieve higher densities. The normal load concentrations are 0.64 and $0.91 \mathrm{~kg} / \mathrm{m}$ for the two hole sizes. The last cartridge in a charge column is normally tamped to stem the hole.

Hercosplit is a specialty explosive used in blasting operations where overbreak control about the perimeter of the opening is desired. Hercosplit is a water-resistant, semigelatine dynamlte. Hercosplit was used in all perimeter holes and usually in the burn holes. Cartridges are $22 \mathrm{~mm}$ in diameter and $0.61 \mathrm{~m}$ long and can be coupled together to form a single long charge. Hercosplit has a borehole load concentration of $0.45 \mathrm{~kg} / \mathrm{m}$. From an improved blasting standpoint, a less dense or smaller diameter product might have been preferred. It was judged that the basic objectives of this initial mining activity could be achieved using the NTS - supplied explosives.

All blast holes were sequenced for detonation with LP Nonel Primadet delay detonators. These nonelectric caps were usually placed at the bottom of the blast hole in the first loaded caxtridge. A normal delay pattern consisted of 16 delays. The total elapsed time for the 16 delay intervals was $9.6 \mathrm{~ms}$. Lead-in lines from individual blast holes were tied to a single length of explosive cord (E Cord). This cord detonates at a high velocity of $7000 \mathrm{~m} / \mathrm{s}$. A blasting cap and safety fuse were used to activate the explosive cord. 


\subsubsection{Drilling for Blasting}

One of the features of the G-Tunnel. WTM evaluations was to assess suitable drilling techniques that may be used for repository-sized excavations. To obtain good drill precision on a production basis, a large twin boom drill jumbo would be necessary. A drill jumbo was not available $\therefore 2$ the NTS for the experiment; thus, one was leased that was suitable for (1) drilling a full face with a single setup and (2) drilling a 3-m round. A used Eimco Secoma drill jumbo was leased based on size, availability, and cost considerations. The drill jumbo was equipped with two Gardner Denver D93 drifter drills. These drills came with 32-mm by 3.7-m drill steels and 44-mm dia production bits, both button and X-type bits. Also, 76- and $102-\mathrm{mm}$ dia button bits were available to drill burn holes.

Jacklegs, which are available in G-Tunnel, were used whenever it was impractical to drill with the drill jumbo or when the drill jumbo was down for repairs. Jacklegs were used to drill the rib (side wall) excavations in Stage $I$ and the final two rourds, 11 and 12.

\subsection{Ground Support}

Three considerations led to the selection of welded wire mesh with grouted rock bolts for ground support for the Demonstration Drift. The first was the rock mass classifications where this type of ground support would be at the upper end of the ranges in both systems (Langkopf and Gnirk, 1986). The second was the evidence in G- 'nnel that rock bolts and wire mesh had pruved to be satisfactory for drifts in moderately welded tuff up to $4.9 \mathrm{~m}$ wide. The third was the nominal rule of thumb used in estimating support requirements on the Nis's. The nominal NTS requirement is that rock bolts and wire mesh can be used with a minimum of a $1.2-\mathrm{m}$ spacing between the bolts, and the ler, ths of the bolts are a minimum of one-half the width of the opening.

The basto PRQED recommcndation was for scven grouted rock bolts, $3.0 \mathrm{~m}$ long and spaced in a $1.5-\times 1.5-\mathrm{m}$ pattern, with welded wire mesh. The recommended wire mesh vas 9-gauge wire velded in a 10.2- x 10.2-cin grid. 
Included in the recommendation wam the provision that the rock bolts and mesn would be installed along with the excavation. SNL made two changes to these recommendations. The first was that a woven wire (chain link) mesh would be used. The welded wire mesh was re ommended because a better view of the rock surface could be available and the welded wire mesh could be used with shotcrete if necessary. Woven wire mesh, made from 11-gauge steel and in a nominal $5 \cdot x 5 \cdot \mathrm{cm}$ pattern, was readily available at G-Tunnel. The second change was related to the use of the woven wire mesh, which was available in rolls $2.4 \mathrm{~m}$ wide. The rock bolt pattern was changed from $1.5 \times 1.5 \mathrm{~m}$ to $1.5 \times 1.2 \mathrm{~m}$ to accommodate the width of the woven wire mesh during installation. Neither of these changes threatened safety aspects in the mining. Thus, the final design shape and ground support pattern was as shown Figure 6-6.

Along with the ground support recommendations, $P B Q \& D$ recommended that alternate ground support systems be demonstrated. It was realized that the drift was too short to conclusively select one ground support method over another, but considerable insight regarding any problems could be gained by demonstratıng different ground support methods in welded tuff. The current practice of using resin-routed rock bolts is quite suitable for ambient temperatures, but they are susceptible to creep when subjected to heat, such as would occur in a repository setting. Therefore, nonresin-based grouts or other types of ground support have more promise for repository applications.

Two types of cementitious grouts were used. Sulfaset, a gypsum-based grout, was used in the two rows immediately following Station $E$ (Round 8). Gypsum-based grouts offer advantages over Portland cement grouts in that they generally set faster and cure to higher ultimate strengths. Expansive Portland cement grouts, made from Type II Chemcomp, are nontoxic, inexpensive, and adaptable to the mechanized bolting system. Portland cement grouts were used for the next two rows of bolts (Round 9) after the gypsum-based grouts . 


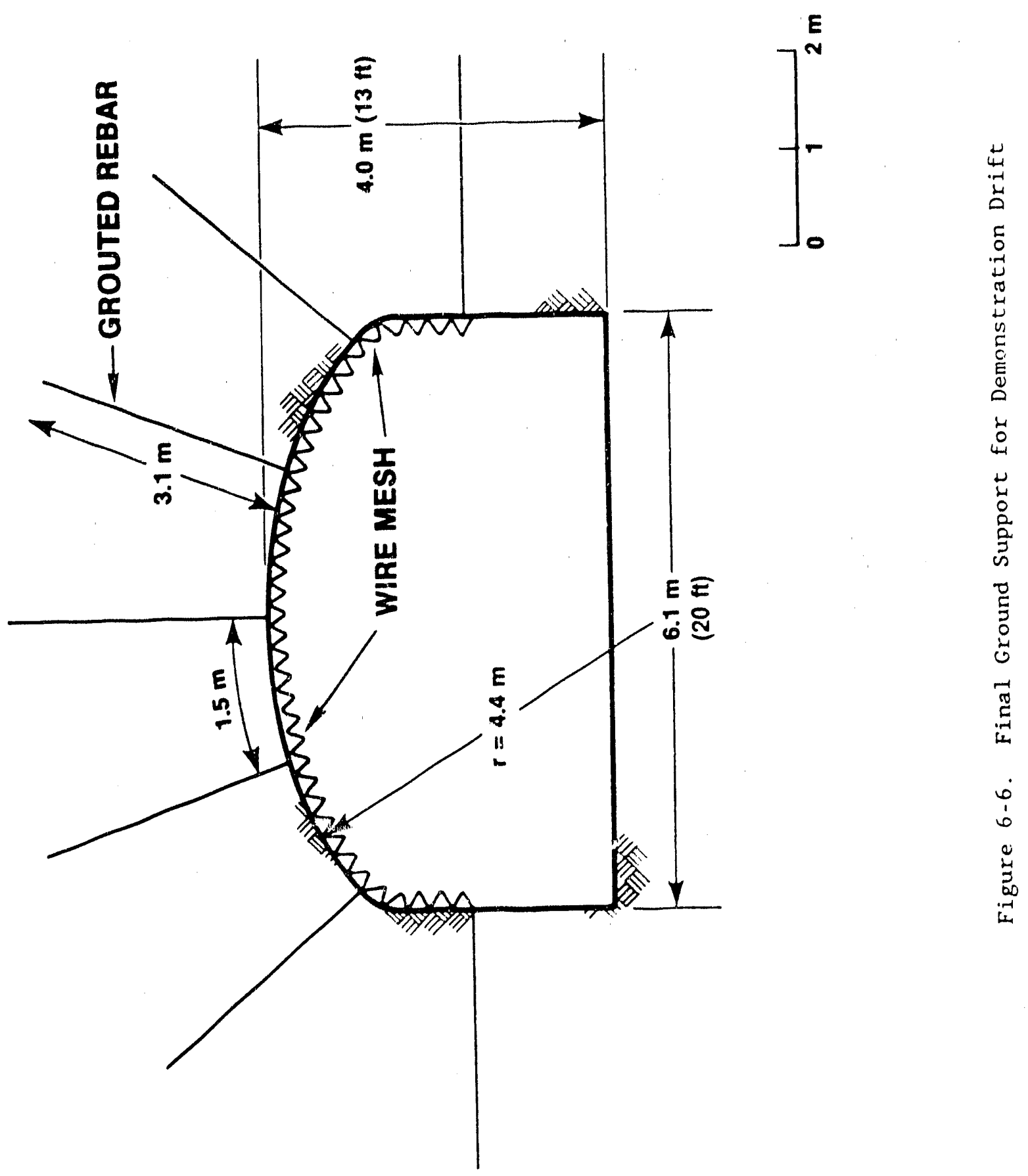


The next two rows of holes, after the cement-based grouts (Round 10) were used, were fitted with Swellex rock bolts. Swellex bolts are friction-type rock bolts that are inserted and expanded against the hole surface with water pressure. They are easily installed and are well suited to situations where a quick primary support is used so that a final support can be installed with some light protection overhead. A disadvantage to the use of Swellex bolts is the possibility of corrosion.

The final ground support for the remainder of the drift was a fibercrete. A steel fiber-reinforced shotcrete was applied directly to the freshly mined surface in thicknesses ranging from $76 \mathrm{~mm}$ (3 in.) to $127 \mathrm{~mm}$ (5 in.). The fibercrete was sprayed on through a hand-held nozzle. Mixing of components was at the nozzle. The fibercrete used had approximately 18 by weight of fibers. 


\subsection{SUMMARY}

6

This report describes the preparations leading to the fielding of the WTM Experiment. The report provides documentation on the experiment layout, the pertinent geology, the DAS, the mining activities, and the instrumentation. Instrumentation discussion was divided into two major chapters associated with the data collection activities: measurements collected on the DAS and measurements collected manually. Instrumentation was described in terms of measurement principle, the equipment used, and the installation details. This report is followed by a data summary report (Zimmerman et a1., 1989), an experiment evaluation report (Zimmerman et al., 1988), and an instrumentation evaluation report (Zimmerman, R. M., R. A. Bellman Jr., K. L. Mann, and T. William Thompson, "G-Tunnel Welded Tuff Mining Experiment Instrumentation Evaluations," SAND88-1331, Sandia National Laboratories, Albuquerque, NM, Draft). 


\subsection{REFERENCES}

Cook, C. W., and E. S. Ames, "Borehole Inclusion Stressmeter Measurements in Bedded Salt," Proceedings 20th U.S. Symposium on Rock Mechanics, Austin, TX, 1979. (NNA.890906.0182)

DOE (U.S. Department of Energy), "Nevada Nuclear Waste Storage Investigations: FY1980 Project Plan and FY1981 Forecast," NV0-196-13, Nevada Operations Office, Las Vegas, NV, February 1980. (NNA.871130.0070)

DOE (U.S. Department of Energy), "Site Characterization Plan, Consultation Draft," Office of Civilian Radioactive Waste Management, Washington, DC, J anuary 1988. (HQS.880517.0937-.0943)

Hawkes, I., and W. V. Bailey, "Design, Develop, Fabricate, Test, and Demonstrate Permissible Low Cost Cylindrical Stress Gages and Associated Components Capable of Measuring Change of Stress as a Function of Time in Underground Coal Mines," OFR-54-75, U.S. Bureau of Mines, Washington, DC, November 1973. (NNA.900418.0001)

Heuze, F. E., W. C. Patrick, R. V. De la Cruz, and C. F. Voss, "In situ Geomechanics, Climax Granite, Nevada Test Site," UCRL-53076, Lawrence Livermore National Laboratory, Livermore, CA, 1981. (NNA.890906.0169)

Hodgkinson, D. P., "Analysis of Steady-State Hydraulic Tests in Fractured Rock," AERE-R 11287, DOE/RW/84.076, United Kingdom Atomic Energy Authority, Oxfordshire, UK, 1984. (NNA.900418.0005)

Hoek, E., and E. T. Brown, Underground Excavations in Rock, The Institution of Mining and Metallurgy, London, England, 1980. (HQS.880517.2301)

Johnstone, J. K., G. R. Hadley, and D. R. Waymire, "In Situ Tuff Water Migration/Heater Experiment: Final Report," SAND81-1918, Sandia National Laboratories, Albuquerque, NM, March 1985. (HQS.880517.1655)

Langefors, U., and B. Kihlstrom, The Modern Technique of Rock Blasting, John Wiley and Sons, New York, NY, 1973. (NNA.901127.0186)

Langkopf, B. S., and E. Eshom, "Site Exploration for Rock-Mechanics Field Tests in the Grouse Canyon Mermber, Belted Range Tuff, U12g Tunnel Complex, Nevada Test Site," SAND81-1897, Sandia National Laboratories, Albuquerque, NM, February 1982. (NNA.9004(3.0379)

Rock Testing Handbook, RTH-381-80, U.S. Army Corps of Engineers, 1980. (NNA. 890327.0042)

Svahholm, B. O., P. A. Persson, and B. Larssor, "Smooth Blasting for Reliable Undergrourd Openings," Proceedings 1st International Symposiun on Storage in Excavated Rock Caverns, V. 3, Stockholm, Sweden, 1977.

(HQS.880517.1712) 
Zimmerman, R. M., and W. C. Vollendorf, "Geotechnical Field Measurements, G-Tunne1, Nevada Test Site," SAND81-1971, Sandia National Laboratories, Albuquerque, NM, May 1982. (HQS.880517.1720)

Zimmerman, R. M., R. L. Schuch, D. S. Mason, M. L. Wilson, M. E. Hall, M. P. Board, R. P. Bellman, and M. P. Blanford, "Final Report: G-Tunnel Heated Block Experiment," SAND84-2620, Sandia National Laboratories, Albuquerque, NM, May 1986. (HQS.880517.1724)

Zimmerman, R. M., and R. E. Finley, "Summary of Geomechanical Measurements Taken in and Around the G-Tunnel Underground Facility, NTS, "SAND86-1015, Sandia National Laboratories, Albuquerque, NM, May 1987. (NNA.870526.0015)

Zimmerman, R. M., R. A. Bellman Jr., K. L. Mann, and D. P. Zerga, "G-Tunnel Welded Tuff Mining Experiment Data Summary," SAND88-0474, Sandia National Laboratories, Albuquerque, NM, 1989. (NNA.900214.0309)

Zimmerman, R. M., R. A. Bellman Jr., K. L. Mann, D. P. Zerga, M. Fowler, and R. L. Johnson, "G-Tunnel Welded Tuff Mining Experiment Evaluations," SAND87-1433, Sandia National Laboratories, libuquerque, NM, 1988. (HQS . 880517.3224) 


\section{APPENDIX}

\section{Candidate Data for RIB}

This report contains no data from or for inclusion in the RIB.

\section{Candidate Data for SEPDB}

This report contains no data from or for inclusion in the SEPDB. 

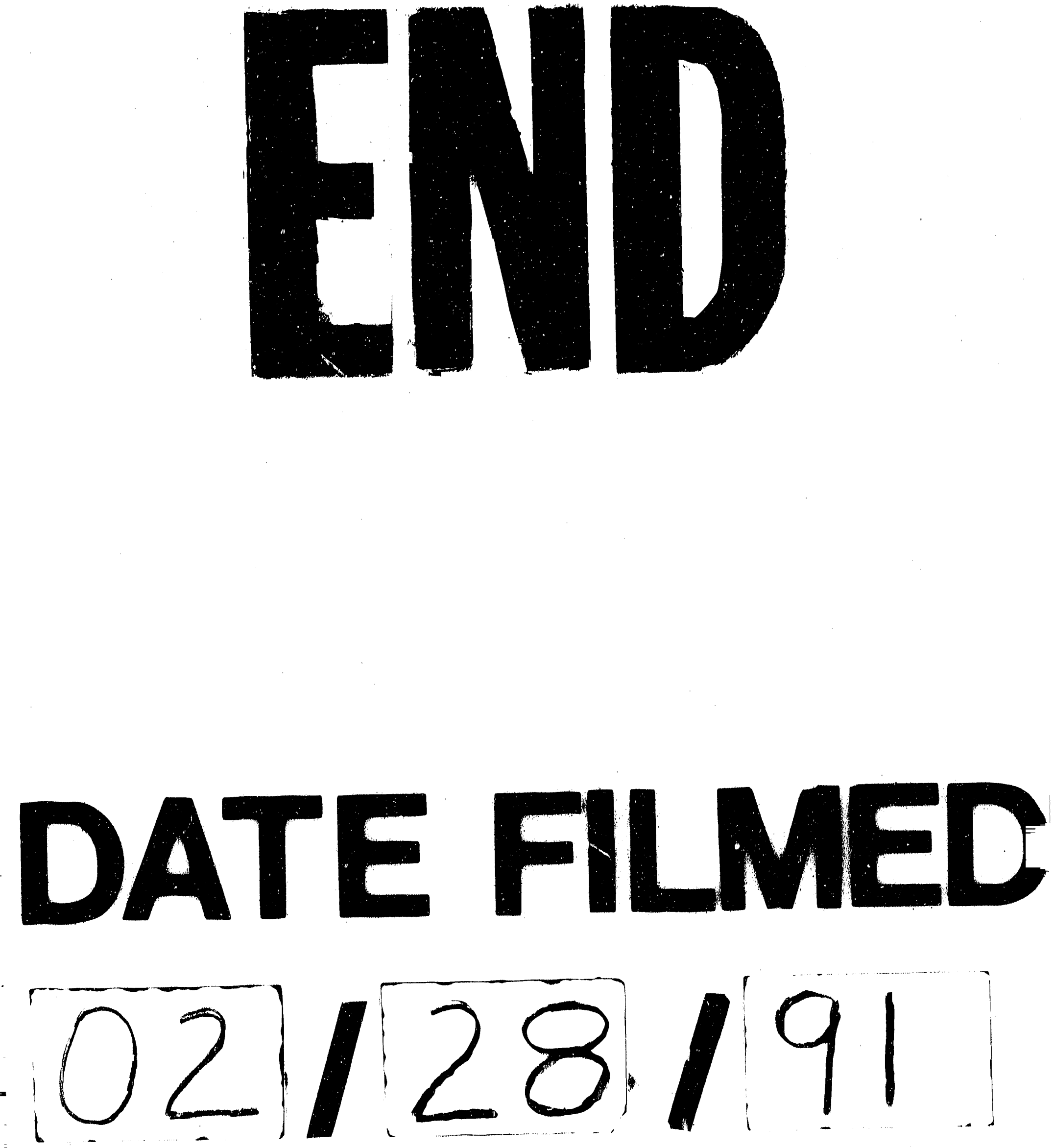
